Aus dem Institut für Pharmakologie und Toxikologie (Prof. Dr. med. W.-H. Zimmermann)

der Medizinischen Fakultät der Universität Göttingen

\title{
Zytostatisches Potenzial neuer Uracilderivate
}

\author{
INAUGURAL-DISSERTATION \\ zur Erlangung des Doktorgrades \\ der Medizinischen Fakultät der \\ Georg-August-Universität zu Göttingen
}

vorgelegt von

Antje Britta Hofmann

aus

Hannover

Göttingen 2018 
Dekan:

Referent:

Ko-Referent:
Prof. Dr. rer. nat. H. K. Kroemer

Prof. Dr. med. H. J. Steinfelder

Prof. Dr. rer. nat. D. Kube

Datum der mündlichen Prüfung: 05.12.2018 
Hiermit erkläre ich, die Dissertation mit dem Titel „Zytostatisches Potenzial neuer Uracilderivate“ eigenständig angefertigt und keine anderen als die von mir angegebenen Quellen und Hilfsmittel verwendet zu haben.

Filderstadt, den 31.05.2018 


\section{Inhaltsverzeichnis}

Abbildungs- und Tabellenverzeichnis ........................................................................ IV

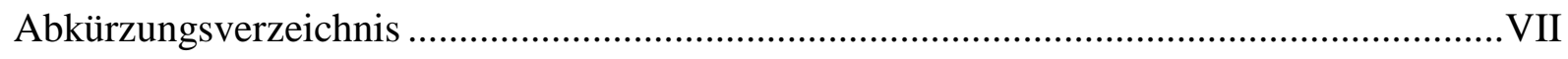

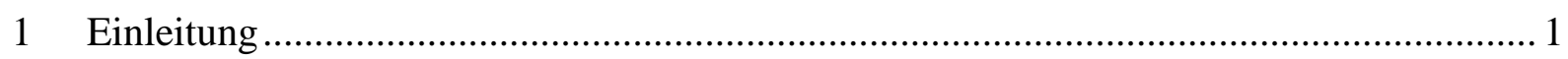

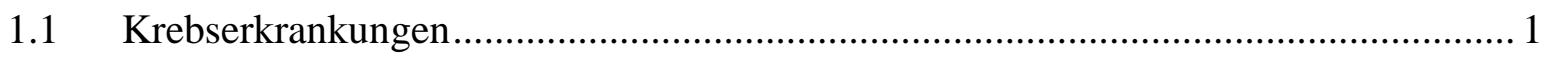

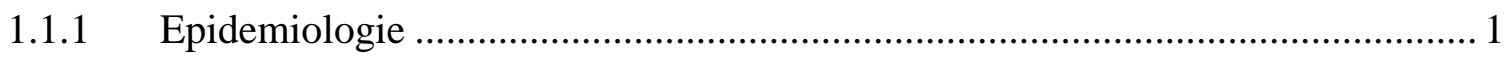

1.1.2 Ätiologie und Pathogenese ............................................................................. 2

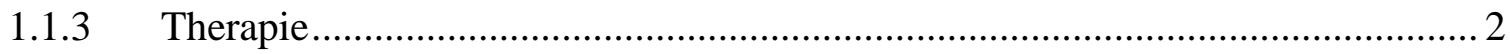

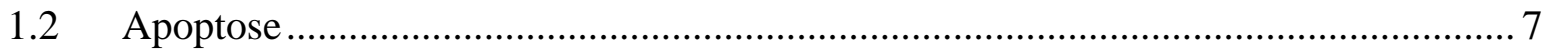

1.2.1 Mechanismen der Apoptoseinduktion.......................................................... 7

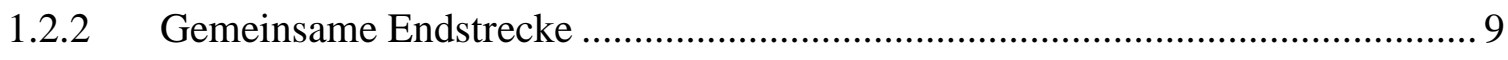

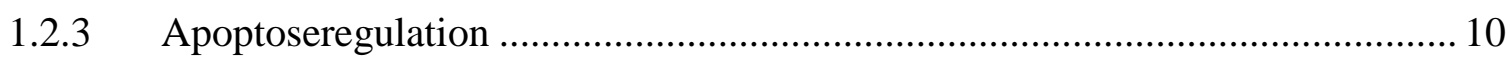

1.3 Entwicklung neuer Uracilderivate ................................................................. 10

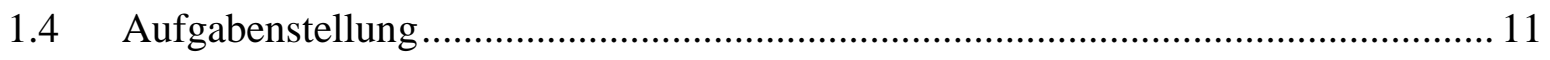

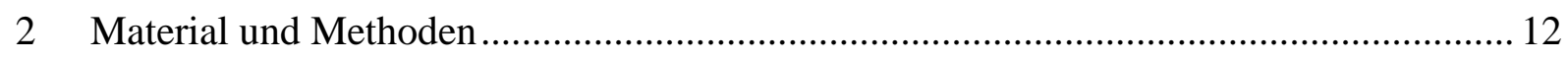

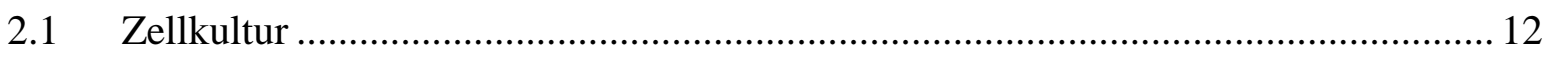

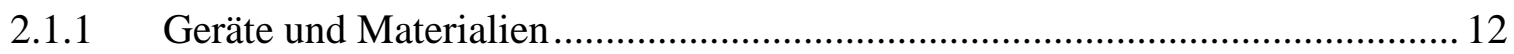

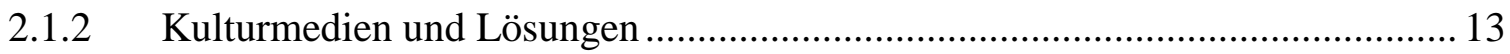

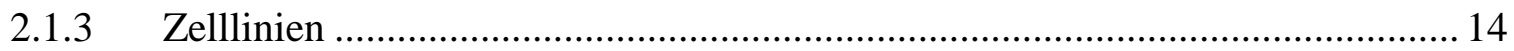

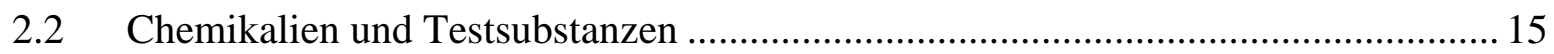

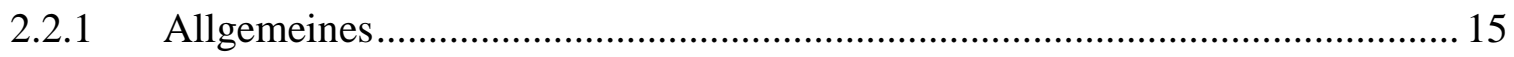

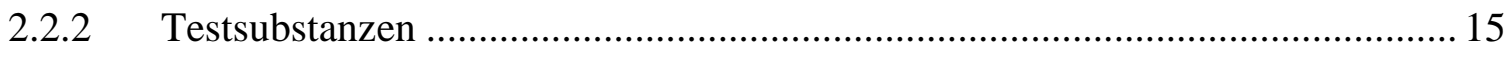

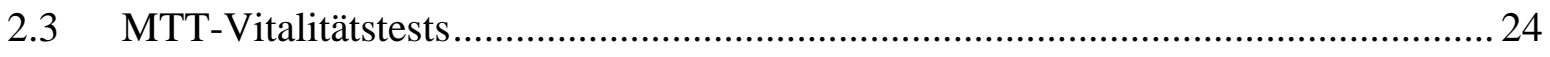

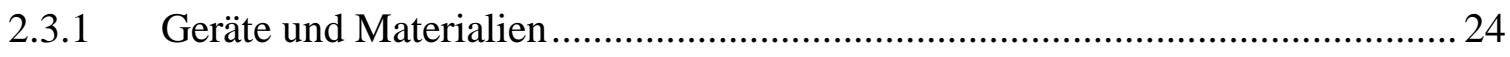

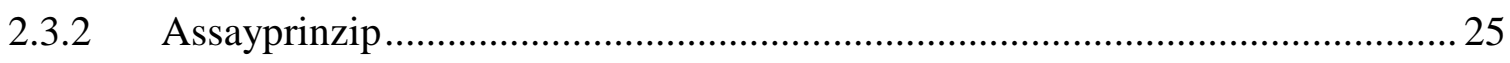




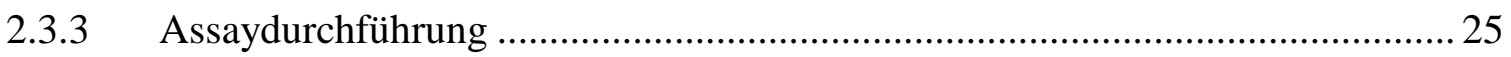

2.4 Messung der Caspaseaktivität als apoptotischer Parameter .................................... 26

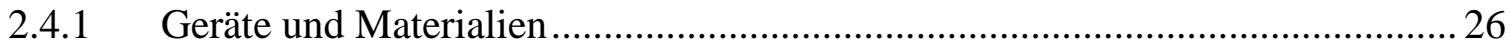

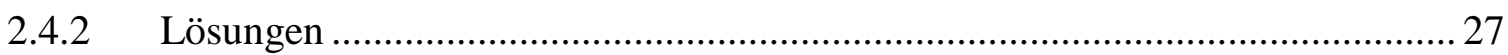

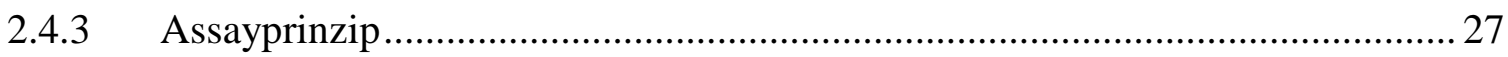

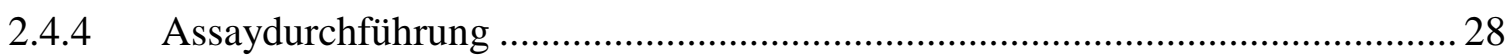

2.5 DNA-Fragmentierung als apoptotischer Parameter ................................................ 29

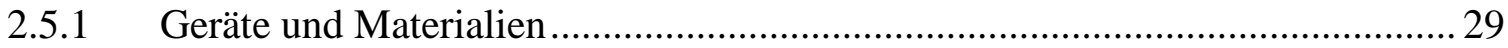

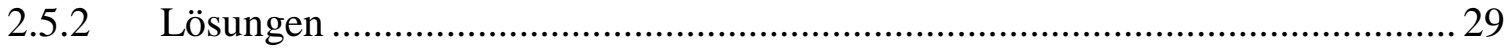

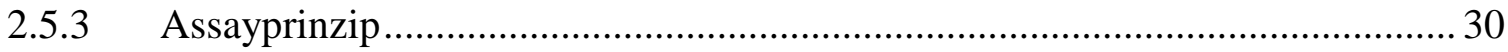

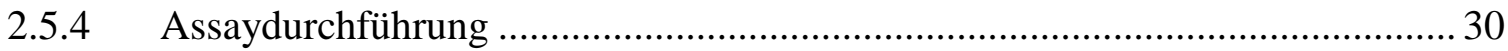

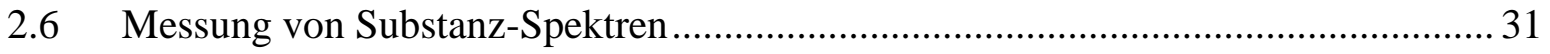

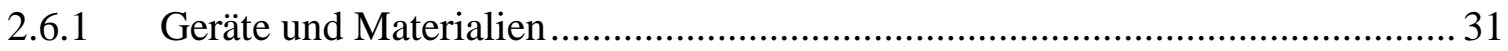

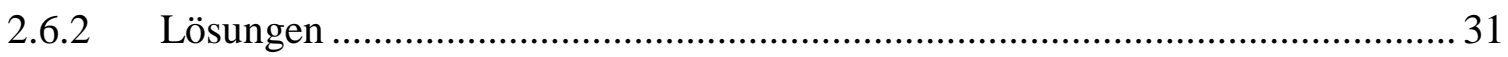

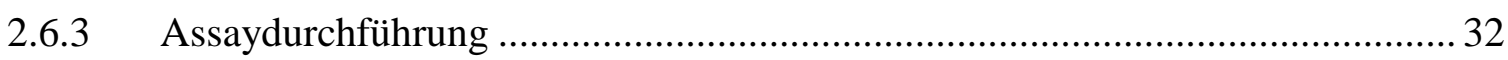

2.7 Assay zur Bestimmung von intra- wie extrazellulärem GSH............................... 32

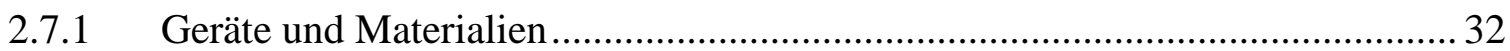

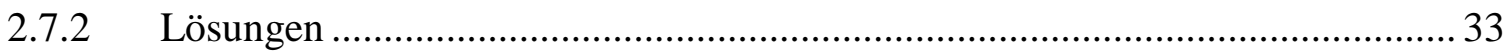

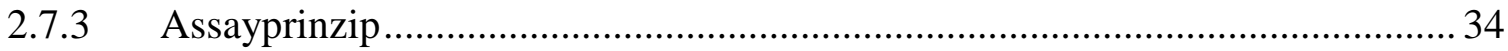

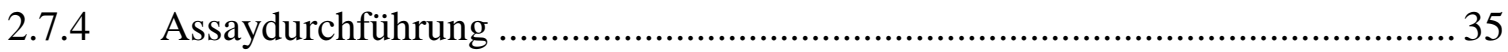

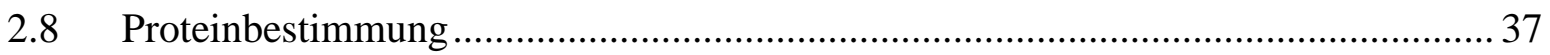

2.8.1 Geräte und Materialien ........................................................................... 37

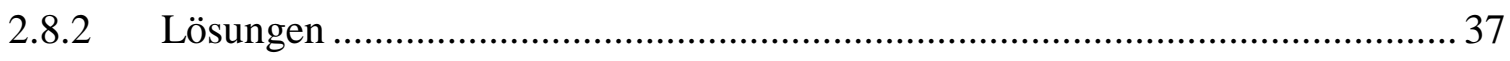

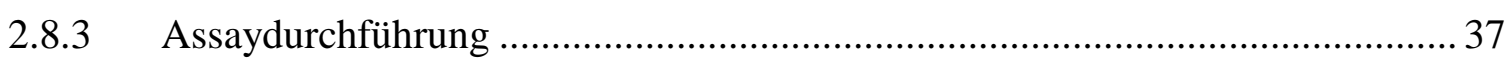

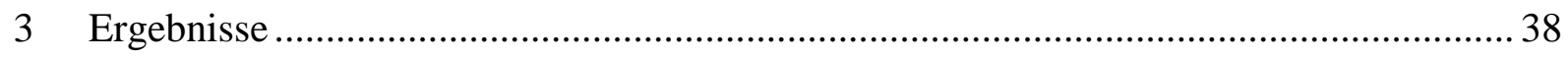

3.1 Untersuchungen zur Zytotoxität von neusynthetisierten Uracilderivaten an humanen

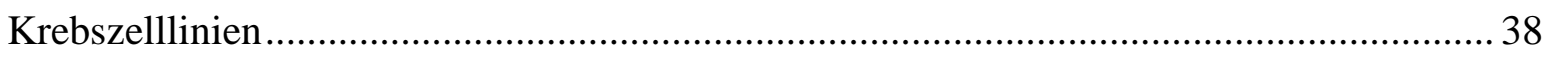

3.1.1 Vitalitätsmessungen an Leukämiezellen ..................................................... 40 
3.1.2 Vitalitätsmessungen an Kolonkarzinomzellen als Beispiel für eine Wirkung auf

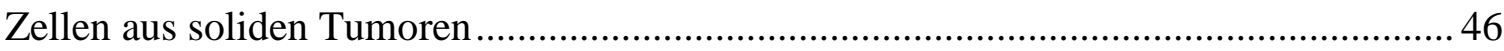

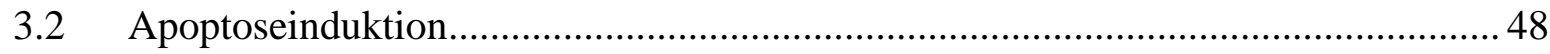

3.2.1 Caspase-3-Aktivitätsmessung in Leukämiezellen .............................................. 48

3.2.2 Caspase-3-Aktivitätsmessung in Kolonkarzinomzellen.................................. 50

3.2.3 DNA-Fragmentierung in HL60-Zellen ....................................................... 51

3.3 NVU- und BEU-Wirkung bei Kombination mit Thiolen ........................................ 52

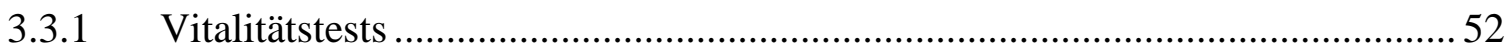

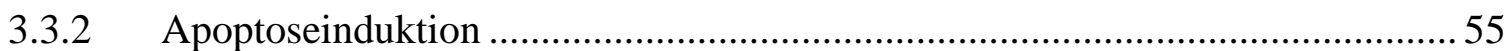

3.3.3 NVU- und BEU-Absorptionsspektren in Kombination mit Thiolen .................. 55

3.3.4 Butanolextraktion zur Erfassung intrazellulärer Anreicherung ......................... 58

3.4 GSH-Messungen nach Behandlung mit NVU und BEU bzw. deren Derivaten ....... 59

3.4.1 GSH-/GSSG-Messungen in Kolonkarzinomzellen ...................................... 60

3.4.2 GSH-/GSSG-Messungen in Leukämiezellen .................................................... 63

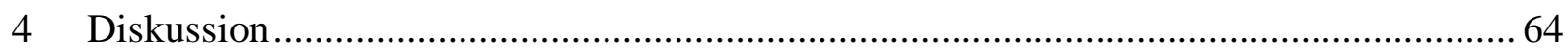

4.1 Zytotoxisches und pro-apoptotisches Potenzial von neusynthetisierten Uracil-

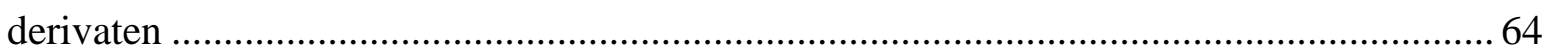

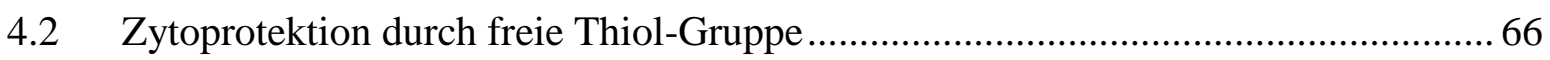

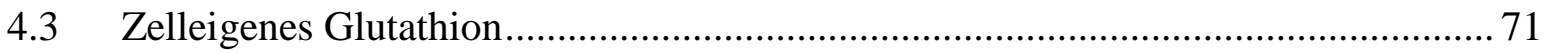

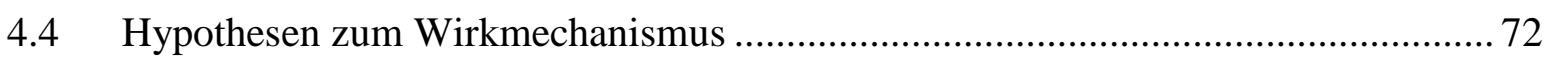

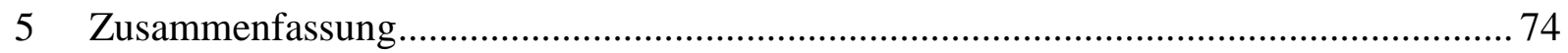

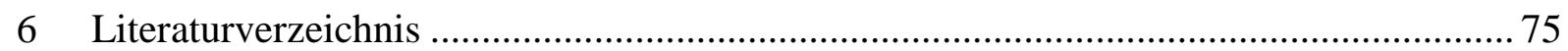




\section{Abbildungs- und Tabellenverzeichnis}

Abbildung 2.1: Reduktion von Glutathion und Entstehung von TNB ................................... 34

Abbildung 3.1: Strukturformeln Uracilderivate - Negativkontrollen..................................... 39

Abbildung 3.2: Strukturformeln potenziell wirksamer Uracilderivate .................................. 39

Abbildung 3.3: Strukturformeln verschiedener BEU-Derivate............................................ 40

Abbildung 3.4: U937 für 24 h behandelt mit NS, NVU und 5-FU ...................................... 41

Abbildung 3.5: HL60 für 24 und 48 h behandelt mit NVU und 5-FU ................................... 41

Abbildung 3.6: HL60 für 24 h behandelt mit TAU, NVU und 5-FU ..................................... 42

Abbildung 3.7: HL60 für 24 h behandelt mit BVU, DiBVU und BEU .................................. 43

Abbildung 3.8: U937 für 24 h behandelt mit BVU, DiBVU und BEU.................................. 43

Abbildung 3.9: HL60 für 24 h behandelt mit DiBVU, BH-DiBVU und B-DiBVU................ 45

Abbildung 3.10: HL60 für 24 h behandelt mit TAU, BH-TAU und TAU ............................. 45

Abbildung 3.11: LoVo für 48 und 72 h behandelt mit 5-FU, NVU und BEU....................... 47

Abbildung 3.12: HCT für 48 und 72 h behandelt mit 5-FU, NVU und BEU .......................... 47

Abbildung 3.13: LoVo für 24 und 72 h behandelt mit B-NVU und B-BEU ........................... 47

Abbildung 3.14: HCT für 24 und 72 h behandelt mit B-NVU und B-BEU ............................ 47

Abbildung 3.15: HL60 für 24 h behandelt mit NVU und Derivaten .................................... 49

Abbildung 3.16: U937 für 24 h behandelt mit NVU und Derivaten ...................................... 49

Abbildung 3.17: HL60 für 24 h behandelt mit BEU und Derivaten ...................................... 50

Abbildung 3.18: U937 für 24 h behandelt mit BEU und Derivaten ...................................... 50

Abbildung 3.19: LoVo für 6, 12 und 24 h behandelt mit NVU und BEU .............................. 51

Abbildung 3.20: HCT für 6, 12 und 24 h behandelt mit NVU und BEU .............................. 51

Abbildung 3.21: HL60 für 24 h mit NVU und BEU behandelt ............................................. 51

Abbildung 3.22: HL60 für 24 h behandelt mit NS, NVU und BEU, zusätzlich Zugabe von NAC .53

Abbildung 3.23: HL60 für 24 h behandelt mit NVU und BEU, zeitlich versetzte Zugabe von NAC 53

Abbildung 3.24: HL60 für 24 h behandelt mit NVU und B-NVU in Kombination mit NAC 54 Abbildung 3.25: HL60 für 24 h behandelt mit BEU und B-BEU in Kombination mit NAC.. 54 Abbildung 3.26: HL60 für 24 h behandelt mit $50 \mu \mathrm{M}$ NVU oder BEU in Kombination mit $\mathrm{N}$-Acetylcystein oder Methionin. .54 Abbildung 3.27: HL60 für 24 h behandelt mit NVU und verschiedenen Konzentrationen NAC 
Abbildung 3.28: HL60 für 24 h behandelt mit BEU und NVU, zeitversetzte Zugabe von

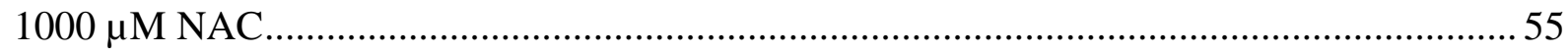

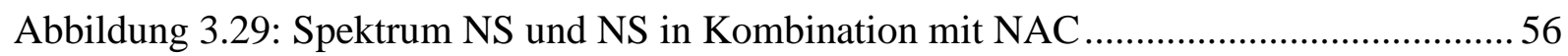

Abbildung 3.30: Spektrum NVU und NVU in Kombination mit NAC .................................... 56

Abbildung 3.31: Spektrum BEU und BEU in Kombination mit NAC .................................... 57

Abbildung 3.32: Spektrum FB-NVU in Kombination mit GSH in PBS/BSA gelöst .............. 58

Abbildung 3.33: Spektrum FB-NVU in Kombination mit GSH in Butanol gelöst ................. 58

Abbildung 3.34: Verschiedene Zellzahlen in PBS/BSA für $1 \mathrm{~h}$ mit FB-NVU behandelt,

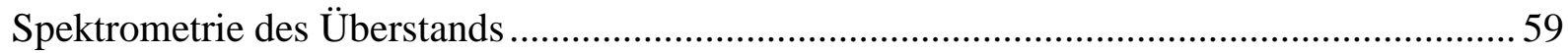

Abbildung 3.35: GSH/GSSG-Gehalt intrazellulär in nmol/10 $10^{6}$ LoVo-Zellen, nativ und für $4 \mathrm{~h}$ behandelt mit NVU

Abbildung 3.36: GSH-Gehalt im Medium in nmol/1,5 ml Medium, nativ und für $4 \mathrm{~h}$ behandelt mit NVU

Abbildung 3.37: GSH/GSSG-Gehalt intrazellulär in nmol/10 $10^{6}$ LoVo-Zellen, nativ und für 4 h behandelt mit FB-NVU

Abbildung 3.38: GSH-Gehalt im Medium in nmol/1,5 ml Medium, nativ und für $4 \mathrm{~h}$ behandelt mit FB-NVU .....

Abbildung 3.39: GSH/GSSG-Gehalt intrazellulär in nmol/10 $10^{6}$ LoVo-Zellen, nativ und für $4 \mathrm{~h}$ behandelt mit BEU

Abbildung 3.40: GSH-Gehalt im Medium in nmol/1,5 ml Medium, nativ und für $4 \mathrm{~h}$ behandelt mit BEU

Abbildung 3.41: GSH/GSSG-Gehalt intrazellulär in nmol/10 $10^{6}$ LoVo-Zellen, nativ und für 4 h behandelt mit FB-BEU

Abbildung 3.42: GSH-Gehalt im Medium in nmol/1,5 ml Medium, nativ und für $4 \mathrm{~h}$ behandelt mit FB-BEU

Abbildung 3.43: GSH-Gehalt intrazellulär in nmol/10 ${ }^{6}$ U937-Zellen, nativ und für $2 \mathrm{~h}$ behandelt mit NVU

Abbildung 3.44: GSH-Gehalt intrazellulär in nmol/10 ${ }^{6}$ U937-Zellen, nativ und für $2 \mathrm{~h}$ behandelt mit BEU. .63

Abbildung 4.1: Uracil und Derivate sowie Nitrostyrol 64

Abbildung 4.2: Thiole 69

Abbildung 4.3: Umsetzung von Amifostin in wirksames „Thiol“ 70 
Tabelle 3-1: Leukämiezellen für 24 h mit verschiedenen NVU-Derivaten behandelt... .44

Tabelle 3-2: Leukämiezellen für $24 \mathrm{~h}$ mit verschiedenen BEU-Derivaten behandelt .44 


\section{Abkürzungsverzeichnis}

2-VP

AEBSF

AIDS

AIF

APO-1

ATP

BCL-2

BSA

CD

DD

DED

DEVD-AFC

DISC

DMSO

DNA

DTNB

DTT

EDTA

FADD

FLIP

G-CSF

GR

GSH

GSSG

HPV

MDR

MTT

PBS
2-Vinylpyridin

4-(2-Aminoethyl)benzensulfonylfluorid

Acquired Immunodeficiency Syndrome

Apoptosis-inducing-factor

Apoptosis antigen 1

Adenosintriphosphat

B-cell-lymphoma 2

Bovines Serumalbumin

Cluster of differentiation

Death domain

Death effector domain

Aspartyl-glutamyl-valyl-aspartyl-7-amido-4-trifluoro-methyl-

Cumarin

Death inducing signaling complex

Dimethylsulfoxid

Deoxyribonucleic acid

Dithiobisnitrobenzoesäure

Dithiothreitol

Ethylendiamintetraessigsäure

Fas-associated death domain protein

Flice inhibitory protein

Granulocyte colony-stimulating factor

Glutathionreduktase

Glutathion reduziert

Glutathion oxidiert

Humanes Papillomavirus

Multidrug resistance

3-(4,5-Dimethyl-2thiazolyl)-2,5-Diphenyl-Tetrazolium-Bromid

Phosphate-buffered saline 
RNA

SDS

SSA

TNF

UPR
Ribonucleic acid

Sodium Dodecylsulfate

Sulfosalicylsäure

Tumornekrosefaktor

Unfolded protein response

Die Abkürzungen für die Testsubstanzen können der Auflistung in Teil 2 (Material und Methoden) entnommen werden. 


\section{Einleitung}

Diese Arbeit beschäftigt sich mit Substanzen vor dem Hintergrund ihrer Eignung als Zytostatika, also der Eignung als Substanz zur Behandlung von Krebserkrankungen. Daher wird im Folgenden kurz auf Krebserkrankungen und grundsätzliche Therapiemöglichkeiten sowie Anforderungen an potenzielle Medikamente eingegangen. Abschließend wird die Aufgabenstellung dargestellt.

\subsection{Krebserkrankungen}

\subsubsection{Epidemiologie}

Krebserkrankungen stellen in Deutschland, nach Herz-Kreislauferkrankungen, die zweithäufigste Todesursache dar. Jeder vierte Todesfall im Jahr 2013 war durch eine bösartige Neubildung bedingt (Statistisches Bundesamt 2015a).

2010 erkrankten 252.400 Männer und 224.900 Frauen an Krebs, für 2014 werden 264.700 Neuerkrankungen bei Männern und 236.200 bei Frauen erwartet, die Inzidenz ist somit steigend. Das Lebenszeitrisiko an Krebs zu erkranken beträgt 51 \% bei Männern und 43 \% bei Frauen (Robert Koch-Institut 2013).

Neben Morbidität und Mortalität der Erkrankung selbst stellen die häufig langwierige und belastende Therapie sowie Angst vor einem Rezidiv eine ausgeprägte psychosoziale Belastung für den Patienten und sein persönliches Umfeld dar.

Durch z. T. erhebliche Therapiekosten sowie mögliche Pflegekosten stellen Krebserkrankungen neben der persönlichen Belastung auch einen enormen gesundheitsökonomischen Faktor dar, so lagen 2008 die durch Krebs bedingten Krankheitskosten für Deutschland bei über 254 Millionen Euro (Statistisches Bundesamt 2015b). 


\subsection{2 Ätiologie und Pathogenese}

Krebs umfasst eine Gruppe sehr heterogener Erkrankungen, durch verschiedene Faktoren kommt es zu einem unregulierten und unkontrollierten Zellwachstum.

Je nach Erkrankung sind verschiedene Risikofaktoren wie z. B. genetische Prädisposition, Umweltfaktoren, Toxine und/oder Infektionen bekannt. Die eigentlichen Ursachen sind bisher nur unvollständig geklärt. Eine Ausnahme bildet hier z. B. das HPV-induzierte Cervixkarziom, hier gilt eine Infektion mit bestimmten Subtypen von humanen PapillomaViren als Ursache der Erkrankung (Morin et al. 2009).

Auch die Pathogenese der Erkrankungen ist unterschiedlich und je nach Tumorentität mehr oder weniger gut untersucht. Das kolorektale Karzinom ist ein Beispiel für eine Erkrankung, deren Pathogenese mittlerweile sehr gut verstanden wird: das in diesem Zusammenhang zu nennende Stichwort ist Adenom-Karzinom-Sequenz (Vogelstein et al. 1988). Diese Sequenz beschreibt wie über verschiedene genetische Veränderungen, wie z. B. Inaktivierungen von Tumorsuppressorgenen oder Aktivierung von Protoonkogenen, vom gesunden Epithel ausgehend über eine gutartige Neubildung (Adenom) ein Karzinom entsteht.

Die Heterogenität dieser Erkrankungsgruppe macht daher, je nach Entität, unterschiedliche Strategien für Prävention, Früherkennung und Therapie notwendig.

\subsubsection{Therapie}

Aufgrund der Heterogenität dieser Erkrankungsgruppe sind je nach Eigenschaften der vorliegenden Neoplasie unterschiedliche Therapieansätze erforderlich. Des Weiteren bestimmen Krankheitsstadium sowie patientenorientierte Faktoren über die Therapiestrategie. Grundsätzlich unterscheidet man drei Säulen der Krebstherapie, die individuell kombiniert werden: chirurgische Maßnahmen, Strahlentherapie und Chemotherapie. In den letzten Jahren wurden deutliche Fortschritte in Bezug auf Senkung der Mortalität und Morbidität von Krebserkrankungen erreicht. Neben Entwicklungen im Bereich der Tumorchirurgie und Radiotherapie sind die Fortschritte v. a. pharmakologischen Entwicklungen zu verdanken. Einen weiteren entscheidenden Beitrag zur Reduktion der Mortalität wird aber auch Früherkennungs- und Präventionsmaßnahmen zugeschrieben (Brawley et al. 2009). 
Aber obwohl in den letzten Jahren deutliche Fortschritte im Sinne einer Reduktion der Mortalität und Verlängerung der Überlebenszeiten gemacht wurden, ist eine adäquate Therapie unter Berücksichtigung einer möglichst guten Lebensqualität sowie möglichst geringer Therapie-assoziierter Morbidität weiterhin schwierig. Schwere Nebenwirkungen und die insbesondere in fortgeschrittenen Krankheitsstadien unzureichende Wirksamkeit der vorhandenen Therapien sowie Resistenzen machen die weitere Entdeckung und Entwicklung neuer Therapien erforderlich.

\subsubsection{Chirurgie}

Bei der Behandlung von soliden Tumoren stellt die komplette Resektion des Tumors einen entscheidenden Schritt im Rahmen einer kurativen Behandlung dar. Unterstützt durch Operationsmikroskope, Markierung mittels Farb- und radioaktiven Stoffen sowie die intraoperative Schnellschnittuntersuchung durch einen Pathologen, ist das Ziel einen bösartigen Tumor makro- und mikroskopisch komplett zu entfernen. Je nach Tumorart, -größe und -stadium ist ein Sicherheitsabstand zur Entfernung im gesunden Gewebe definiert und gegebenenfalls die Mitentfernung von lymphatischem Gewebe empfohlen (Sausville et al. 2009).

Bei der chirurgischen Therapie ist die Erfahrung des behandelnden Arztes entscheidend für den Therapieerfolg. Studien konnten zeigen, dass z. B. beim Kolonkarzinom Prognoseunterschiede von bis zu 30 \% durch die Qualität der chirurgischen Therapie bedingt waren (Sausville et al. 2009).

\subsubsection{Strahlentherapie}

Die Strahlentherapie wird unter anderem neoadjuvant zur Tumormassereduktion oder adjuvant zur Reduktion des Risikos eines (Lokal-)Rezidivs eingesetzt, bei ausgewählten Erkrankungen, wie z. B. beim Prostatakarzinom oder bestimmten hämatologischen Neoplasien im Frühstadium, kann sie allerdings auch als alleinige Maßnahme kurative Therapie sein (Müller und Bischof 2006, Zierhut 2006). Aber auch im palliativen Setting, z. B. aus schmerztherapeutischen Gründen oder zur Stabilisation des Knochens bei ossären Metastasen zur Verhinderung pathologischer Frakturen, hat die Strahlentherapie einen hohen Stellenwert (Treiber et al. 2006) 
Erfolgsentscheidender Faktor der Strahlentherapie ist, neben der genauen Indikationsstellung (nicht jeder Tumor ist strahlensensibel), die Konzentration der Strahlung (quantifiziert in Gray), die den Tumor erreicht, unter möglichst geringer Belastung umliegender Gewebe/Organe.

Dank Entwicklung von Technik und Lagerungsmethoden ist es mittlerweile möglich, relativ gezielt hohe Strahlungskonzentrationen im Zielgebiet zu erreichen, unter Schonung des umliegenden Gewebes. Ein Beispiel hierfür ist die sogenannte Mantelfeldbestrahlung bei M. Hodgkin. Des Weiteren wird bei einer perkutanen Bestrahlung die Gesamtdosis auf mehrere kleine Einzeldosen verteilt, die kontinuierlich an aufeinander folgenden Tagen appliziert werden, was auch die toxische Wirkung auf gesundes Gewebe mindert (Müller und Bischof 2006).

Zusätzlich zur perkutanen Bestrahlung gibt es die so genannte Brachytherapie, bei der ein Strahlungsträger möglichst nahe an den Tumor heran gebracht wird. Das Verfahren wird, wie die Implantation radioaktiver Metallstäbchen (Seeds) beim Prostatakarzinom, alternativ zur operativen Versorgung oder adjuvant eingesetzt. Strahlentherapie findet mittlerweile auch intraoperativ Verwendung (Fritz et al. 2006, Treiber und Oertel 2006).

Akutnebenwirkungen der Therapie sind v. a. Schädigungen der Haut und Schleimhäute sowie Knochenmarkschäden. Langfristig können Zweittumoren induziert werden, so treten z. B. intrakranielle Tumoren häufiger bei Menschen auf, die eine Schädelbestrahlung erhalten haben, verglichen mit einer Population ohne zerebrale Bestrahlung (Chowdhardy et al. 2012).

\subsubsection{Chemotherapie}

Die dritte Säule der Krebstherapie ist die Chemotherapie, die eine sehr heterogene Gruppe verschiedener Medikamente/Substanzen umfasst. Sie wird kurativ v. a. bei hämatologischen Neoplasien verwendet, bei soliden Tumoren eher neoadjuvant zur Reduktion der Tumorgröße beziehungsweise adjuvant zur Senkung des Rezidivrisikos und palliativ zur Tumorkontrolle.

Während unter Chemotherapie im engeren Sinne die Gabe eines klassischen Zytostatikums verstanden wird, so gehört zu dieser Gruppe im weiteren Sinne mittlerweile auch ein breites Spektrum an anderen Substanzen, wie Antikörper, Hormonrezptorantagonisten sowie -agonisten, Tyrosinkinaseinhibitoren und Neoangiogeneseinhibitoren (Herold 2012).

Ziel einer optimalen Chemotherapie sollte sein, möglichst selektiv alle bösartigen Zellen zu zerstören und gesunde Zellen nicht zu belasten. Im Rahmen einer klassischen zytostatischen Therapie gelingt dies im Moment nur bedingt, da durch diese Medikamente sich schnell 
teilende Zellen unselektiv geschädigt werden. So stellen Akutnebenwirkungen wie Übelkeit und Erbrechen, Knochenmarksdepression u. a. mit Folge der Immunsuppression sowie Anämien häufig einen Therapie-limitierenden Faktor dar. Als Spätfolgen können auch bei dieser Therapieform Zweitneoplasien oder Fertilitätsstörungen auftreten (Lüllmann et al. 2006).

Zu den klassischen Zytostatika zählen z. B. die Alkylantien, die über Interaktionen mit der DNA-Struktur wirken, bestimmte Antibiotika (z. B. Doxorubicin), die Alkaloide, die über Enzymhemmung und Störung der tubulären Strukturen der Zelle wirken und die Antimetabolite, die anstatt der normalen Basen in DNA oder RNA eingebaut werden und zum Syntheseabbruch führen und dadurch den Zellstoffwechsel stören. In diese Gruppe gehört auch das 5-Fluoruracil (5-FU), welches im Rahmen dieser Arbeit als Referenz verwendet wurde (Lüllmann et al. 2006).

Im Rahmen der Forschung war es eine Zielsetzung, Zytostatika mit möglichst tumorselektiver Wirkung $\mathrm{zu}$ entwickeln. Es entstand eine neue Gruppe von chemotherapeutischen Medikamenten, die auch unter dem Begriff targeted therapies bekannt sind. Unter targeted therapies werden Therapien mit selektiv wirkenden Medikamenten, zurzeit häufig Antikörper, verstanden. Die Antikörper haben molekulare Zielstrukturen. In ihrer Wirkungsweise gibt es zwei verschiedene Mechanismen: 1. an den Antikörper wird eine funktionelle Gruppe z. B. in Form eines Zytostatikums oder Radionukleotids gekoppelt, der Antikörper selbst dient nur der Anreicherung des Medikamentes im Zielgebiet oder 2. der Antikörper selbst ist der aktive Wirkstoff, der z. B. durch Enzym- oder Rezeptorinhibition seine Wirkung entfaltet. Bekannte Beispiele sind die Radiojodtherapie, die im Rahmen von bös- aber auch gutartigen Schilddrüsenerkrankungen eingesetzt wird oder Trastuzumab (Herceptin ${ }^{\circledR}$ ) in der Brustkrebstherapie (Lüllmann et al. 2006). Die targeted therapies verursachen aufgrund ihrer Selektivität nicht mehr zwangsläufig die typischen Symptome einer klassischen Chemotherapie, können aber auch z. T. schwerwiegende Nebenwirkungen haben (wie z. B. Anaphylaxie) (Herold 2012).

Neben der Tumorselektivität ist ein weiteres wichtiges Kriterium für ein Chemotherapeutikum der Mechanismus, über den eine bösartige Zelle zerstört wird. Es werden zwei Arten von Zelltod, Nekrose und Apoptose, unterschieden. Die Nekrose stellt einen unkontrollierten Zelluntergang mit starker Umgebungsreaktion dar. Die Apoptose dagegen ist ein gezielter Abbau einzelner Zellen ohne starke Endzündungsreaktion und ist daher gewünschtes Ziel einer medikamentösen zytostatischen Behandlung. 
Die Anforderung an ein ideales Chemotherapeutikum ist also, dass dieses möglichst selektiv in Tumorzellen Apoptose induziert und somit gesundes Gewebe nicht beeinträchtigt, um Nebenwirkungen minimal zu halten.

Substanzen zu finden, die o.g. Kriterium entsprechen, ist Gegenstand von aktuellen Forschungen.

\subsubsection{Supportive Maßnahmen}

Erwähnenswert ist, dass die sogenannte supportive Therapie, medikamentös wie nicht-medikamentös, an Bedeutung gewonnen hat. Diese Maßnahmen tragen entscheidend zur besseren Verträglichkeit der Therapie sowie auch zur Akzeptanz der Erkrankung selbst und somit zur Optimierung der Lebensqualität von Krebspatienten bei.

So konnte man z. B. durch die Einführung einer Kombinationstherapie von Antiemetika vom Typ der 5-HT $\mathrm{H}_{3}$-Rezeptorantagonisten (sogenannte Setrone) und Steroiden, die emetischen Nebenwirkungen einer Chemotherapie deutlich senken und damit die subjektive Therapieverträglichkeit steigern (Lüllmann et al. 2006).

Der Einsatz von hämatopoetischen Wachstumsfaktoren wie G-CSF, die die granulozytopenische Phase stark verkürzen und somit im Rahmen der Infektionsprophylaxe sehr erfolgreich sind, verbesserte auch die objektive Verträglichkeit. Zusammen mit Erythrozyten- und Thrombozytenkonzentraten werden damit die dosislimitierenden Effekte von Knochenmarktoxizität gemindert beziehungsweise zumindest in höhere Dosisbereiche verschoben (Lüllmann et al. 2006).

Nierenschäden können durch einen ausreichenden Flüssigkeitsumsatz verhindert beziehungsweise reduziert werden. Ein Tumorlyse-Syndrom - mit massivem Anfall von Harnsäure - kann durch das Enzym Rasburicase erfolgreich behandelt werden (Herold 2012).

Des Weiteren fallen auch eine ausreichende Schmerztherapie und eine gute psychosoziale Betreuung in die Gruppe der supportiven Therapien. Wie wichtig gerade die letzten beiden Maßnahmen sind, zeigte eine Studie von Temel (Temel et al. 2010). Diese Arbeitsgruppe konnte zeigen, dass neben einer Verbesserung der Lebensqualität auch eine Verlängerung der Überlebenszeit durch eine frühzeitige und adäquate palliativmedizinische Versorgung erzielt werden kann. 


\subsection{Apoptose}

Apoptose ist heute mehr denn je im Fokus der Forschung. Dies ist insbesondere darin begründet, dass für viele Erkrankungen eine gesteigerte (z. B. neurodegenerative Erkrankungen wie Alzheimer und Parkinson, AIDS) oder mangelnde (z. B. Krebs, Autoimmunerkrankungen) Apoptoseinduktion ursächlich ist (Gewies 2003).

Der Begriff Apoptose ist griechischen Ursprungs und steht für das Fallen von Baumblättern im Herbst. Eingeführt wurde dieser Begriff 1972 von Kerr (Kerr et al. 1972), wobei der Erstbeschreiber der charakteristischen morphologischen Abläufe Carl Vogt war (Vogt 1842).

Diese typischen morphologischen Veränderungen umfassen das Schrumpfen der Zelle, die Kondensation des Chromatins und schließlich die Fragmentation der DNA. Die Zellmembran stülpt sich aus (Zeiose), und es werden so genannte apoptotische Körperchen (Abschnürungen der Zellmembran) gebildet (blebbing). Die apoptotischen Körperchen werden dann phagozytiert (Gewies 2003).

Bei Nekrose zeigt sich morphologisch dagegen ein Anschwellen der Zelle (Oncose) bis zur Zerstörung der Plasmamembran, wobei der Zellinhalt in den extrazellulären Raum freigesetzt wird und dadurch eine Entzündungsreaktion auslöst (Gewies 2003).

Apoptose ist ein komplexer Prozess, der strengster Kontrolle unterliegt. Oft wird Apoptose synonym mit dem Begriff „programmierter Zelltod“ verwendet, dieses ist aber nicht ganz korrekt. Der programmierte Zelltod ist im Rahmen von Wachstums- und Entwicklungsprozessen sowie Aufrechterhaltung der Homöostase essenziell für einen Organismus und läuft über Apoptose ab. Apoptose dagegen läuft nicht immer nur im Rahmen von physiologischen Prozessen ab, sondern kann durch Zellschädigung z. B. durch Ethanol oder Zytostatika induziert werden (Lawen 2003).

\subsubsection{Mechanismen der Apoptoseinduktion}

Man unterscheidet je nach Initiationsphase drei Typen:

o Typ1 = extrinsischer Weg

o Typ2 = intrinsischer Weg

o $\quad$ Typ3 = endoplasmatisches Retikulum-stressinduzierter Weg 


\subsubsection{Extrinsischer Weg}

Der extrinsische Weg der Apoptoseinduktion erfolgt über transmembranäre Zellmembranrezeptoren, auch Todesrezeptoren genannt. 1989 wurde CD95 (APO-1/FAS) als erster Apoptose-induzierender Rezeptor beschrieben (Trauth et al. 1989). Die Todesrezeptoren gehören zur Gruppe der Tumornekrosefaktor-Rezeptoren (TNF-Rezeptoren), diese zeichnen sich alle durch cysteinreiche extrazelluläre Domänen (2-6) sowie durch eine intrazelluläre Domäne, die auch als Todesdomäne (DD, death domain) bezeichnet wird, aus. Diese Rezeptoren werden physiologisch durch spezifische Liganden aktiviert (Krammer 2000, Gewies 2003).

Binden Liganden oder auch agonistische Antikörper an die Todesrezeptoren, kommt es zu einer Trimerisierung des Rezeptors, welche entscheidend ist für die Signaltransduktion (Peitsch und Tschopp 1995). Die intrazelluläre Domäne (DD) verfügt über keine eigene enzymatische Funktion, aber im aktivierten Zustand binden bestimmte Proteine, die ebenfalls über eine DD verfügen (FADD, Fas-associated death domain protein) an die Rezeptoren. Diese Komplexe werden als DISC (death inducing signalling complex) bezeichnet (Kischkel et al. 1995).

Die DD der FADD verfügen zusätzlich noch über eine Todeseffektordomäne (DED, death effector domain). An die DED kann ein Proenzym, die Procaspase-8, binden, das nun autokatalytisch in die aktive Form - Caspase-8 - überführt wird.

Caspasen sind eine Gruppe von Proteasen, die ein Cystein im aktiven Zentrum besitzen und Proteine spezifisch nach der Aminosäure Aspartat spalten: also Cystein-Aspartasen oder eben kurz Caspasen.

Caspase-8 aktiviert nun eine Reihe weiterer Caspasen, eine Kaskade wird in Gang gesetzt, daher bezeichnet man die Caspase-8 auch als Initiatorcaspase. Neben der Caspase-8 gehören auch Caspasen-2,-9 und -10 zu den Initiatorcaspasen. Die Endstrecke der Caspasekaskade stellen die Effektorcaspasen dar, zu denen u. a. Caspase-3, -6 und -7 gehören. Diese spalten dann die entsprechenden zellulären Substrate und verursachen die typische Morphologie (Krammer 2000, Gewies 2003).

Die Effektorcaspasen sind im Einzelnen nicht für die Apoptose entscheidend, das Fehlen einer Caspase kann durch eine andere ausgeglichen werden (Kuida et al. 1996). Dagegen ist das Vorhandensein von Caspase-8 entscheidend für den Ablauf des Apoptoseprogramms (Varfolomeev et al. 1998). 


\subsubsection{Intrinsischer Weg}

Bei der intrinsischen Aktivierung der Apoptose spielen die Mitochondrien der Zelle eine zentrale Rolle. Durch oxidativen Stress oder DNA-Schäden kommt es zu Veränderungen des mitochondrialen Transmembranpotenzials sowie zu einer Veränderung der Permeabilität der inneren Mitochondrienmembran. Es kommt zum Efflux verschiedener Proteine wie z. B. Apoptosis-inducing-factor (AIF) und Cytochrom C. Diese Proteine können die Caspasekaskade aktivieren und so die Apoptose auslösen (Krammer 2000, Gewies 2003).

\subsubsection{Endoplasmatisches Retikulum-stressinduzierter Weg}

Das endoplasmatische Retikulum ist ein Zellorganell, das eine zentrale Rolle im Proteinstoffwechsel einer Zelle spielt. Im Inneren werden Proteine in ihre Tertiär- und Quartär-Struktur gefaltet.

Veränderungen des intrazellulären ATP-Spiegels, pH-Werts oder Kalziumlevels führen zu einer Ausschüttung von un- bzw. nicht vollständig gefalteten Proteinen, man bezeichnet das auch als unfolded protein response (UPR). Infolge der UPR kommt es zum Zellzyklusarrest, die Proteinsynthese wird eingestellt, der Abbau von ungewollten Proteinaggregaten wird gesteigert und die Chaperonbildung wird induziert. Reichen diese Maßnahmen nicht aus, um das intrazelluläre Gleichgewicht wieder herzustellen, wird die Apoptose entweder über einen Transkriptionsfaktor oder über einen Caspase-12-abhängigen Weg induziert. Zusammenfassend muss man sagen, dass dieser Typ der Apoptoseinduktion noch nicht umfassend verstanden wird (Szegezdi et al. 2003).

\subsubsection{Gemeinsame Endstrecke}

Unabhängig vom Induktionsweg mündet die Apoptose in einem geordneten Abbau der betroffenen Zelle mit bereits oben beschriebenen typischen morphologischen Veränderungen.

Im Rahmen der Abbauprozesse kommt es zu einer Fragmentation der DNA zwischen den Nukleosomen durch Endonukleasen. Bei diesem Prozess entstehen DNA-Stücke mit einer charakteristischen Länge (Krammer 2000). 


\subsubsection{Apoptoseregulation}

Aufgrund der essenziellen Bedeutung der Apoptose für einen Organismus muss diese streng kontrolliert und reguliert werden. Daher gibt es verschiedene Mechanismen, die an unterschiedlichen Stellen in den Apoptosesignalpfaden ansetzen.

Ein wichtiger Regulator des Rezeptor-vermittelten Signalpfandes ist das sogenannte flice inhibitory protein (FLIP). Flice ist ein Synonym für Caspase-8. FLIP kann das Binden von Procaspase-8 an den DISC und damit die autokatalytische Aktivierung von Caspase-8 verhindern. Wie bereits oben ausgeführt, ist dies der entscheidende Schritt in dem Rezeptorsignalpfad, wird dieser blockiert, kommt es nicht zur Apoptoseinduktion (Scaffidi et al. 1999).

Auch Viren können FLIP bilden und verhindern im Rahmen einer viralen Infektion die Apoptose der Zelle und begünstigen damit die Virusausbreitung.

Ein weiterer wichtiger Regulator ist die B-cell-lymphoma 2-Familie (Bcl-2), diese umfasst eine ganze Reihe verschiedener antiapoptotischer Moleküle, aber auch Proteine die Apoptose auslösen oder eine Aktivierung verstärken können: z. B. Bax, Bak oder Bid. Diese Proteine sind v. a. mitochondrial lokalisiert und greifen daher v. a. in den mitochondrial vermittelten Apoptosepfad ein (Gewies 2003).

\subsection{Entwicklung neuer Uracilderivate}

Das bisher als Virustatikum verwendete 5-(2-Bromvinyl)-2-desoxyuridin (BVDU), bekannt unter dem Handelsnamen Zostex®, rückte in den letzten Jahren in den Fokus der Forschung, da sich für dieses Präparat zytotoxische und pro-apoptotische Eigenschaften zeigen ließen. Des Weiteren scheint die Kombination von BVDU mit anderen Chemotherapeutika, zu einer Verminderung von der Ausprägung von Resistenzen (z. B. MDR) zu führen (Tomicic et al. 2003).

In der Abteilung für Pharmazeutische Chemie der Universität Leipzig verfolgte man diesen Ansatz weiter. Es wurden verschiedene Berechnungen durchgeführt. Gestützt durch computerbasierte Modelle kam man zu dem Schluss, dass 5-Bromethinyl-2-desoxyuridin (BEDU) ebenfalls eine mögliche zytostatische Substanz sei. 
Die Dissertationen von Heinze und Führer (beide 2008) haben sich mit der Synthese dieser Substanz (BEDU) sowie Analoga des BVDU befasst. Im Rahmen der Entwicklung effektiver Synthesevorschriften entstanden neben den angestrebten Produkten in Form von Fehlprodukten und Synthesevorstufen viele verschiedene neue Uracilderivate. Diese wurden dann noch durch zusätzliche Substituenten verändert. Detaillierte Informationen können den beiden Dissertationen entnommen werden.

\subsection{Aufgabenstellung}

Zielsetzung dieser Arbeit war, die in Leipzig - ausgehend von dem Virostatikum Brivudin synthetisierten Verbindungen nun auf eine mögliche zytostatische Wirkung an humanen Krebszelllinien im Vergleich zu dem etablierten Chemotherapeutikum und Uracilderivat 5-Fluoruracil zu testen.

Begonnen wurde zunächst mit den in Position 5 des Uracils unterschiedlich substituierten Derivaten. Für die Testung wurden zwei Suspensionszelllinien (Leukämiezellen) als Beispiel für die Wirkung bei hämatologischen Neoplasien sowie zwei adhärente Zelllinien (Kolonkarzinomzellen) als Beispiel für die Wirkung an soliden Tumoren eingesetzt. Darauf aufbauend sollte die Einführung weiterer lipophiler bzw. hydrophiler Reste in Position 1 der jeweiligen Uracilreste mit ihrer Auswirkung auf tumortoxische Effizienz sowie Potenz untersucht werden. Mit den effizienten Substanzen waren dann Tests auf deren pro-apoptotische Wirkung (Caspaseassays und DNA-Fragmentierungen) vorgesehen. Zur Eingrenzung des Wirkmechanismus sollten die wichtigsten neuen Wirkstoffe auf Ähnlichkeiten sowie Unterschiede bei der Beeinträchtigung des GSH-Haushaltes der Zellen untersucht werden. Zudem sollte versucht werden, die neuen Substanzen nach Behandlung intrazellulär nachzuweisen. Des Weiteren sollten mögliche zytoprotektive Effekte von $\mathrm{N}$-Acetylcystein bzw. Methionin untersucht werden. 


\section{Material und Methoden}

In diesem Kapitel werden die im Rahmen des experimentellen Teils dieser Arbeit verwendeten Materialien und Testverfahren vorgestellt.

\subsection{Zellkultur}

\subsubsection{Geräte und Materialien}

\begin{tabular}{|c|c|c|}
\hline Autoclav & Bioclav & Schütt (Göttingen) \\
\hline Glaspipetten & Brand 1 - $20 \mathrm{ml}$ & Krannich (Göttingen) \\
\hline Inkubator & $\mathrm{CO}_{2}$-Inkubator 160 & Mytron (Heiligenstadt) \\
\hline Mikroskop & TMS-F & Nikon (Düsseldorf) \\
\hline Neubauerkammer & $0,1 \mathrm{~mm}$ & Brand (Wertheim) \\
\hline Pasteurpipetten & Brand, 25 mm, 2 ml Volumen & Krannich (Göttingen) \\
\hline Pipetten & $2,5-5000 \mu l$ & Eppendorf (Hamburg) \\
\hline Pipettenspitzen & $2,5-5000 \mu \mathrm{l}$ & Eppendorf (Hamburg) \\
\hline Pipettierhilfe & Glass Master & Rainin (Woburn, USA) \\
\hline Schüttler & Vortex VF 2 & IKA-Labortechnik (Staufen) \\
\hline Sterilbank & Steril Guard Hood & Baker Company (Sanford, USA) \\
\hline Wasserbad & Kötterman Typ 3047 & Schütt (Göttingen) \\
\hline Zentrifuge & Universal $16 \mathrm{R}$ & Hettich (Tuttlingen) \\
\hline Zentrifugenröhrchen & 15 und $50 \mathrm{ml}$ & Sarstedt (Nümbrecht) \\
\hline Zellkulturflaschen & 25 und $75 \mathrm{~cm}^{2}$ Flaschen & Sarstedt (Nümbrecht) \\
\hline
\end{tabular}


Zellkulturschalen

Zellkulturschalen

Zellschaber
3,5 cm; 6- und 96-Well Platte

24-Well Platte, BD Falcon

BD Biosciences (San Jose, USA)

\subsubsection{Kulturmedien und Lösungen}

\section{$\underline{\text { RPMI }}$}

Zur Herstellung des Mediums wurde RPMI-Konzentrat der Firma c.c.pro (Oberdorla) und zweifach destilliertes sowie autoklaviertes Wasser verwendet. Des Weiteren enthielt das Medium folgende Zusätze: Natriumbikarbonat $2 \mathrm{~g} / \mathrm{l}$; Natriumpyruvat $1 \mathrm{mM}$; L-Glutamin $2 \mathrm{mM}$; Hepes $10 \mathrm{mM}$, MEM NEAA einfach konzentriert, Penicillin/Streptomycin 10.000 E/10 mg/l; Amphotericin B $25 \mu \mathrm{g} / \mathrm{l}$ (alle c.c.pro (Oberdorla)) und $10 \%$ FCS, Biochrom (Berlin).

Die Herstellung des Mediums erfolgte unter sterilen Bedingungen.

Der pH-Wert des Mediums wurde mit $\mathrm{NaOH}$ auf 7,4 eingestellt. Die Lagerung erfolgte bei $4{ }^{\circ} \mathrm{C}$.

Das RPMI wurde zur Kultivierung der Suspensionszelllinien (HL60 und U937) verwendet.

\section{$\underline{\text { DMEM }}$}

Zur Herstellung des Mediums wurde DMEM-Konzentrat der Firma c.c.pro (Oberdorla) und zweifach destilliertes sowie autoklaviertes Wasser verwendet. Des Weiteren enthielt das Medium folgende Zusätze: Natriumbikarbonat 3,7 g/l; Natriumpyruvat $1 \mathrm{mM}$; L-Glutamin 4 mM; Hepes 10 mM; Penicillin/Streptomycin 10.000 E/10 mg/l; Amphotericin B 25 нg/l (alle c.c.pro (Oberdorla)) und 8 \% FCS, Biochrom (Berlin).

Die Herstellung des Mediums erfolgte unter sterilen Bedingungen.

Der pH-Wert des Mediums wurde mit $\mathrm{NaOH}$ auf 7,4 eingestellt. Die Lagerung erfolgte bei $4^{\circ} \mathrm{C}$.

Das DMEM wurde zur Kultivierung der adhärenten Zellen (LoVo und HCT) verwendet. 


\section{Phosphat-gepufferte Salzlösung (PBS)}

Für das PBS wurden 2,7 mM KCL; 1,5 mM KH $2 \mathrm{PO}_{4} ; 137 \mathrm{mM} \mathrm{NaCl}$ und $10 \mathrm{mM} \mathrm{Na} 2 \mathrm{HPO}_{4}$ der Firma Biochrom (Berlin) in destilliertem Wasser angesetzt.

Die PBS-Lösung wurde unter anderem zur Aufarbeitung der adhärenten Zelllinien (Reinigung vom Kulturmedium vor Zugabe der Trypsinlösung) verwendet.

\section{$\underline{\text { Trypsin }}$}

Zur Herstellung der gebrauchsfertigen Trypsinlösung wurden 50 mg/l Trypsin und 20 mg/l EDTA der Firma c.c.pro (Oberdorla) in PBS angesetzt.

Die Trypsinlösung wurde zur Ablösung der adhärenten Zellen von dem Kulturgefäß eingesetzt.

\subsubsection{Zelllinien}

Im Rahmen dieser Arbeit wurden folgende Zelllinien verwendet:

Leukämiezellen:

HL60 (= Suspensionszellen), von der Deutschen Sammlung von Mikroorganismen und Zellkulturen (DSMZ) in Braunschweig.

Lymphomzellen:

U937 (= Suspensionszellen), aus dem Zoologischen Institut der Universität Leipzig.

Kolonkarzinomzellen:

LoVo (= adhärente Zellen), aus der Abteilung Hämatologie und Onkologie des Zentrums für Innere Medizin der Universität Göttingen.

HCT (= adhärente Zellen) aus der Abteilung Molekulare Medizin, Göttingen.

Die Zellen wurden im Inkubator bei $37^{\circ} \mathrm{C}, 100 \%$ Luftfeuchtigkeit und $5 \% \mathrm{CO}_{2}$ gelagert. Eine Zelldichte von $10^{5}-10^{6}$ Zellen pro ml Medium wurde angestrebt, je nach Bedarf wurden die Zellkulturen entsprechend 2-3 mal pro Woche ausgedünnt. Alle Arbeiten mit 
Zellen wurden unter sterilen Bedingungen in einer Sterilbank durchgeführt. Bei Verwendung der adhärenten Zellen wurde das Medium (DMEM) vorsichtig abgesaugt, die Zellen mit PBS gewaschen und mit einer Trypsinlösung von der Kulturflasche gelöst. Die Aktivität des Trypsins wurde dann durch Zugabe von serumhaltigem Medium beendet, die Zellen vorsichtig suspendiert und in ein Zentrifugenröhrchen überführt. Dann wurden die Zellen für $3 \mathrm{~min}$ bei $800 \mathrm{U} / \mathrm{min}$ zentrifugiert. Das Medium wurde verworfen und das Zellpellet in frischem Medium resuspendiert und anschließend wurden die Zellen mit Hilfe einer Neubauerkammer gezählt. Danach konnten die Zellen in gewünschter Verdünnung weiter verarbeitet bzw. kultiviert werden.

Die Suspensionszellen konnten, ebenfalls mit Hilfe einer Neubauerkammer, direkt gezählt werden. Die gewünschte Zellmenge wurde in ein Zentrifugenröhrchen gegeben und die Zellen bei $1500 \mathrm{U} / \mathrm{min}$ für 5 min zentrifugiert. Das Zellpellet wurde in gewünschtem Volumen Medium (RPMI) wieder aufgenommen und entsprechend verarbeitet.

\subsection{Chemikalien und Testsubstanzen}

\subsubsection{Allgemeines}

Alle Standardchemikalien wie Puffer, Lösungsmittel und andere wurden in p.a.-Qualität von den Firmen Applichem, Boehringer Mannheim, Calbiochem, Fluka, Merck, Roth oder Sigma-Aldrich bezogen.

\subsubsection{Testsubstanzen}

Die Testsubstanzen wurden uns freundlicherweise von der Abteilung Pharmazeutische Chemie der Universität Leipzig zur Verfügung gestellt und entstanden dort im Rahmen der Dissertationen von Nicole Heinze und Martin Führer (beide 2008).

Die Substanzen wurden in DMSO in Stocklösungen von 25 bzw. 100 mM angesetzt und diese bei $-20^{\circ} \mathrm{C}$ gelagert. Kontrollzellen wurden ebenfalls immer mit der gleichen Konzentration DMSO (Endkonzentration immer unter 0,5 \%) behandelt. Weitere Verdünnungen erfolgten in Medium. 


\begin{tabular}{|c|c|c|c|c|}
\hline Testsubstanz & Abkürzung & Strukturformel & MG & Herkunft \\
\hline trans- $\beta$-Nitrostyrol & NS & & $\begin{array}{l}149,15 \\
\mathrm{~g} / \mathrm{mol}\end{array}$ & $\begin{array}{c}\text { Abteilung } \\
\text { Pharmazeutische } \\
\text { Chemie, } \\
\text { Universität } \\
\text { Leipzig }\end{array}$ \\
\hline 5-Fluorouracil & 5-FU & & $\begin{array}{l}130,08 \\
\mathrm{~g} / \mathrm{mol}\end{array}$ & $\begin{array}{c}\text { Merck } \\
\text { (Darmstadt) }\end{array}$ \\
\hline $\begin{array}{l}\text { 5-(1H-(1,2,3)triazol- } \\
\text { 4yl)-1H-pyrimidine- } \\
\text { 2,4 dione }\end{array}$ & TAU & & $\begin{array}{c}179,14 \\
\mathrm{~g} / \mathrm{mol}\end{array}$ & $\begin{array}{c}\text { Abteilung } \\
\text { Pharmazeutische } \\
\text { Chemie, } \\
\text { Universität } \\
\text { Leipzig }\end{array}$ \\
\hline $\begin{array}{c}\text { 1-Benzhydryl-5-(1H- } \\
\text { (1,2,3)triazol-4- } \\
\text { yl)1H-pyrimidine- } \\
\text { 2,4-dione }\end{array}$ & BH-TAU & & $\begin{array}{c}345,36 \\
\mathrm{~g} / \mathrm{mol}\end{array}$ & $\begin{array}{c}\text { Abteilung } \\
\text { Pharmazeutische } \\
\text { Chemie, } \\
\text { Universität } \\
\text { Leipzig }\end{array}$ \\
\hline $\begin{array}{l}\text { 1-Benzyl-5-(1H } \\
\text { (1,2,3)triazol-4-yl)- } \\
\text { 1H-pyrimidine-2,4- } \\
\text { dione }\end{array}$ & B-TAU & & $\begin{array}{c}269,26 \\
\mathrm{~g} / \mathrm{mol}\end{array}$ & $\begin{array}{c}\text { Abteilung } \\
\text { Pharmazeutische } \\
\text { Chemie, } \\
\text { Universität } \\
\text { Leipzig }\end{array}$ \\
\hline 5- Ethinyluracil & EU & & $\begin{array}{l}136,11 \\
\mathrm{~g} / \mathrm{mol}\end{array}$ & $\begin{array}{c}\text { Abteilung } \\
\text { Pharmazeutische } \\
\text { Chemie, } \\
\text { Universität } \\
\text { Leipzig }\end{array}$ \\
\hline
\end{tabular}




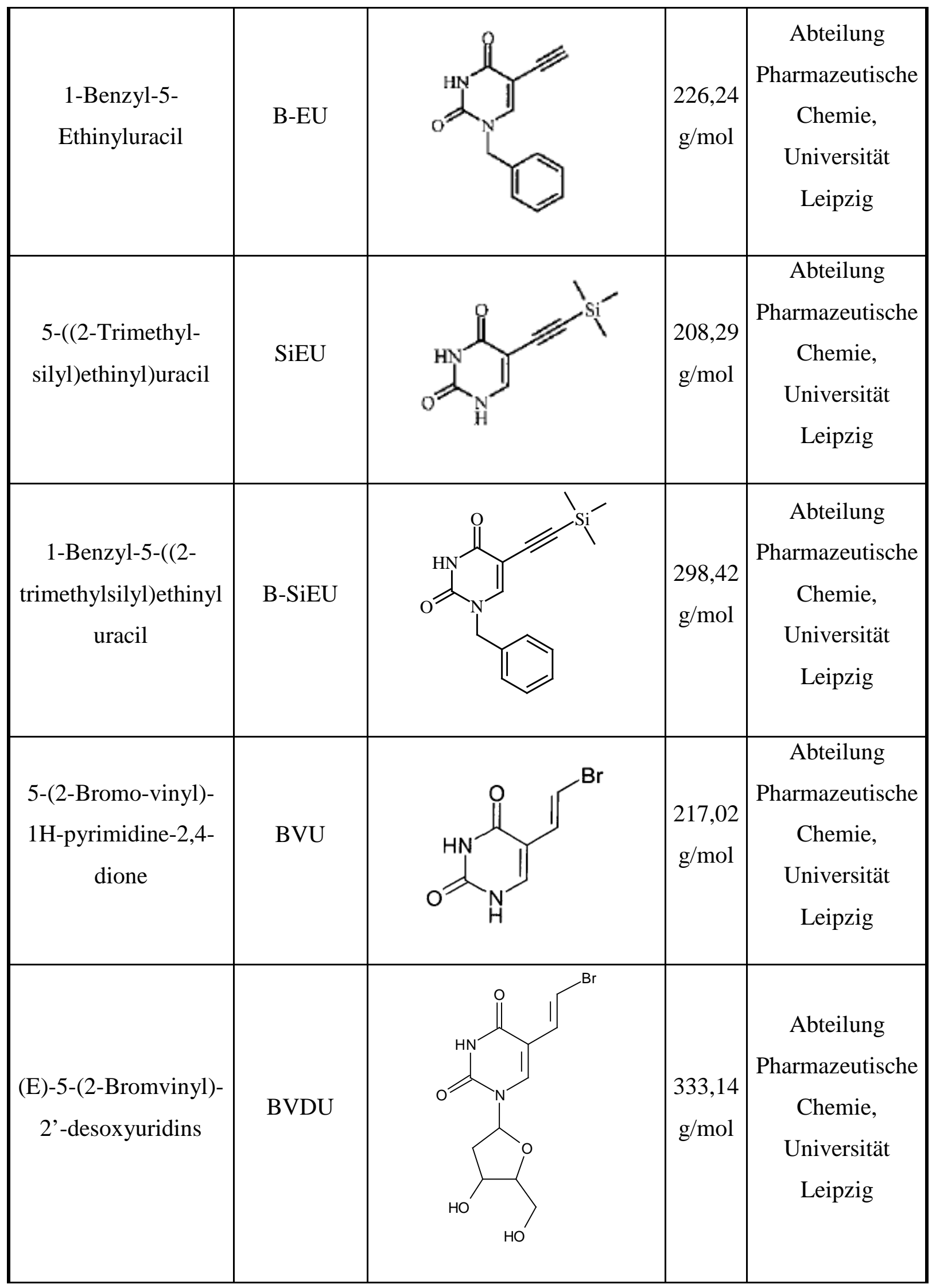




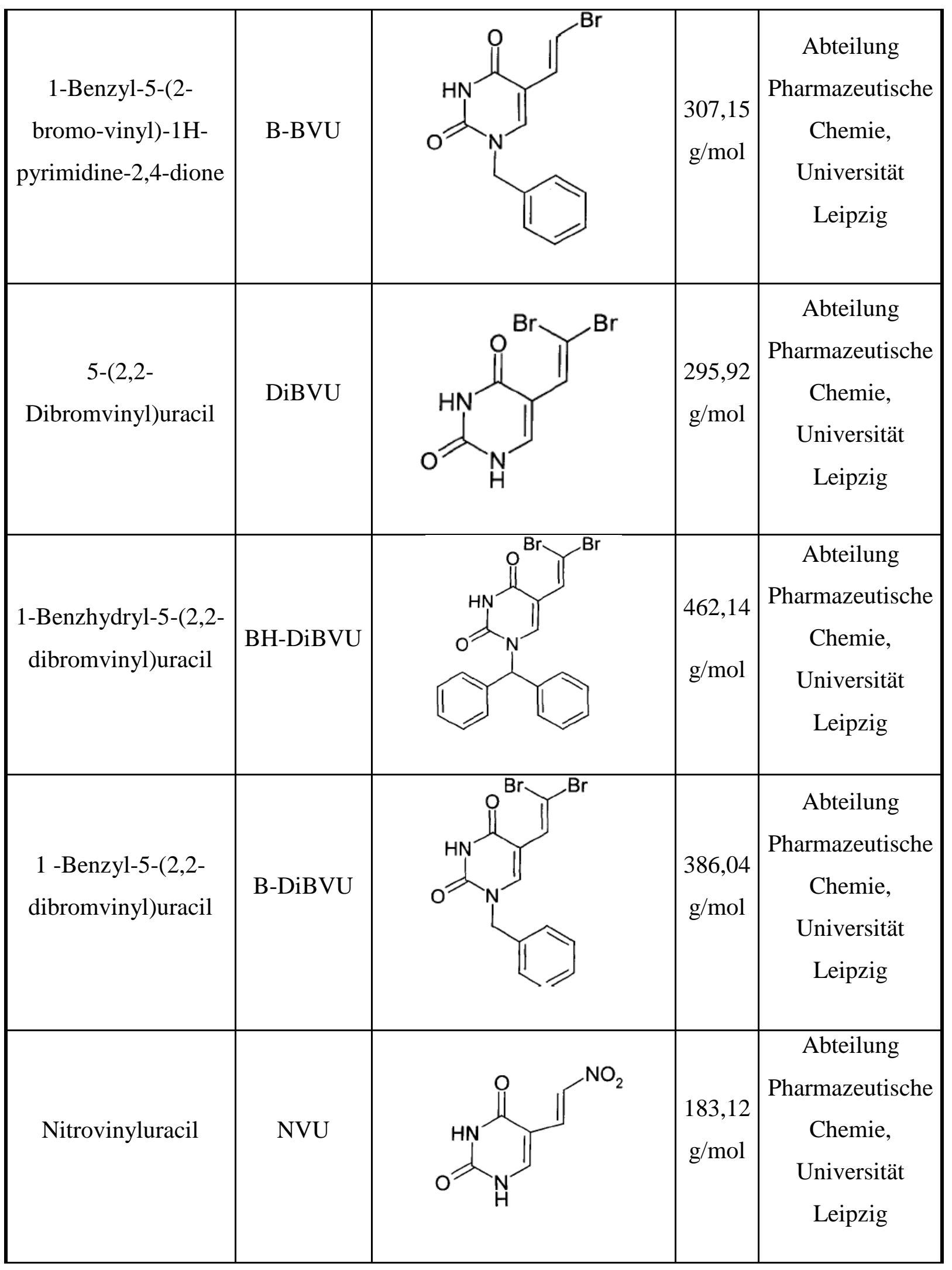




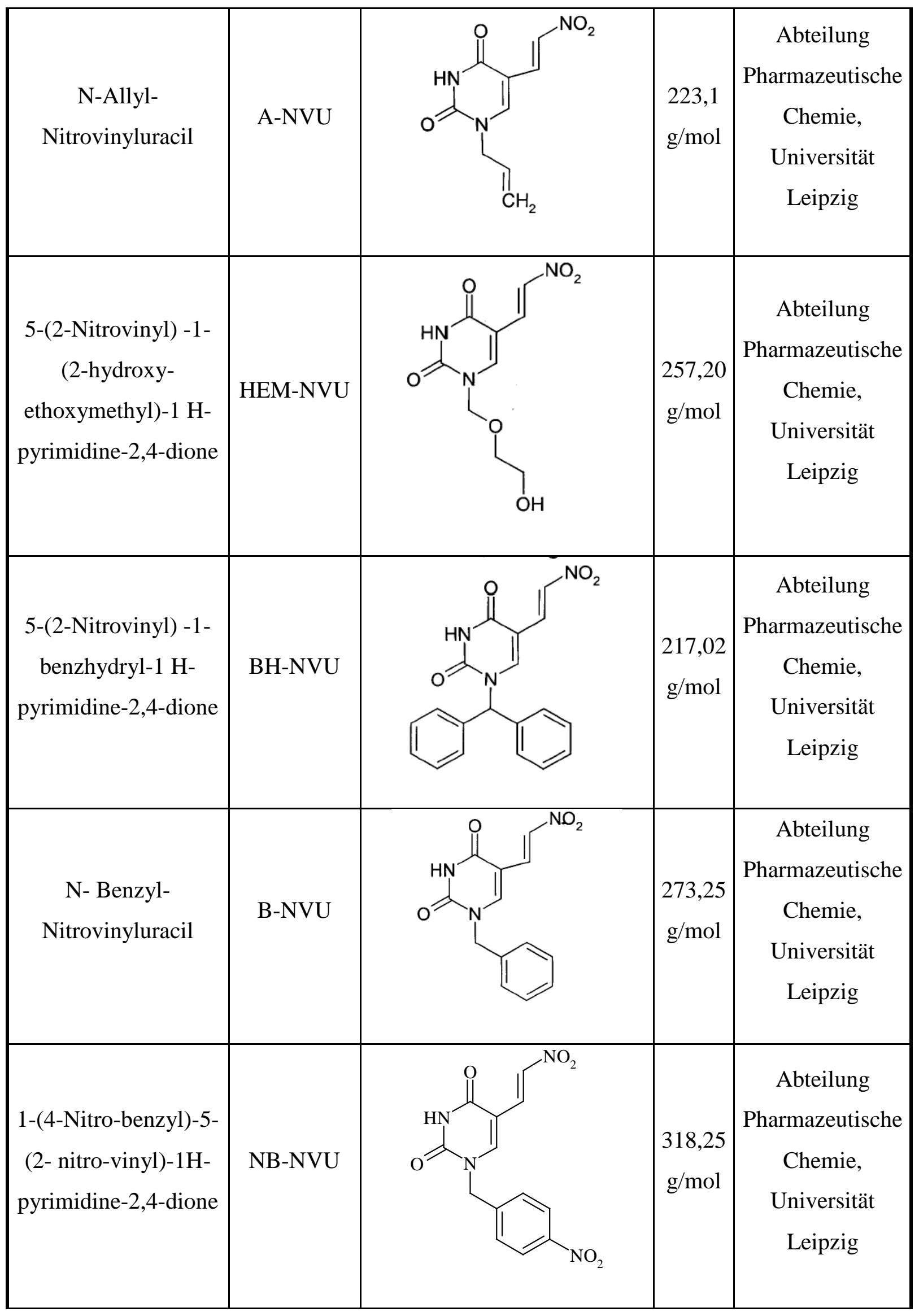




\begin{tabular}{|c|c|c|c|c|}
\hline $\begin{array}{l}\text { 1-(1- Phenyl -ethyl) - } \\
\text { 5-(2- nitrovinyl)-1H- } \\
\text { pyrimidine-2,4-dione }\end{array}$ & PE-NVU & $\mathrm{O} \quad \Gamma^{\mathrm{NO}}$ & $\begin{array}{c}287,28 \\
\mathrm{~g} / \mathrm{mol}\end{array}$ & $\begin{array}{c}\text { Abteilung } \\
\text { Pharmazeutische } \\
\text { Chemie, } \\
\text { Universität } \\
\text { Leipzig }\end{array}$ \\
\hline $\begin{array}{c}\text { 1-(4-Methoxy - } \\
\text { benzyl)- 5-(2- } \\
\text { Nitrovinyl)-1H- } \\
\text { pyrimidine-2,4-dione }\end{array}$ & MB-NVU & (l) & $\begin{array}{c}303,28 \\
\mathrm{~g} / \mathrm{mol}\end{array}$ & $\begin{array}{c}\text { Abteilung } \\
\text { Pharmazeutische } \\
\text { Chemie, } \\
\text { Universität } \\
\text { Leipzig }\end{array}$ \\
\hline $\begin{array}{l}\text { 1-(3,4,5- } \\
\text { Trimethoxybenzyl)- } \\
\text { 5-(2-Nitrovinyl)-1H- } \\
\text { pyrimidine-2,4-dione }\end{array}$ & $\begin{array}{c}\text { TriMB- } \\
\text { NVU }\end{array}$ & & $\begin{array}{c}363,33 \\
\mathrm{~g} / \mathrm{mol}\end{array}$ & $\begin{array}{c}\text { Abteilung } \\
\text { Pharmazeutische } \\
\text { Chemie, } \\
\text { Universität } \\
\text { Leipzig }\end{array}$ \\
\hline $\begin{array}{l}\text { 1-(4-Fluoro-benzyl)- } \\
\text { 5-(2-nitro-vinyl)-1H- } \\
\text { pyrimidine-2,4-dione }\end{array}$ & FB-NVU & & $\begin{array}{c}291,24 \\
\mathrm{~g} / \mathrm{mol}\end{array}$ & $\begin{array}{c}\text { Abteilung } \\
\text { Pharmazeutische } \\
\text { Chemie, } \\
\text { Universität } \\
\text { Leipzig }\end{array}$ \\
\hline $\begin{array}{l}\text { 1-(3,4- } \\
\text { Difluorobenzyl)-5-(2- } \\
\text { nitrovinyl)-1H- } \\
\text { pyrimidine-2,4-dion }\end{array}$ & $\begin{array}{c}\text { 3,4 DiFB- } \\
\text { NVU }\end{array}$ & & $\begin{array}{l}309,23 \\
\mathrm{~g} / \mathrm{mol}\end{array}$ & $\begin{array}{c}\text { Abteilung } \\
\text { Pharmazeutische } \\
\text { Chemie, } \\
\text { Universität } \\
\text { Leipzig }\end{array}$ \\
\hline
\end{tabular}




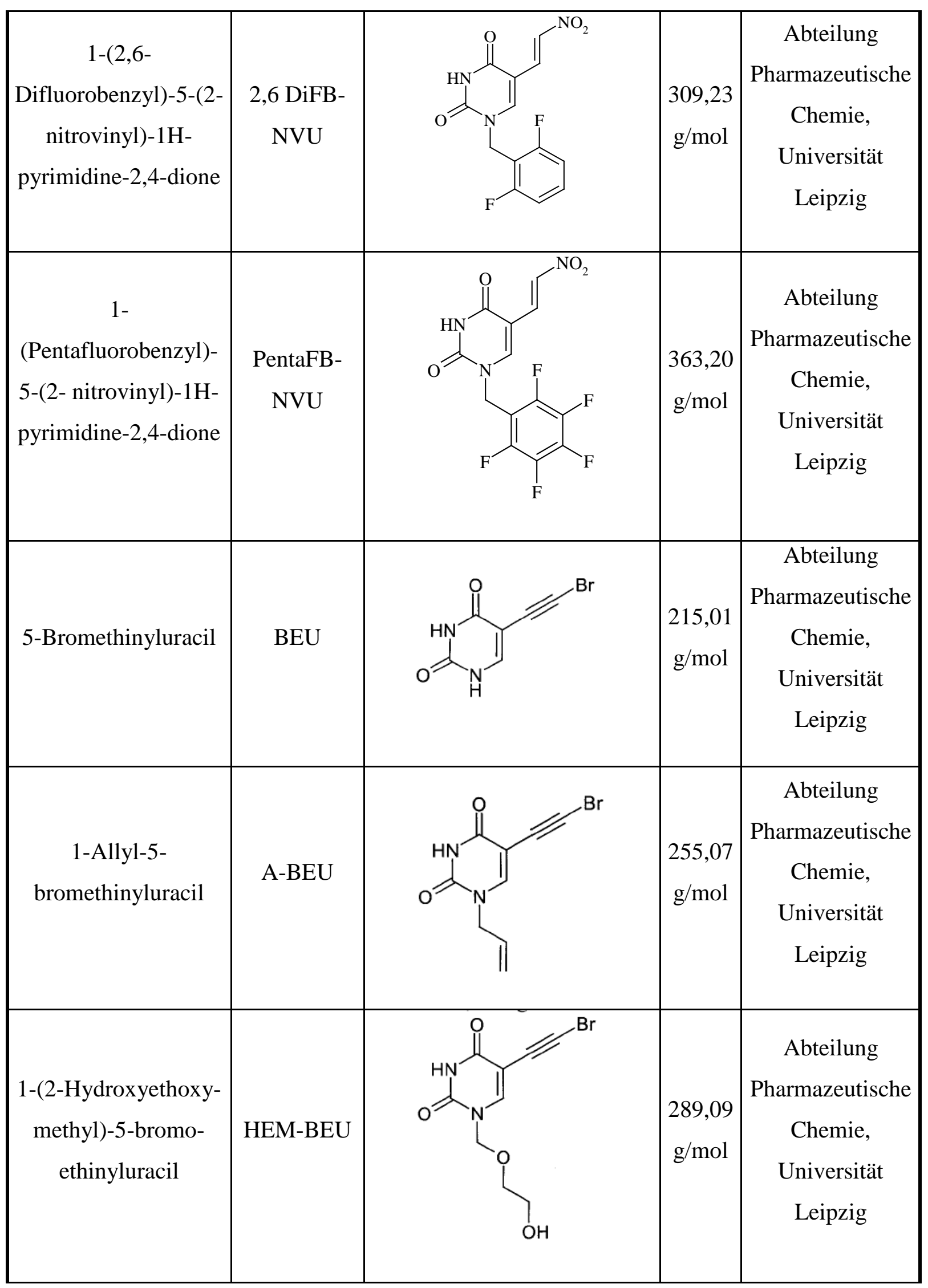




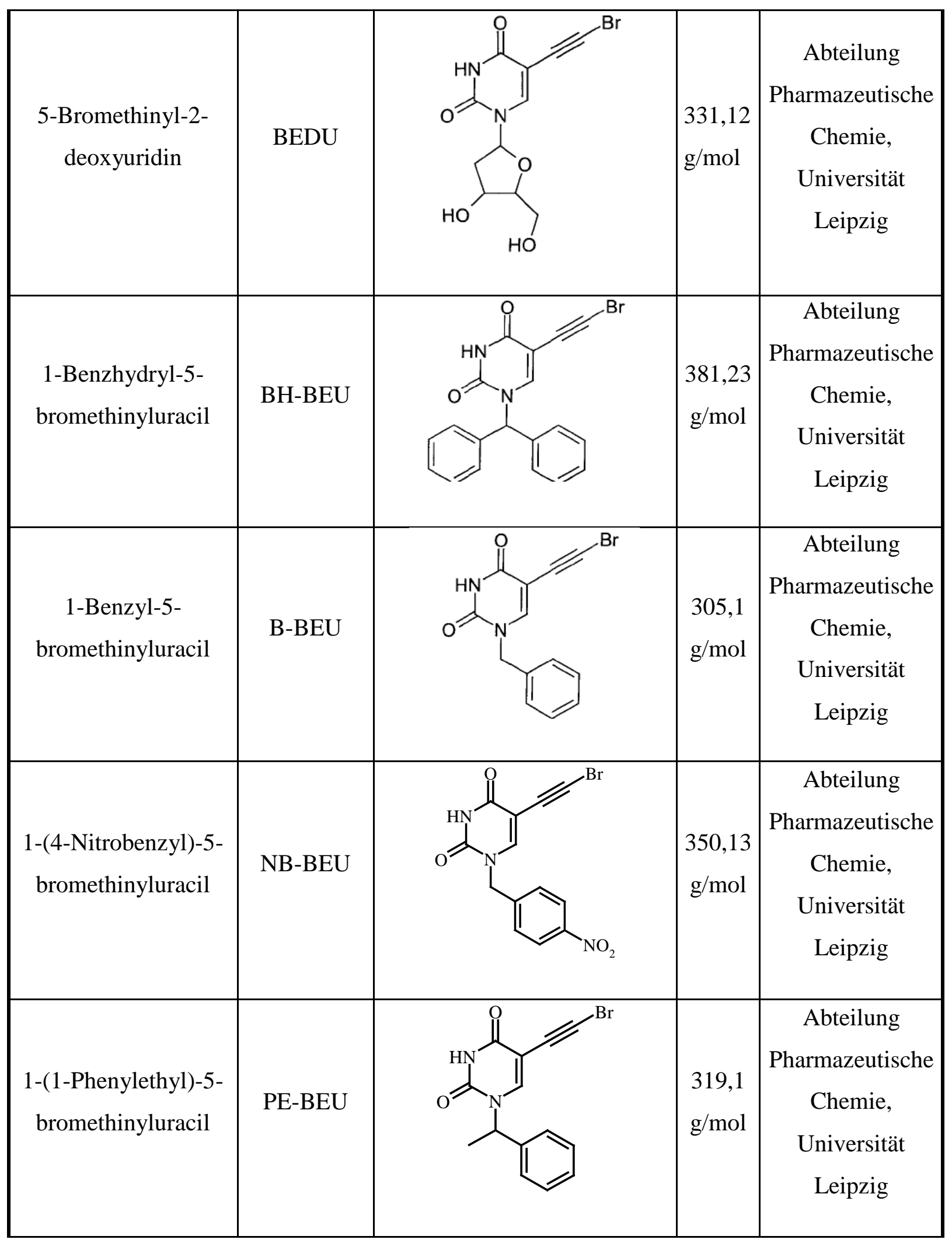




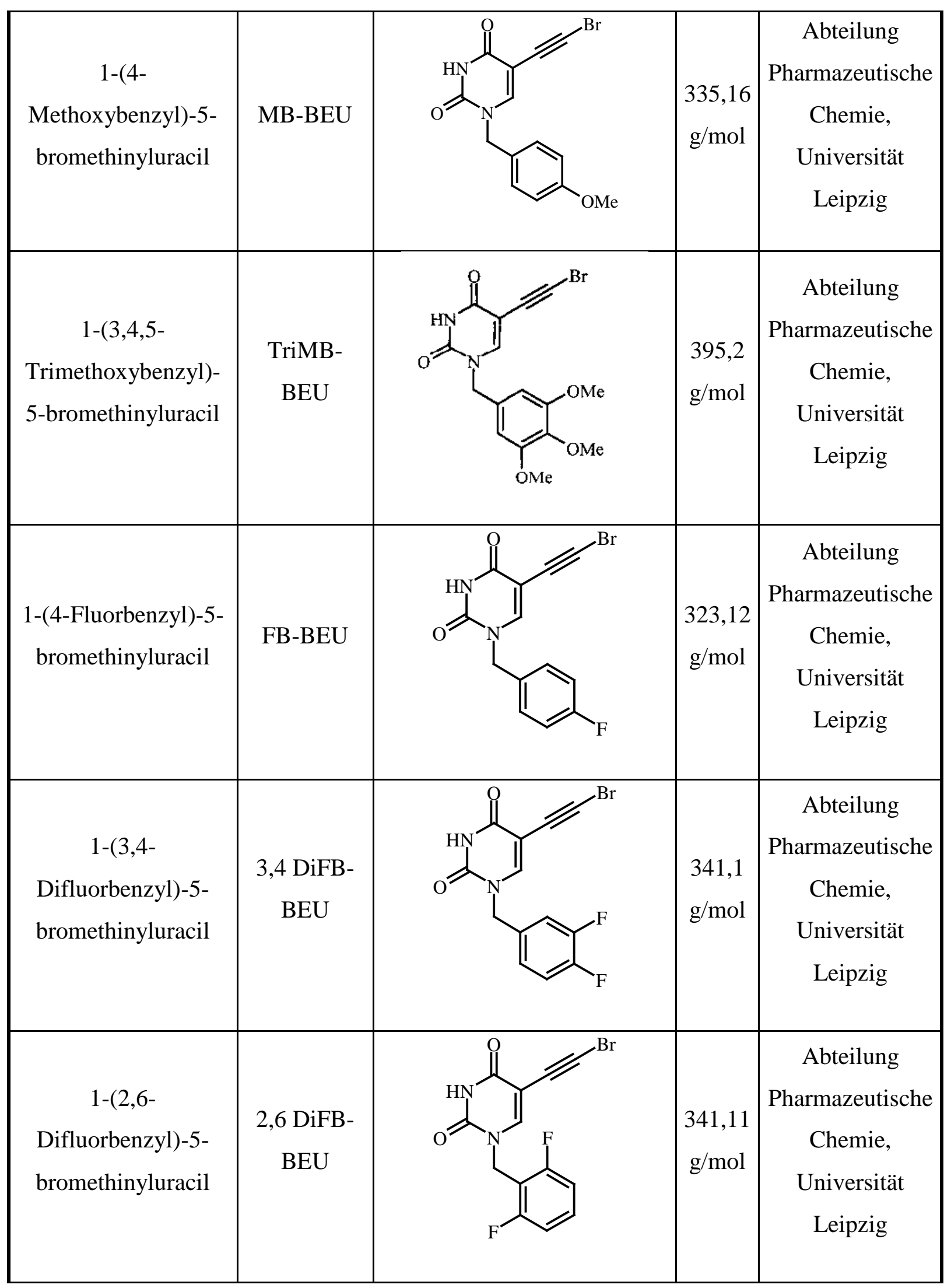




\begin{tabular}{|c|c|c|c|c|c|}
\hline N-Acetylcystein & NAC & & Sigma-Aldrich \\
(Steinheim)
\end{tabular}

\subsection{MTT-Vitalitätstests}

\subsubsection{Geräte und Materialien}

MTT

Plattenphotometer

SDS

Zellkulturplatten
$5 \mathrm{mg} / \mathrm{ml}$ in PBS

UVmax

$20 \%$ in 0,02 N HCL

96-Well
Sigma-Aldrich (Steinheim)

Molecular Devices (Sunnyvale, USA)

AppliChem (Darmstadt)

Sarstedt (Nümbrecht) 


\subsubsection{Assayprinzip}

Der gelbe Farbstoff 3-(4,5-Dimethyl-2-thiazolyl)-2,5-Diphenyl-Tetrazolium-Bromid (MTT) wird in vitalen Zellen durch mitochondriale Dehydrogenasen (Succinat-TetrazoliumReduktase) zum dunkelblauen Formazan umgesetzt. Das Formazan kann bei einer Wellenlänge von $550 \mathrm{~nm}$ photometrisch bestimmt werden. Somit kann über den MTT-Umsatz in Bezug auf eine unbehandelte Kontrolle auf den Anteil an lebenden Zellen geschlossen werden (Mosmann 1983, von Zezschwitz et al. 1997).

Das Assayprotokoll wurde modifiziert nach Protokollen von Werner (Werner 2005) und Kaap (Kaap2004).

\subsubsection{Assaydurchführung}

Adhärente Zellen wurden am Vortag, Suspensionszellen am Behandlungstag plattiert. Die Zellzahl je Well wurde abhängig von der verwendeten Zelllinie wie folgt gewählt:

HL60: 25.000,

U937: $\quad 50.000$,

LoVo: $\quad 5.000$,

HCT: $\quad 5.000$.

Die Randwells der 96-Well-Platten wurden nur mit jeweils $100 \mu$ l Medium gefüllt, um Störungen durch Verdunstungseffekte zu vermeiden.

Am Behandlungstag wurde das Medium von den adhärenten Zellen vorsichtig abgesaugt und $100 \mu$ l Medium mit entsprechender Behandlung bzw. nur DMSO-Anteil für die Kontrollen auf die Zellen gegeben. Bei Verwendung von Suspensionszellen wurden $25 \mu \mathrm{l}$ Behandlung/DMSO für die Kontrolle vorgelegt und die Zellen in $75 \mu$ l Medium dazu pipettiert um eine gute Durchmischung zu erreichen.

Entsprechend der geplanten Behandlungsdauer wurden die Platten im Brutschrank inkubiert. Nach Ablauf der Behandlungszeit wurden je Well $10 \mu$ l MTT-Lösung hinzugegeben und dann die Platte je nach Zellart für 1-3 h (Suspensionszellen: 3 h, HCT 2 h, LoVo 1 h) wieder in den Inkubator gestellt. Danach wurden die Zellen durch Zugabe von $100 \mu$ l SDS-Lösung je Well 
lysiert und erneut für 1-2 h (Suspensionszellen: 1 h, HCT: 2 h, LoVo: 1 h) inkubiert, unterbrochen durch regelmäßiges Schütteln (alle 5-10 min). Dann wurde die Extinktionen bei 550 nm im Plattenphotometer gemessen und die ermittelten Werte auf die unbehandelte Kontrolle bezogen.

\subsection{Messung der Caspaseaktivität als apoptotischer Parameter}

\subsubsection{Geräte und Materialien}

$\begin{array}{lll}\text { AEBSF } & 50 \mathrm{mM} & \text { AppliChem (Darmstadt) } \\ \text { AFC } & 10 \mathrm{mM} & \text { Bachem (Weil am Rhein) } \\ \text { Digitonin } & & \text { Merck (Darmstadt) } \\ \text { DTT } & 1 \mathrm{M} & \text { AppliChem (Darmstadt) } \\ \text { DEVD-AFC } & 10 \mathrm{mM} & \text { Bachem (Weil am Rhein) } \\ \text { HEPES } & 1 \mathrm{M} & \text { c.c.pro (Oberdorla) } \\ \text { Na-EDTA } & 0,1 \mathrm{M} & \text { AppliChem (Darmstadt) } \\ \text { NP-40 (Tergitol) } & 10 \% & \text { Sigma-Aldrich (Steinheim) } \\ \text { Plattenfluorimeter } & \text { Fusion } & \text { Packhard Bioscience (Waltham, USA) } \\ \text { Plattenzentrifuge } & 5804 \mathrm{R} & \text { Eppendorf (Hamburg) } \\ \text { Wasserbad } & \text { Köttermann Typ 3047 } & \text { Schütt (Göttingen) } \\ \text { Zellkulturplatten } & \text { Falcon 24-Well } & \text { BD Biosciences (San Jose, USA) }\end{array}$




\subsubsection{Lösungen}

\section{$\underline{\text { Caspase 0 + Digitonin-Puffer: }}$}

Für den Puffer wurden $1 \mathrm{ml}$ Hepes 1 M, $10 \mathrm{ml} \mathrm{NP-40} 10 \%$ und 2,5 mg Digitonin mit destilliertem Wasser auf $90 \mathrm{ml}$ aufgefüllt.

\section{Lysispuffer:}

Für $10 \mathrm{ml}$ wurden $9 \mathrm{ml}$ Caspase 0 + Digitonin-Puffer mit $260 \mu \mathrm{l} \mathrm{Na-EDTA} \mathrm{0,1} \mathrm{M;} 200 \mu \mathrm{l}$ AEBSF 50 mM; $100 \mu$ l DTT $1 \mathrm{M}$ und $440 \mu$ l destilliertem Wasser gemischt.

Substratpuffer:

Dem Lysispuffer wurde DEVD-AFC zugesetzt (Endkonzentration $25 \mu \mathrm{M}$ ).

\subsubsection{Assayprinzip}

Dieser Test erfasst die Caspaseaktivität durch Messung eines Fluoreszenzfarbstoffes, der bei dem Umsatz eines spezifischen Substrates freigesetzt wird und somit als Maß für die vorhandene Enzymmenge dient.

Caspasen erkennen eine bestimmte Aminosäuresequenz und spalten diese vor der Asparaginsäure. Das macht man sich experimentell zu Nutze, in dem man Caspasesubstrate mit der spezifischen Aminosäuresequenz und einem Fluoreszenzfarbstoff synthetisiert hat: Aspartyl-glutamyl-valyl-aspartyl-7-amido-4-trifluoro-methyl-Cumarin (DEVD-AFC) besteht aus einer spezifischen Erkennungssequenz der Caspase 3/7 und dem Farbstoff AFC, welcher erst nach Abspaltung des Peptids fluorometrisch messbar wird (Nicholson et al. 1995, Thornberry und Lazebnik 1998, Slee et al. 1999).

Das Assayprotokoll wurde modifiziert nach Protokollen von Werner (Werner 2005) und Kaap (Kaap 2004). 


\subsubsection{Assaydurchführung}

Adhärente Zellen wurden am Vortag, Suspensionszellen am Behandlungstag in 24-WellPlatten plattiert. Zellzahl je Well:

HL60: $\quad 500.000$,

U937: $\quad$ 1.000.000,

LoVo: $\quad$ 100.000,

HCT: $\quad 100.000$.

Am Behandlungstag wurde das Medium von den adhärenten Zellen vorsichtig abgesaugt und $1000 \mu \mathrm{l}$ Medium mit Behandlung bzw. nur DMSO für die Kontrolle auf die Zellen gegeben. Bei Verwendung von Suspensionszellen wurden je Well $250 \mu$ l Behandlung bzw. DMSO für die Kontrolle vorgelegt und die Zellen in $750 \mu$ l Medium dazu pipettiert um eine gute Durchmischung zu erreichen. Entsprechend der geplanten Behandlungsdauer wurden die Platten im Brutschrank inkubiert. Nach Ablauf der Behandlungszeit wurden die Platten bei Raumtemperatur zentrifugiert, Suspensionszellenzellen: $1500 \mathrm{U} / \mathrm{min}$ für $20 \mathrm{~min}$, adhärente Zellen: $800 \mathrm{U} / \mathrm{min}$ für 15 min.

Nach der Zentrifugation wurde das Medium vorsichtig abgenommen und je Well $250 \mu \mathrm{l}$ Lysis- puffer hinzu gegeben. Die Platten wurden für $15 \mathrm{~min}$ auf Eis gestellt und zwischendurch immer wieder vorsichtig geschwenkt. Dann wurden die Platten in flüssigem Stickstoff gefroren und bis zur Messung bei $-20{ }^{\circ} \mathrm{C}$ gelagert.

Die Platten wurden auf Eis aufgetaut, bzw. nach dem Auftauen sofort auf Eis gestellt. In jedes Well wurden $50 \mu$ l Substratpuffer hinzugefügt. Als Referenzwert wurde $1 \mu$ l AFC mit $299 \mu$ l Lysispuffer in eine entsprechende Anzahl von Wells gegeben. Die Leerwerte wurden wie die Proben behandelt.

Am Plattenfluorometer wurde die Freisetzung von AFC bei einer Exzitationswellenlänge von $440 \mathrm{~nm}$ und einer Emissionswellenlänge von 515 nm gemessen. Über einen Zeitraum von 2 Stunden wurden alle 5-10 min Messungen durchgeführt. Die Platten wurden zwischen den Messungen bei $37^{\circ} \mathrm{C}$ im Wasserbad inkubiert. Aus dem linear ansteigenden Teil der Kurve ließ sich die Freisetzung von AFC pro Zeiteinheit berechnen. Die Proben wurden auf die unbehandelten Kontrollen bezogen und die Caspase-3-Aktivität als Vielfaches der Kontrolle dargestellt. 


\subsection{DNA-Fragmentierung als apoptotischer Parameter}

\subsubsection{Geräte und Materialien}

\begin{tabular}{|c|c|c|}
\hline Agarosegelkammer & Horizon 58 & Gibco Life Technologies (Eggenstein) \\
\hline $\mathrm{CsCl}$ & & Sigma-Aldrich (Steinheim) \\
\hline Ethidiumbromid & & Fluka (Buchs, Schweiz) \\
\hline Ficoll & & Pharmacia (Erlangen) \\
\hline Geldokumentationssystem & BioDoc-System & Biometra (Göttingen) \\
\hline Nusive Agarose & & FMC BioProducts (Rockland, USA) \\
\hline Orange G & & Promega (Mannheim) \\
\hline RNase & & Qiagen (Hilden) \\
\hline SDS & $1,2 \%$ in $\mathrm{H}_{2} 0$ dest. & AppliChem (Darmstadt) \\
\hline UV-Transilluminator & $\mathrm{T} 1$ & Biometra (Göttingen) \\
\hline Zentrifuge & $5415 \mathrm{D}$ & Eppendorf (Hamburg) \\
\hline & 3К30 & Sigma-Aldrich (Steinheim) \\
\hline
\end{tabular}

\subsubsection{Lösungen}

\section{CsCl-Lösung}

3 M Cäsiumchlorid, 1 M Kaliumacetat und $4 \%$ (v/v) Essigsäure in zweifach destilliertem Wasser.

Ethidiumbromidlösung

$10 \mu \mathrm{L}$ Ethidiumbromid auf $100 \mathrm{ml}$ zweifach destilliertes Wasser. 
$\underline{\text { Stoppmix Orange G }}$

2 \% Ficoll, 0,5 \% SDS, 50 mM EDTA (pH 8) und 0,2 \% Orange G.

\section{$\underline{\text { TAE-Puffer }}$}

40 mM Tris, 20 mM Eisessig und 1 mM EDTA (pH 8).

\section{$\underline{\text { TE-Puffer }}$}

pH 7,5: 1 M Tris/HCL (pH 7,5) und 0,5 M EDTA (pH 8) in zweifach destilliertem Wasser.

pH 8: 1 M Tris/HCL (pH 8) und 0,5 M EDTA (pH 8) in zweifach destilliertem Wasser.

\section{$\underline{\text { Ansatz Agarosegel }}$}

Je Gel 480 mg NuSieve Agarose mit 30 ml TAE-Puffer aufkochen, in Gelkammer gießen und fest werden lassen, danach mind. eine Stunde bei $4{ }^{\circ} \mathrm{C}$ kühlen.

\subsubsection{Assayprinzip}

Bei diesem Assay ist es Ziel, die bei der Apoptose entstandenen DNA-Fragmente im Agarosegel aufzutrennen und darzustellen, als Nachweis einer abgelaufenen Apoptose.

Das Assayprotokoll wurde modifiziert nach Protokollen von Steinfelder (Steinfelder et al. 2000), Werner (Werner 2005) und Kaap (Kaap 2004).

\subsubsection{Assaydurchführung}

Es wurden 1 Mio. Zellen je Well in $2 \mathrm{ml}$ Medium/Behandlung in 6-Well-Platten, entsprechend dem Behandlungsplan, im Brutschrank inkubiert. Nach Ablauf des Behandlungsintervalls wurden die Wells vorsichtig durchmischt und $1 \mathrm{ml}$ Medium in ein 2-ml-Eppendorfgefäß überführt. Dieses wurde bei $1000 \mathrm{xg} 5 \mathrm{~min}$ zentrifugiert und der Überstand verworfen. Das Pellet wurde im TE-Puffer pH 7 mit RNase resuspendiert und dann mit SDS lysiert. Die CsCl-Lösung wurde zugesetzt und alles für 15 min auf Eis inkubiert. Es erfolgte ein erneuter Zentrifugationsschritt mit 14000 xg für 15 min bei Raumtemperatur. Ein Teil des Überstandes wurde entnommen und mit kaltem Isopropanol versetzt über Nacht bei $-20^{\circ} \mathrm{C}$ behandelt. 
Am nächsten Tag wurden die Proben für 10 min mit $14000 \mathrm{xg}$ bei $4{ }^{\circ} \mathrm{C}$ zentrifugiert und der Überstand verworfen. Es folgten zwei Waschschritte mit kaltem Ethanol (70 und 100 \%). Dieses wurde ebenfalls abzentrifugiert und durch Lufttrocknen der Probe wurde der restliche Alkohol durch Verdunstung entfernt. Die Proben wurden dann mit TE-Puffer pH 8 aufgenommen und mit dem Stoppmix versetzt in die Geltaschen aufgetragen. Bei einer Spannung von $40 \mathrm{~V}$ über 10 min wurden die Proben in das Gel eingelaufen und dann bei $70 \mathrm{~V}$ über 60 min aufgetrennt. Das Gel wurde in einer Ethidiumbromidlösung für 10 min gefärbt und in zweifach destilliertem Wasser entfärbt. Die Banden wurden mit Hilfe von UV-Licht (312 nm) sichtbar gemacht und das Gel zur Dokumentation abfotografiert.

\subsection{Messung von Substanz-Spektren}

\subsubsection{Geräte und Materialien}

BSA

Spektrophotometer

Zentrifuge

Universal $16 \mathrm{R}$
Sigma-Aldrich (Steinheim)

Shimadzu (Duisburg)

Hettich (Tuttlingen)

\subsubsection{Lösungen}

BSA-Verdünnung

$190 \mu \mathrm{l}$ BSA $2 \mathrm{mg} / \mathrm{ml}$ in 9,81 ml PBS

$\underline{\text { PBS/BSA-Lösung }}$

PBS und BSA-Verdünnung 1:1 vermischen. 


\subsubsection{Assaydurchführung}

\subsubsection{Allgemein}

Für die Spektrenmessung wurden die Substanzen in einer PBS/BSA-Lösung angesetzt und im Bereich von 200-500 nm im Spektrophotometer gemessen.

\subsubsection{Spektren mit Zellen}

Die gewünschte Menge Zellen wurde zentrifugiert (Suspensionszellen 1500 U/min für 5 min), der Überstand abgenommen, die Zellen mit PBS gewaschen und in $1000 \mu$ l Behandlung + $1000 \mu \mathrm{l}$ PBS/BSA-Lösung resuspendiert. Nach entsprechender Inkubationszeit im Brutschrank wurden die Zellen in 2-ml-Eppendorfcups überführt und erneut zentrifugiert

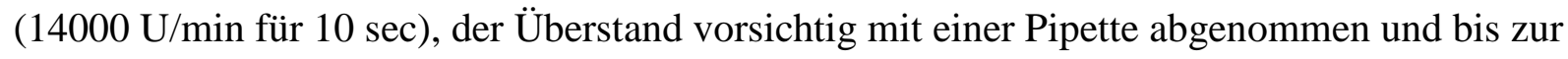
Messung auf Eis gelagert. Zur Messung wurde der Überstand in eine Küvette überführt. Die Messung erfolgte im Spektrophotometer im Bereich von 200-500 nm.

\subsection{Assay zur Bestimmung von intra- wie extrazellulärem GSH}

\subsubsection{Geräte und Materialien}

2-Vinylpyridin (2-VP)

Dinatriumhydrogenphosphat-Dihydrat

Dithiobisnitrobenzoesäure (DTNB)

EDTA

Glutationreduktase

Kaliumdihydrogenphosphat

L-Glutathion, oxidiert
Sigma-Aldrich (Steinheim)

Merck (Darmstadt)

AppliChem (Darmstadt)

AppliChem (Darmstadt)

Sigma-Aldrich (Steinheim)

Merck (Darmstadt)

AppliChem (Darmstadt) 
$\mathrm{NADPH}$

Plattenphotometer

Schüttler

Sulfosalicylsäure (SSA)

Triethanolamin

Zellschaber

Zentrifuge
UVmax

Vortex VF2 IKA-Labortechnik (Staufen)

AppliChem (Darmstadt)

AppliChem (Darmstadt)

Sarstedt (Nümbrecht)

3K30

Sigma-Aldrich (Steinheim)
AppliChem (Darmstadt)

Molecular Devices (Sunnyvale, USA)

\subsubsection{Lösungen}

\section{$\underline{\text { Sörensen-Puffer }}$}

Um einen End-pH von 6,5 zu erreichen wurden 31,3 ml Dinatriumhydrogen-Dihydrat-Lösung (11,876 g/1000 ml dest. Wasser) mit Kaliumdihydrogenphosphat-Lösung (9,078 g/1000 ml dest. Wasser) auf $100 \mathrm{ml}$ aufgefüllt.

\section{$\underline{\text { Assaypuffer }}$}

Für 100 ml Assaypuffer wurden zu 0,5 ml EDTA (0,1 M; pH 7,4) 999,5 ml Sörensen-Puffer gegeben und gut gemischt.

\section{$\underline{\text { SSA-Reagenz }}$}

0,29 g SSA in $10 \mathrm{ml}$ Assaypuffer.

\section{$\underline{\text { Team-Reagenz }}$}

1:10 Verdünnung von $4 \mathrm{M}$ Triethanolamin mit dest. Wasser.

\section{2-VP-Lösung}

$108 \mu \mathrm{l} 2-\mathrm{VP}$ in $892 \mu \mathrm{l}$ Ethanol. 


\section{$\underline{\text { Assay-Reagenz }}$}

Das Assay-Reagenz enthielt 3326,4 U/L Glutathionreduktase; 266,67 $\mu \mathrm{M}$ NADPH und 133,33 $\mu \mathrm{M}$ DTNB in Assaypuffer.

\subsubsection{Assayprinzip}

Dieser Assay nutzt die Reaktivität der Thiol-Gruppe zur Bestimmung des Glutathiongehalts einer Probe.

In einem ersten Reaktionsschritt wird durch die zugesetzte Glutathionreduktase das in der Probe enthaltene oxidierte Glutathion (GSSG) in die reduzierte Form (GSH) überführt. Im zweiten Reaktionsteil reagiert GSH spontan mit Dithiobisnitrobenzoesäure (DTNB) zu GSTNB (gemischtes Disulfid) und TNB. Das entstandene Disulfid GSTNB wird ebenfalls von der Glutathionreduktase GR umgesetzt, es entsteht ein weiteres Molekül TNB sowie GSH. Dieses kann nun erneut mit DTNB reagieren, sodass der zweite Reaktionsschritt zyklisch abläuft (siehe Abbildung 2.1).

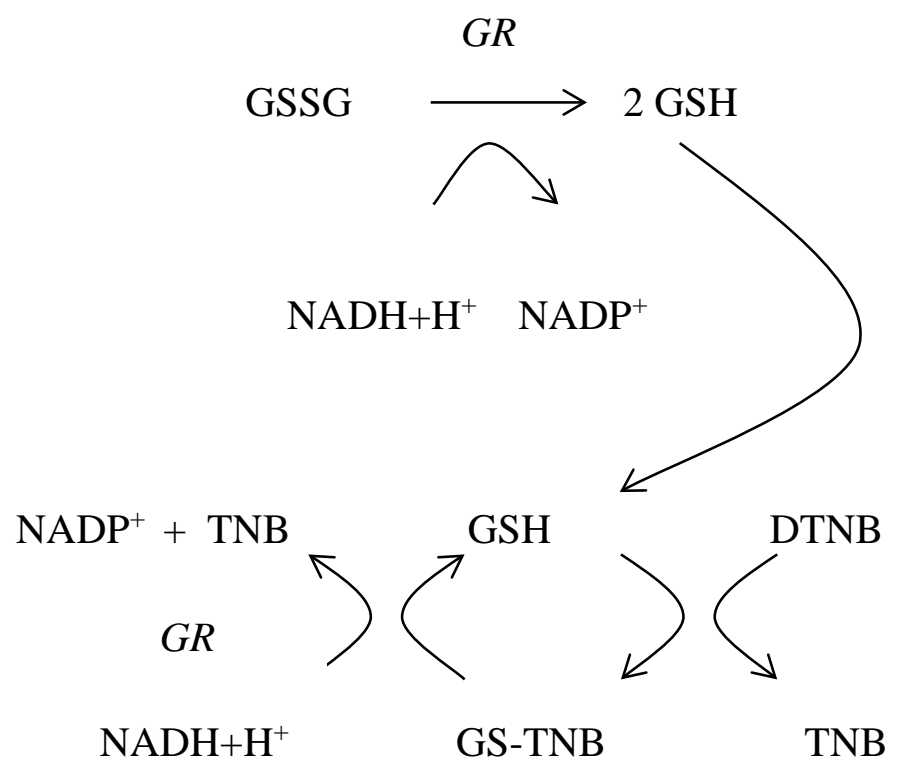

(TNB: $\lambda 405 \mathrm{~nm})$

Abbildung 2.1: Reduktion von Glutathion und Entstehung von TNB, modifiziert nach Tietze 1969 
Das entstandene TNB lässt sich photometrisch bei einer Wellenlänge von $405 \mathrm{~nm}$ erfassen. Über eine Eichkurve mit bekannten Glutathionkonzentrationen kann nun auf die GesamtGlutathionkonzentration (oxidierte und reduzierte Form) einer Probe geschlossen werden.

Um eine Aussage über das Verhältnis von oxidiertem (GSSG) und reduziertem Glutathion (GSH) einer Probe zu erhalten, sind folgende Schritte erforderlich: Es erfolgte die Anfertigung eines Parallelansatz von jeder Probe. Dieser wurde mit 2-Vinylpyridin inkubiert. 2-VP bildet mit GSH ein Konjugat, das nicht von der Glutathionreduktase umgesetzt werden kann. Somit wird in diesem Reaktionsansatz nur das GSSG gemessen (Tietze 1969, Griffith 1980).

\subsubsection{Assaydurchführung}

Adhärente Zellen wurden am Vortag der Behandlung in einer 6-Well-Platte plattiert, 500.000 Zellen pro Well in 1,5 ml DMEM. Am Behandlungstag wurde das Medium vorsichtig abgesaugt. Dann wurde frisches Medium, welches entweder mit der entsprechenden Testsubstanz oder DMSO (Kontrollen) versetzt war, aufgebracht. Suspensionszellen wurden am Behandlungstag ebenfalls in 6-Well-Platten, mit je 5 Mio. Zellen in 5 ml RPMI pro Well, plattiert. Die Platten wurden entsprechend der gewünschten Behandlungsdauer im Brutschrank inkubiert.

Nach Ablauf der Behandlungszeit wurden die adhärenten Zellen vom Well abgekratzt und im Medium in ein 2-ml-Eppendorfcup überführt. Das Well wurde mit 0,5 ml kaltem PBS gespült und dieses dann auch noch in das entsprechende Eppendorfgefäß gegeben und dann für $10 \mathrm{~min}$ bei $4{ }^{\circ} \mathrm{C}$ bei $200 \mathrm{xg}$ zentrifugiert.

Nach der Zentrifugation wurden $1800 \mu \mathrm{l}$ des Medium-haltigen Überstandes abgenommen und auf Eis gelagert. Der restliche Überstand wurde vorsichtig abgesaugt und das Zellpellet in kaltem PBS resuspendiert und dann erneut für 5 min bei $4{ }^{\circ} \mathrm{C}$ bei $200 \mathrm{xg}$ zentrifugiert. Dieser Waschschritt wurde ein weiteres Mal ausgeführt, nach einer erneuten Zentrifugation unter oben genannten Bedingungen wurde das Zellpellet nun in Assaypuffer aufgenommen und resuspendiert.

Die Suspensionszellen wurden im Medium in $15 \mathrm{ml}$ Zentrifugenröhrchen überführt, die Wells mit $1 \mathrm{ml}$ kaltem PBS gespült und dieses ebenfalls zu den Zellen gegeben. Es erfolgte eine Zentrifugation mit $1.000 \mathrm{xg}$ bei $4{ }^{\circ} \mathrm{C}$ für 10 min. Das Medium wurde komplett abgenommen 
und das Zellpellet in kaltem PBS in 2-ml-Eppendorfgefäße überführt. Es erfolgten zwei Waschschritte mit kaltem PBS (Zentrifugation für 10 min mit $1.000 \mathrm{xg}$ bei $4^{\circ} \mathrm{C}$ ) und dann wurde das Zellpellet in Assaypuffer aufgenommen.

Die nun folgenden Arbeitsschritte waren für die verschiedenen Zelllinien identisch.

Zum Zellaufschluss wurde ein Frier-Tau-Verfahren mit flüssigem Stickstoff genutzt. Danach wurde die Suspension für 15 min bei $4{ }^{\circ} \mathrm{C}$ bei 10.000 xg zentrifugiert. Von dem Überstand wurden $50 \mu \mathrm{l}$ für die Proteinbestimmung abgenommen und bei $-20^{\circ} \mathrm{C}$ bis zur Assaydurchführung gelagert. Für den GSH-Assay wurden $400 \mu \mathrm{l}$ des Überstandes in 1,5-ml-Eppendorfcups überführt und bis zur weiteren Verarbeitung auf Eis gelagert.

Zur Deproteinierung der Proben wurden diese mit $10 \mu$ SSA-Reagenz je $100 \mu$ l Probe versetzt und gut gemischt. Die initial abgenommenen Medium-Proben wurden ab diesem Schritt mitbehandelt. Das Gemisch wurde für 10 min bei Raumtemperatur inkubiert und dann für 5 min bei 5000 xg zentrifugiert. Der Überstand wurde vorsichtig abgenommen und konnte bei $-20^{\circ} \mathrm{C}$ bis zur weiteren Verarbeitung gelagert oder direkt weiter verarbeitet werden. War die Probe eingefroren, wurde diese zur erneuten Bearbeitung bei Raumtemperatur aufgetaut.

Die Proben wurden mit $5 \mu$ l Team-Reagenz je $100 \mu$ l Probe versetzt und gut gemischt. Die Medium-Proben wurden nach diesem Schritt noch 1:4 mit Assaypuffer verdünnt. Jetzt wurden die Proben in zwei Ansätze aufgeteilt. Der Ansatz zur GSH-Messung wurde mit Assay-Puffer 1:3 verdünnt. Der Ansatz für die GSSG-Messung wurde mit $1 \mu \mathrm{l}$ des 2-VP-Reagenz je $100 \mu \mathrm{l}$ Probe gut vermischt. Der GSSG-Ansatz musste für 90 min bei Raumtemperatur inkubieren. Die Parallelansätze wurden solange auf Eis gelagert.

Je Ansatz mussten entsprechend eigene Standards für die Eichkurve vorbereitet werden, also für die GSH-Messung GSH in Assay-Puffer, für die GSSG-Messung GSH mit 2-VP-Reagenz in Assaypuffer und für die Medium-Proben GSH in mit Assaypuffer entsprechend verdünntem Medium. Für die Messung wurden $50 \mu$ l je Standard bzw. Probe in ein Well einer 96-Well-Platte gegeben. Dann wurde das Assay-Reagenz frisch zubereitet. Solange lagerte die Probenplatte auf Eis. Mit der Multipipette wurden je Well $150 \mu$ l Assay-Reagenz zugegeben, danach wurde die Platte im Dunkeln bei Raumtemperatur für 25 min inkubiert. Während der Inkubationszeit wurde die Platte mehrfach vorsichtig geschüttelt. Nach Ablauf der 25 min erfolgte die Messung im Plattenphotometer bei 405 nm. Der Gehalt der Proben an GSH bzw. GSSG konnte dann mit Hilfe der Eichkurve extrapoliert werden. Dazu wurde die Softmax-Software genutzt. 


\subsection{Proteinbestimmung}

Um eine bessere Vergleichbarkeit der verschiedenen Zelllinien untereinander zu gewährleisten, wurden von allen Proben Proteinbestimmungen durchgeführt, mit dem Ziel eine einheitliche vergleichbare Bezugsgröße zu haben.

\subsubsection{Geräte und Materialien}

BCA Protein Assay Kit

BSA

Plattenphotometer

Zellkulturplatten

\subsubsection{Lösungen}

\section{$\underline{\text { Assay-Puffer }}$}

s. Assay-Puffer GSH-Assay
Thermo Scientific (Rockford, USA)

Sigma-Aldrich (Steinheim)

Molecular Devices (Sunnyvale, USA)

Sarstedt (Nümbrecht)

\subsubsection{Assaydurchführung}

Die Proben für die Proteinbestimmung wurden bei Raumtemperatur aufgetaut, derweil die Standards, eine BSA-Verdünnungsreihe in Assay-Puffer sowie das Pierce-Reagenz (nach Herstellerangaben) vorbereitet. Auch von den Proben wurden Verdünnungsreihen angefertigt. In einer 96-Well-Platte wurden je Well $10 \mu \mathrm{l}$ Standard bzw. Probe pipettiert und dann mit $200 \mu \mathrm{l}$ Pierce-Reagenz versetzt. Die Platte wurde für $30 \mathrm{~min}$ bei $37^{\circ} \mathrm{C}$ im Wasserbad inkubiert und dann bei $550 \mathrm{~nm}$ im Plattenphotometer gemessen. Mit Hilfe der Eichkurve konnte der Proteingehalt der Probe extrapoliert werden. Hierfür fand die Softmax-Software Verwendung. 


\section{Ergebnisse}

In diesem Kapitel werden die Ergebnisse des experimentellen Teils dieser Arbeit dargestellt.

\subsection{Untersuchungen zur Zytotoxität von neusynthetisierten Uracilderivaten an humanen Krebszelllinien}

Basierend auf der Bedeutung von modifizierten Nukleobasen und Nukleosiden als zytostatische Anti-Metaboliten bzw. Virostatika wurden von der Abteilung Pharmazeutische Chemie der Universität Leipzig neue Uracilderivate mit zytotoxischem und damit AntitumorPotenzial synthetisiert. Anlehnung fand dieses Vorgehen an dem etablierten Anti-Metaboliten 5-Fluoruracil wie auch dem gegen Zosterinfektionen eingesetzten Virostatikum Brivudin, dem Nukleosid des Bromvinyluracils (Führer 2008, Heinze 2008).

Ausgehend von den drei in Abb. 3.1 dargestellten Verbindungen wurden vier in 5'-Position modifizierte neue Uracilderivate, eine Nitrovinylverbindung, zwei Bromvinyl- sowie eine Bromethinylverbindung hergestellt (s. Abb. 3.2). Zur Beurteilung der neuen Eigenschaften konnten die Ausgangssubstanzen (s. Abb. 3.1) als Negativkontrollen herangezogen werden. Dabei ergaben sich für das Nitrovinyl- und das Bromethinyluracil zytotoxische und wie zu zeigen sein wird, auch pro-apoptotische Eigenschaften. Im Weiteren wurden zusätzliche Substitutionen vorgenommen, die die Lipophilie der ursprünglichen Basen veränderte. Beispielhaft ist dies in Abb. 3.3 für das Bromethinyluracil dargestellt. Da auch in diesen noch Substitutionen erfolgten, wurden über 80 Substanzen zur biologischen Testung bezüglich einer toxischen Wirkung auf Tumorzellen zur Verfügung gestellt.

Als Grundverbindungen werden die Verbindungen bezeichnet, die nur in der 5'-Position eine zusätzliche funktionelle Gruppe haben. So konnten sieben Verbindungen unterschieden werden: Drei Ausgangsstoffe für die Synthese (s. Abb. 3.1) 5-(1H-(1,2,3)triazol-4yl)-1Hpyrimidine-2,4-dione (TAU), 5- Ethinyluracil (EU) und 5-((2-Trimethylsilyl)ethinyl)uracil (SiEU) und als neue potenziell funktionelle Produkte (s. Abb. 3.2) 5-(2-Bromovinyl)-1Hpyrimidine-2,4-dione (BVU), 5-(2,2-Dibromovinyl)-1H-pyrimidine-2,4-dione (DiBVU), 5-Bromethinyluracil (BEU) und Nitrovinyluracil (NVU). 
<smiles>O=c1[nH]cc(-c2c[nH]nn2)c(=O)[nH]1</smiles>

TAU<smiles>C#Cc1c[nH]c(=O)[nH]c1=O</smiles>

EU<smiles>C[Si](C)(C)C#Cc1c[nH]c(=O)[nH]c1=O</smiles>

SiEU

Abbildung 3.1: Strukturformeln Uracilderivate - Negativkontrollen<smiles>O=c1[nH]cc(/C=C/Br)c(=O)[nH]1</smiles>

BVU<smiles>O=c1[nH]cc(C=C(Br)Br)c(=O)[nH]1</smiles>

DiBVU<smiles>O=c1[nH]cc(/C=C/[N+](=O)[O-])c(=O)[nH]1</smiles>

NVU<smiles>O=c1[nH]cc(C#CBr)c(=O)[nH]1</smiles>

BEU

Abbildung 3.2: Strukturformeln potenziell wirksamer Uracilderivate

Von diesen Verbindungen wurden dann noch jeweils Derivate mit verschiedenen Substituenten in 1'-Position: Benzyl- (B-), Benzhydryl- (BH-), Allyl- (A-) und Hydroyxmethylgruppen (HEM-) oder aber einem Zuckerrest in Nukleosid-Form von einer Desoxyuridingruppe (-DU) synthetisiert (s. Abb. 3.3).

Von den Benzylderivaten wurden des Weiteren ausgewählte verschiedene Derivate mit zusätzlichen Fluoratomen am Benzylrest hergestellt.

Um eine erste Einschätzung der Wirksamkeit der verschiedenen Substanzen zu erhalten, erfolgte eine Einteilung in Gruppen, um deren zytotoxische Wirkung an vier Tumorzelllinien mittels MTT-Tests zu ermitteln. Die Ausgangsverbindungen zur Synthese dienten als Negativkontrolle. Von den potenziellen Wirkstoffen erwiesen sich zwei als wirksam und wurden im Anschluss eingehender charakterisiert. 
<smiles>O=c1[nH]c(=O)n(Cc2ccccc2)cc1C#CBr</smiles>

B-BEU

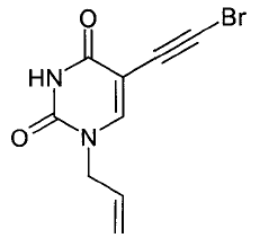

HEM-BEU<smiles>O=c1[nH]c(=O)n(C(c2ccccc2)c2ccccc2)cc1C#CBr</smiles>

BH-BEU<smiles>O=c1[nH]c(=O)n(COCCO)cc1C#CBr</smiles>

A-BEU

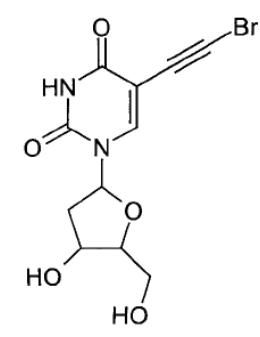

BEDU

Abbildung 3.3: Strukturformeln verschiedener BEU-Derivate

\subsubsection{Vitalitätsmessungen an Leukämiezellen}

\subsubsection{Zytotoxisches Potenzial von 5'-modifizierten Uracilen}

Begonnen wurde die Testung mit der Grundverbindung NVU, die aufgrund der Identität der Seitenkette mit dem aus vorangegangenen Arbeiten bekannten funktionellen Anteil des Nitrostyrols (NS) (Kaap et al. 2002, Werner 2005) als potenziell wirksam eingeschätzt wurde. Getestet wurden beide Nitroverbindungen im Vergleich mit dem etablierten und strukturverwandten Chemotherapeutikum 5-Fluorouracil (5-FU).

Die drei Substanzen zeigten gewisse Unterschiede in ihrer zeit- und konzentrationsabhängigen zytotoxischen Wirkung. Während die beiden Nitroverbindungen bereits nach einer Behandlungszeit von 24 h zu einer deutlichen Vitalitätsreduktion führten, konnten beim 5-FU erst nach einer Inkubationszeit von 48 h Effekte beobachtet werden.

NVU erwies sich in U937-Zellen mit einer maximalen Reduktion der Vitalität auf 44 \% bei $100 \mu \mathrm{M}$ bei einer LC50 von $90 \mu \mathrm{M}$ etwas weniger wirksam und weniger potent als NS mit 
einer maximalen Vitalitätsreduktion auf $12 \%$ bei $50 \mu \mathrm{M}$ und einer LC50 von ca. $12 \mu \mathrm{M}$ (s. Abb. 3.4).

In HL60-Zellen war mit einer Konzentration von $100 \mu \mathrm{M}$ NVU eine Reduktion der Zellen auf $3 \%$ der Kontrolle zu erreichen, die LC50 lag bei ca. $40 \mu \mathrm{M}$. Die Dosis-Wirkungskurve nach $48 \mathrm{~h}$ Inkubationszeit war nahezu deckungsgleich mit der nach $24 \mathrm{~h}$. Das in diesem Versuch als Referenz für ein therapeutisch genutztes Zytostatikum verwendete 5-FU konnte erst nach $48 \mathrm{~h}$ eine deutliche Reduktion vitaler Zellen erreichen. Es erwies sich mit einer maximalen Vitalitätsreduktion auf $30 \%$ der Kontrolle bei $250 \mu \mathrm{M}$ und einer LC50 von ca. $100 \mu \mathrm{M}$ weniger wirksam und potent (s. Abb. 3.5).

Im nächsten Schritt wurde TAU, die Synthesevorstufe von NVU, im MTT-Test an den Leukämiezellen getestet. Die Verbindung TAU, in der 5'-Position war anstelle der Nitrovinylgruppe eine Triazol-Gruppe, erwies sich als unwirksam, auch bei Dosierungen bis zu 200 M konnte keine Reduktion der Vitalität erreicht werden (s. Abb. 3.6).

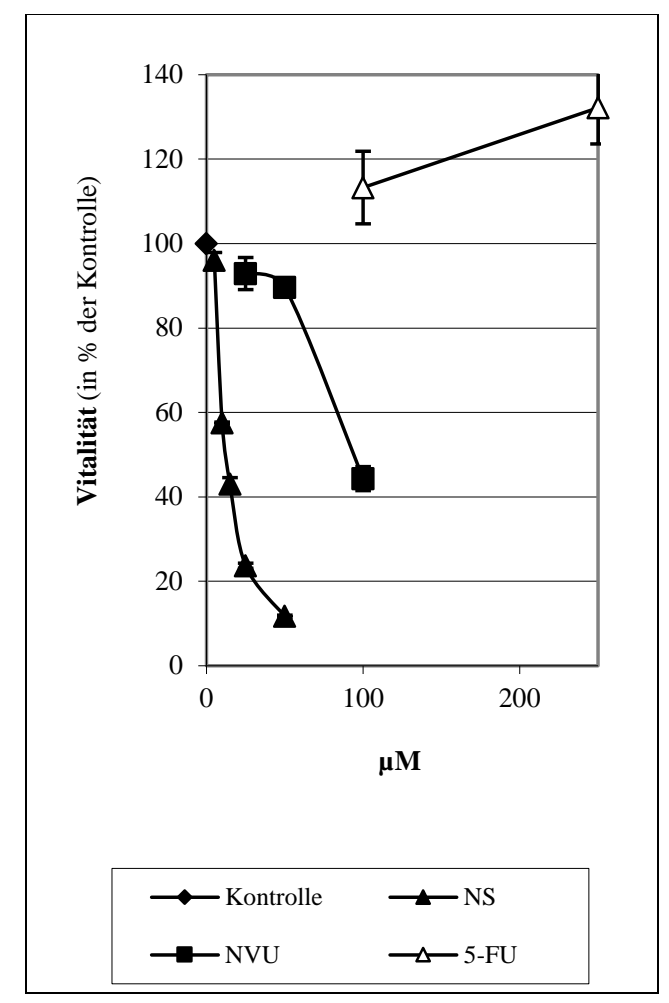

Abbildung 3.4: U937 für 24 h behandelt mit NS, NVU und 5-FU, $\mathrm{n}=5$

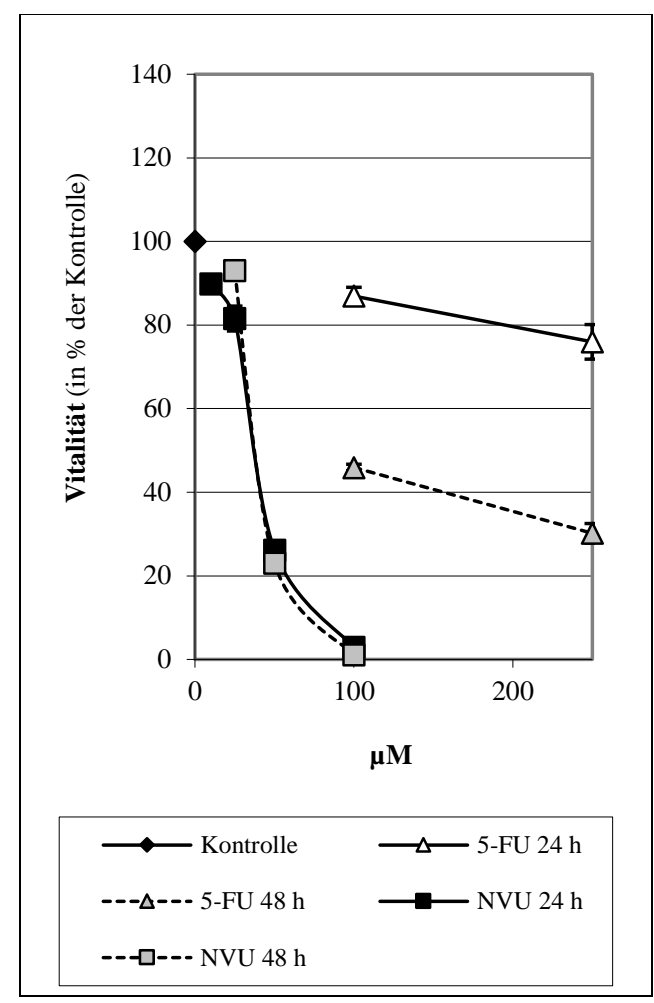

Abbildung 3.5: HL60 für 24 und 48 h behandelt mit NVU und 5-FU, $\mathrm{n}=4$ 


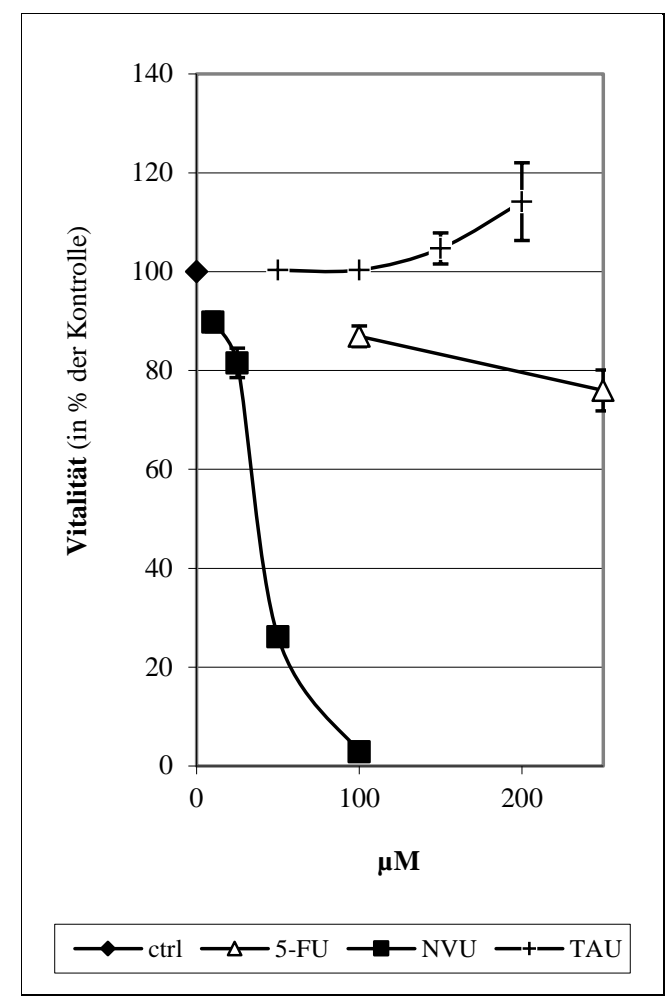

Abbildung 3.6: HL60 für 24 h behandelt mit TAU, NVU und 5-FU, $n=4$

Die nächste Gruppe von Verbindungen wies in der Seitenkette anstelle der funktionell bedeutsamen Nitrogruppe ein oder zwei Bromatome auf.

Die strukturverwandten Verbindungen BVU und DiBVU waren an beiden Leukämiezelllinien unwirksam. Es konnte im untersuchten Konzentrationsbereich bis $100 \mu \mathrm{M}$ keine Zytotoxität festgestellt werden (Abb. 3.7 + 3.8). Dagegen zeigte die Ethinylverbindung BEU in HL60und U937-Zellen eine deutliche Zytotoxität. Eine maximale Vitalitätsreduktion auf unter $5 \%$ der Kontrolle wurde bei $100 \mu \mathrm{M}$ beobachtet. Die LC50 betrug ca. $35 \mu \mathrm{M}$. Damit schien BEU vergleichbar wirksam und potent wie NVU (Abb. $3.7+3.8$ ).

Da sich mit BEU eine Ethinylverbindung als wirksam erwies, wurden als nächstes die beiden Synthesevorstufen EU und SiEU, die ebenfalls über eine Ethinylgruppe in der Seitenkette verfügten, in HL60-Zellen getestet. Es konnte keine Reduktion der Zellzahl erreicht werden, bei Konzentrationen bis zu $200 \mu \mathrm{M}$ lagen die Messwerte im Bereich der unbehandelten Kontrolle (ohne Abbildung). Auf eine Testung an U937-Zellen wurde daraufhin verzichtet, da sich die Substanzen in den vorangegangenen Test an den beiden Zelllinien ähnlich verhalten haben. 


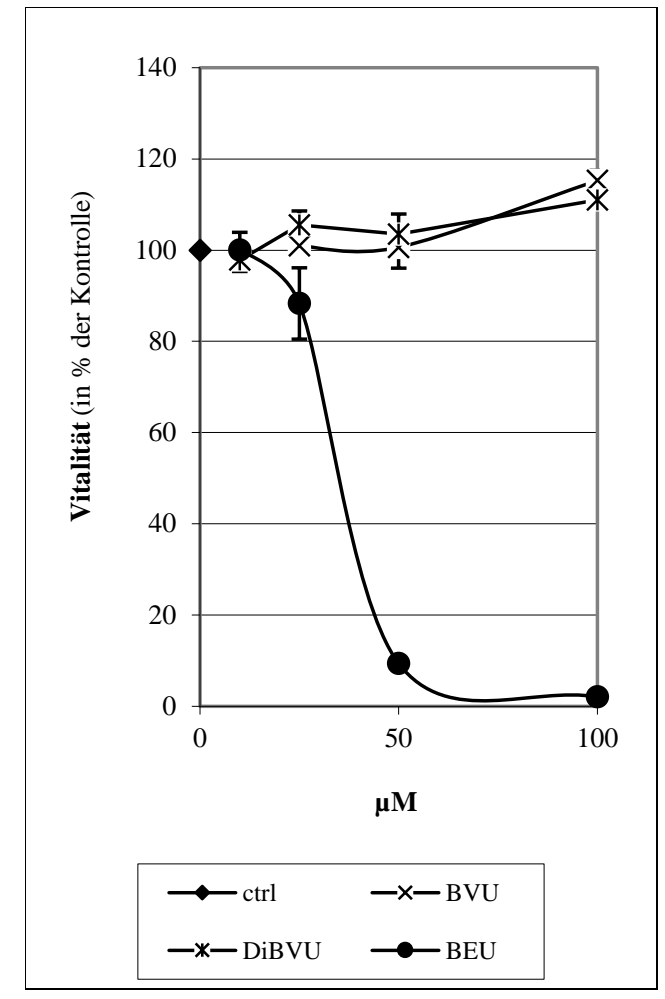

Abbildung 3.7: HL60 für 24 h behandelt mit BVU, DiBVU und BEU, $\mathrm{n}=4$

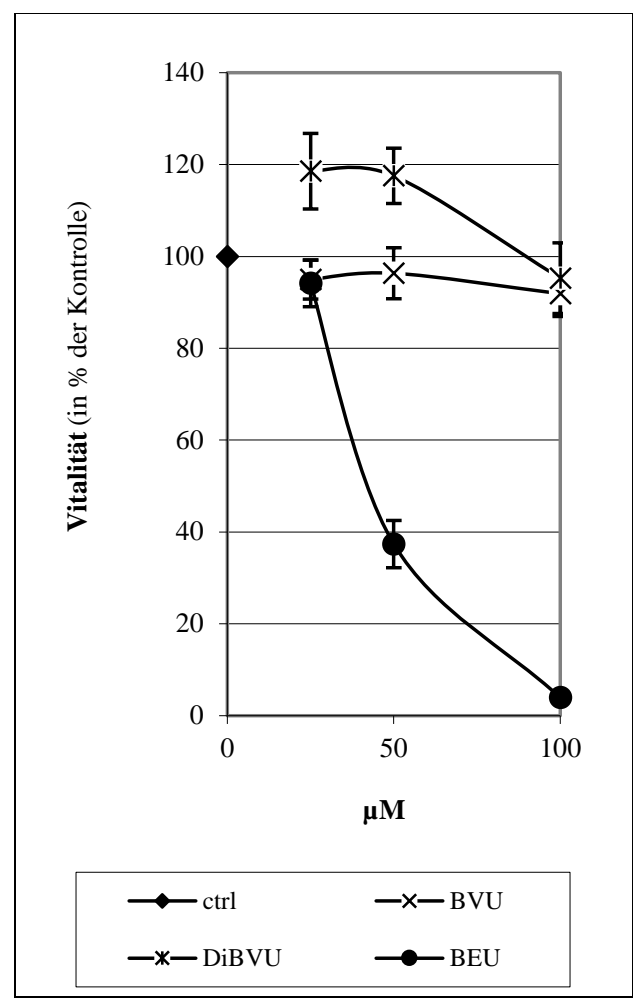

Abbildung 3.8: U937 für 24 h behandelt mit BVU, DiBVU und BEU, $n=4$

3.1.1.2 Zytotoxisches Potenzial hydrophiler bzw. lipophiler Derivate von Nitrovinyl- und Bromethinyluracil

Die Nitrovinyl- sowie die Bromethinylverbindung haben sich somit als zytotoxisch wirksam erwiesen. In einem nächsten Schritt wurden Derivate dieser Verbindungen, die durch Einbringen hydrophiler (Hydroxymethyl- (HEM-), Desoxyribose) bzw. lipophiler Seitengruppen (Allyl- (A-), Benzyl- (B-) und Benzhydryl- (BH-)) in der 1'-Position substituiert wurden, getestet, um zu überprüfen, wie diese Modifikation die Wirksamkeit und Potenz der Substanzen beeinflussten. Durch Einführung lipophiler Seitengruppen wurden Wirksamkeit und Potenz im Vergleich mit den Grundverbindungen z. T. erheblich gesteigert, während hydrophile Seitengruppen in der 1'-Position die Potenz senkte (s. Tab. 3.1 + 3.2).

Aufgrund der Vielzahl der Substanzen wurde der Großteil der Verbindungen ausschließlich an HL60-Zellen getestet. Bis auf wenige Ausnahmen verhielten sich die an beiden Leukämiezelllinien getesteten Verbindungen ähnlich, wobei sich die HL60-Zellen insgesamt etwas empfindlicher sowohl gegenüber den NVU- wie auch den BEU-Derivaten zeigten. 


\begin{tabular}{|c|c|c|c|c|}
\hline & \multicolumn{3}{|c|}{ HL 60neo (25000 Zellen) } & \multicolumn{2}{c|}{ U937 (100000 Zellen) } \\
\hline & \multicolumn{5}{|c|}{$\mu \mathrm{M}$. } \\
\hline & LC 50 & $<10 \%$ Vitalität & LC 50 & $<10 \%$ Vitalität \\
\hline NVU & 40,0 & 100,0 & 90,0 & $>100,0$ \\
\hline B-NVU & 2,5 & 5,0 & 9,0 & $<10,0$ \\
\hline A-NVU & 20,0 & 50,0 & $>50,0$ & $>50,0$ \\
\hline BH-NVU & $<1$ & 1,0 & 14,0 & 50,0 \\
\hline HEM-NVU & 75,0 & 150,0 & $>50,0$ & $>50,0$ \\
\hline NB-NVU & 6,0 & 10,0 & & \\
\hline PE-NVU & 2,0 & 5,0 & & \\
\hline MB-NVU & 2,5 & 7,5 & & \\
\hline TriMB-NVU & 4,0 & 7,5 & & \\
\hline FB-NVU & 4,0 & 7,5 & & \\
\hline 3,4 Di-FB-NVU & 3,0 & 5,0 & & \\
\hline 2,6 Di-FB-NVU & 2,5 & 5,0 & & \\
\hline Penta FB-NVU & 2,5 & 5,0 & & \\
\hline
\end{tabular}

Tabelle 3-1: Leukämiezellen für 24 h mit verschiedenen NVU-Derivaten behandelt

\begin{tabular}{|c|c|c|c|c|}
\hline & HL 60r & (25000 Zellen) & U937 & 0000 Zellen) \\
\hline & \multicolumn{4}{|c|}{$\mu \mathrm{M}$} \\
\hline & LC 50 & $<10 \%$ Vitalität & LC 50 & $<10 \%$ Vitalität \\
\hline BEU & 20,0 & 50,0 & 55 & 100,0 \\
\hline B-BEU & 2,5 & 25,0 & $30,0,0$ & $>50,0$ \\
\hline A-BEU & 35,0 & $>50,0$ & 80,0 & $>100,0$ \\
\hline $\mathrm{BH}-\mathrm{BEU}$ & 30,0 & 50,0 & 40,0 & $>100,0$ \\
\hline HEM-BEU & 50,0 & $>50,0$ & 50,0 & $>50,0$ \\
\hline NB-BEU & 6,0 & 10,0 & & \\
\hline PE-BEU & 30,0 & $>50,0$ & & \\
\hline MB-BEU & 7,5 & 25,0 & & \\
\hline TriMB-BEU & 12,0 & 25,0 & & \\
\hline FB-BEU & 5,0 & 25,0 & & \\
\hline 3,4 Di-FB-BEU & 6,0 & $>10,0$ & & \\
\hline 2,6 Di-FB-BEU & 9,0 & $>10,0$ & & \\
\hline BEDU & 40,0 & 100,0 & $>50,0$ & $>50,0$ \\
\hline
\end{tabular}

Tabelle 3-2: Leukämiezellen für 24 h mit verschiedenen BEU-Derivaten behandelt

Da sich die Wirksamkeit der Substanzen durch die Einführung lipophiler Seitenketten erheblich steigern ließ, wurden im nächsten Schritt auch entsprechende Derivate primär unwirksamer Uracile getestet.

Von den Ethinylverbindungen EU und SiEU standen jeweils die Benzyl-Derivate zur Verfügung, es konnte im getesteten Konzentrationsbereich bis $200 \mu \mathrm{M}$ keine zytotoxische Wirkung nachgewiesen werden (ohne Abbildung). 
Im Gegensatz dazu zeigte sich das Benzhydryl-Derivat der Dibromverbindung 1-Benzhydryl5-(2,2-dibromvinyl)uracil (BH-DiBVU) mit einer LC50 von ca. $50 \mu \mathrm{M}$ im Vergleich zum DiBVU als wirksamer, wobei das Benzyl-Derivat 1-Benzyl-5-(2,2-dibromvinyl)uracil B-DiBVU) keine bessere Wirksamkeit als die Grundverbindung aufwies (s. Abb. 3.9).

Bei der Triazolverbindung TAU erwies sich nun neben dem Benzhydryl-Derivat 1-Benzhydryl-5-(1H-(1,2,3)triazol-4-yl)1H-pyrimidine-2,4-dione (BH-TAU) (LC50 $50 \mu \mathrm{M})$ auch das Benzyl-Derivat 1-Benzyl-5-(1H(1,2,3)triazol-4-yl)-1H-pyrimidine-2,4-dione (B-TAU) (LC50 $100 \mu \mathrm{M}$ ) als zytotoxisch wirksam (s. Abb. 3.10).

Für weitere Versuche wurde sich aufgrund der höheren Potenz und Wirksamkeit auf die Verbindungen NVU und BEU sowie einige ihrer Derivate beschränkt. Da sich bei den lipophilen NVU- und BEU-Derivaten kaum Unterschiede in der Potenz fanden, wurden nur einige ausgewählte Verbindungen eingesetzt.

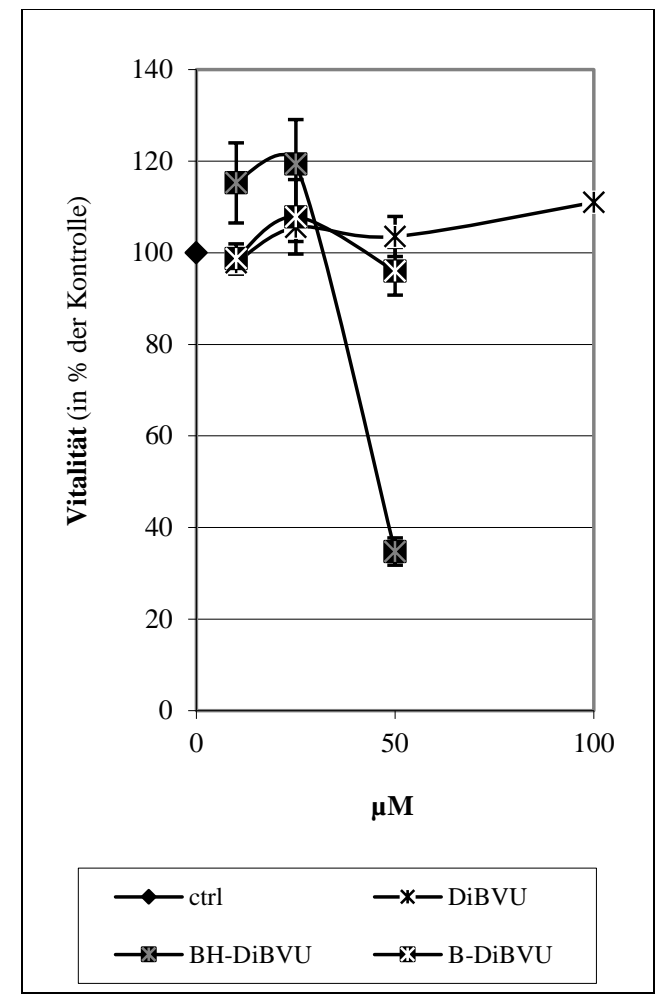

Abbildung 3.9: HL60 für 24 h behandelt mit DiBVU, BH-DiBVU und B-DiBV, $\mathrm{n}=4$

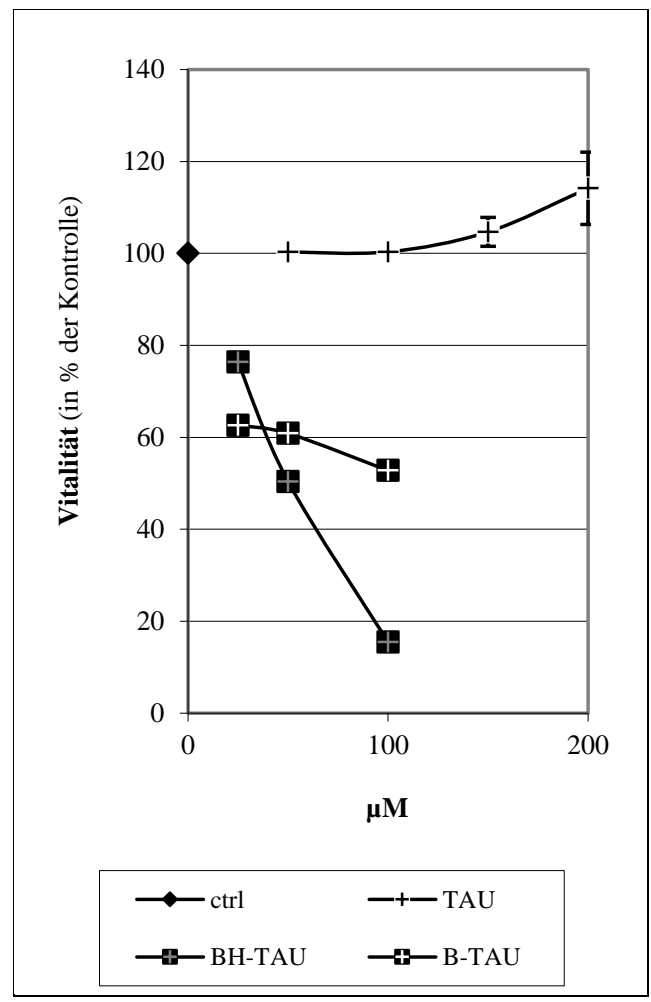

Abbildung 3.10: HL60 für 24 h behandelt mit TAU, BH-TAU und TAU, $n=4$ 


\subsubsection{Vitalitätsmessungen an Kolonkarzinomzellen als Beispiel für eine Wirkung auf Zellen aus soliden Tumoren}

Das Uracilderivat 5-Fluoruracil (5-FU) ist ein Standardpräparat v. a. in der Dickdarmkrebstherapie. Da die Testsubstanzen als Uracilderivate 5-FU strukturell verwandt sind, wurden diese auch in den humanen Kolonkarzinomzellreihen LoVo und HCT getestet. Hierbei wurde 5-FU zum Vergleich als Referenzpräparat eingesetzt.

Für den Einsatz mit den adhärenten Zellen war im Vergleich zu den Suspensionszellen eine längere Inkubationszeit notwendig. 5-FU wirkte ab $48 \mathrm{~h}$, eine längere Behandlungszeit steigerte die Wirksamkeit.

LoVo-Zellen reagierten im Vergleich mit HCT-Zellen weniger ausgeprägt auf 5-FU, dafür aber empfindlicher auf die Testsubstanzen. Eine maximale Reduktion der Vitalität wurde nach 72 h Behandlung mit $250 \mu \mathrm{M}$ 5-FU bei LoVo-Zellen auf ca. 40 \%, bei den HCT-Zellen auf ca. 5 \% der Kontrolle (s. Abb. $3.11+3.12$ ) beobachtet.

Auch bei den Zellen aus soliden Tumoren zeigten die Verbindungen NVU und BEU eine Zytotoxität. Bei LoVo-Zellen wurde nach 72 h mit $200 \mu \mathrm{M}$ eine Vitalitätsreduktion auf $10 \%$ der Kontrolle durch beide Substanzen erreicht, bei einer LC50 von $150 \mu$ M für NVU und $175 \mu \mathrm{M}$ für BEU (s. Abb. 3.11). Bei HCT-Zellen wurde sowohl mit NVU als auch mit BEU eine Reduktion der Vitalität um 80 \% erreicht, die LC50 betrug bei beiden Substanzen ca. $100 \mu \mathrm{M}$ (s. Abb. 3.12).

In beiden Zelllinien war in den entsprechenden Konzentrationsbereichen mit den beiden Bromvinyluracilen keine sichere Zytotoxität nachzuweisen (nicht dargestellt).

Im nächsten Schritt wurden die lipophileren Benzyl-Derivate von NVU und BEU getestet, um $\mathrm{zu}$ überprüfen, ob sich auch in diesen Zellen eine Steigerung der Lipophilie günstig auf Wirkungslatenz, Wirksamkeit und Potenz auswirkte.

Wie in den Leukämiezellen waren in den Zelllinien aus soliden Tumoren die BenzylVerbindungen von beiden neuen Wirkstoffen um ein Vielfaches potenter als die Grundsubstanz (s. Abb. $3.13+3.14$ ). Bei einer Behandlungszeit von 72 h konnte bereits bei einer Konzentration von $25 \mu \mathrm{M}$ B-NVU oder B-BEU eine Reduktion der Vitalität auf $10 \%$ der Kontrolle erreicht werden. Interessanterweise war bereits nach Behandlungszeiten von 24 h ein deutlich ausgeprägter zytotoxischer Effekt zu beobachten (s. Abb. $3.13+3.14$ ). 


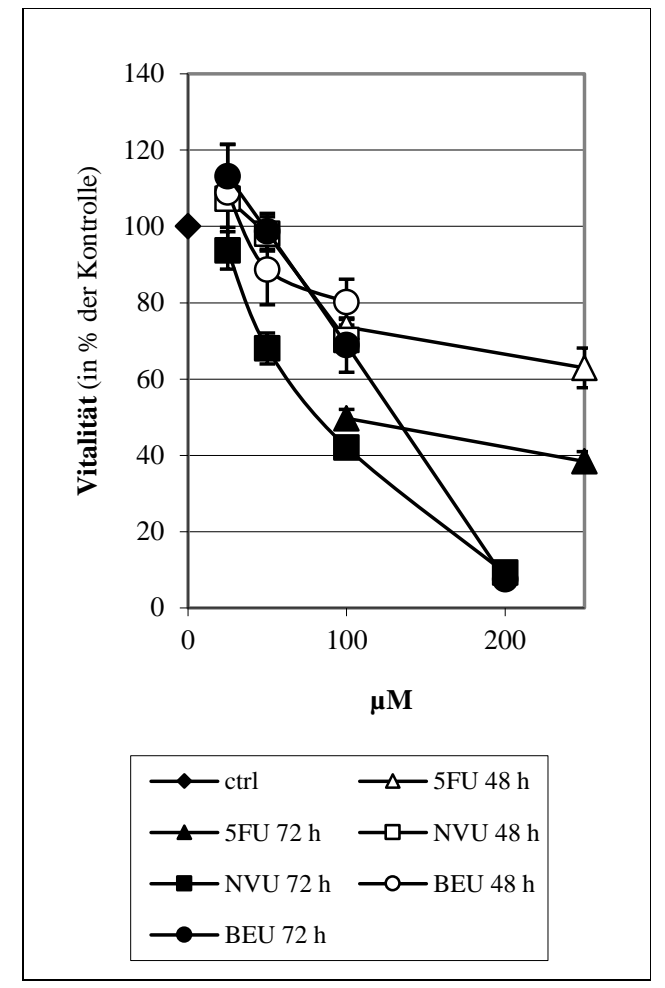

Abbildung 3.11: LoVo für 48 und 72 h behandelt mit 5-FU, NVU und BEU, $n=3$

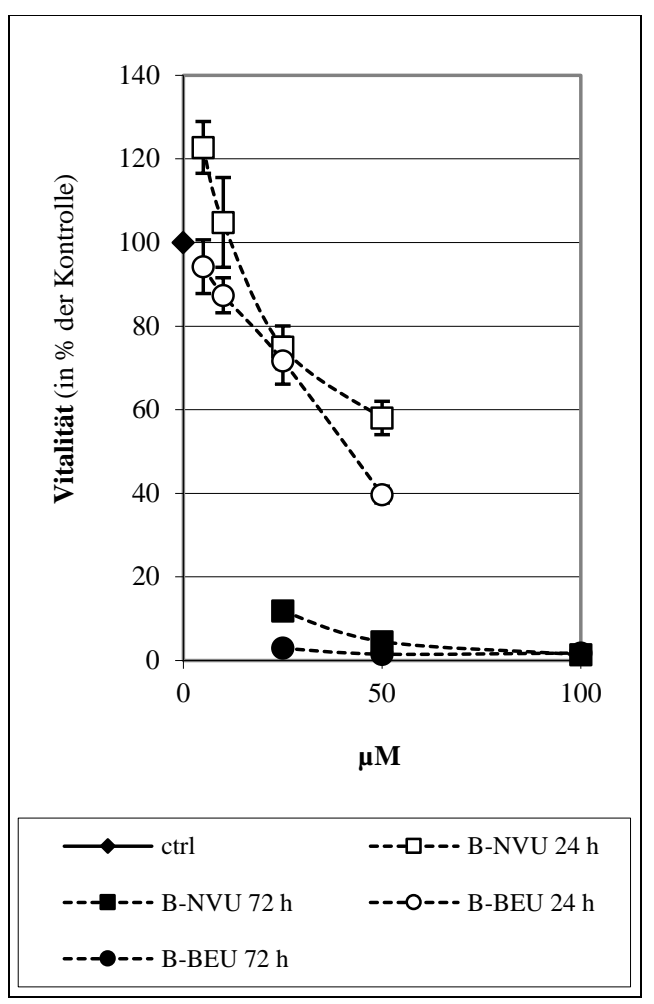

Abbildung 3.13: LoVo für 24 und 72 h behandelt mit B-NVU und B-BEU, $\mathrm{n}=4$

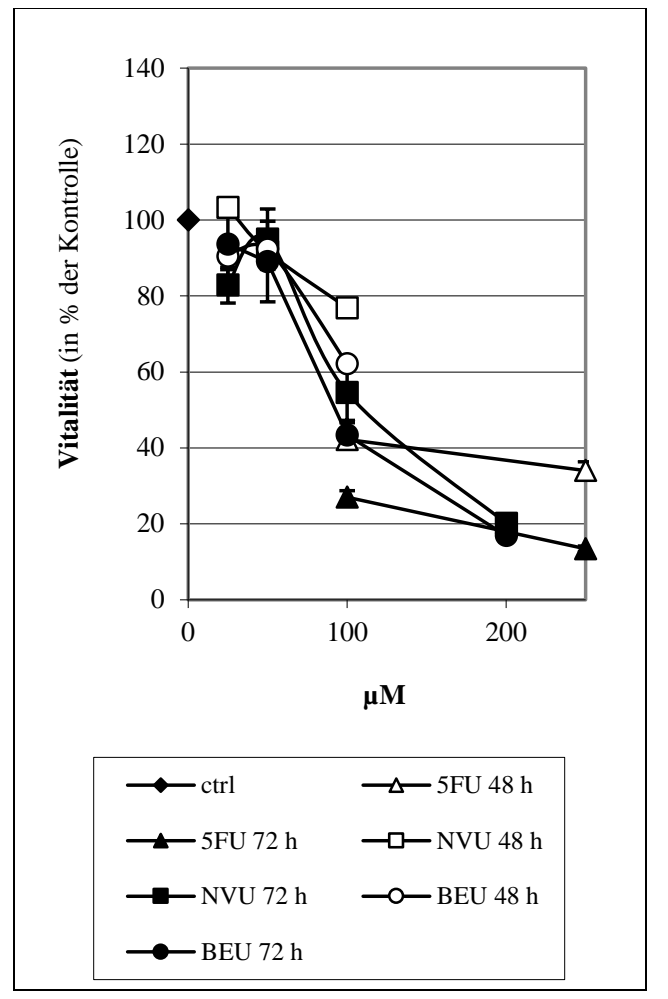

Abbildung 3.12: HCT für 48 und 72 h behandelt mit 5-FU, NVU und BEU, $n=3$

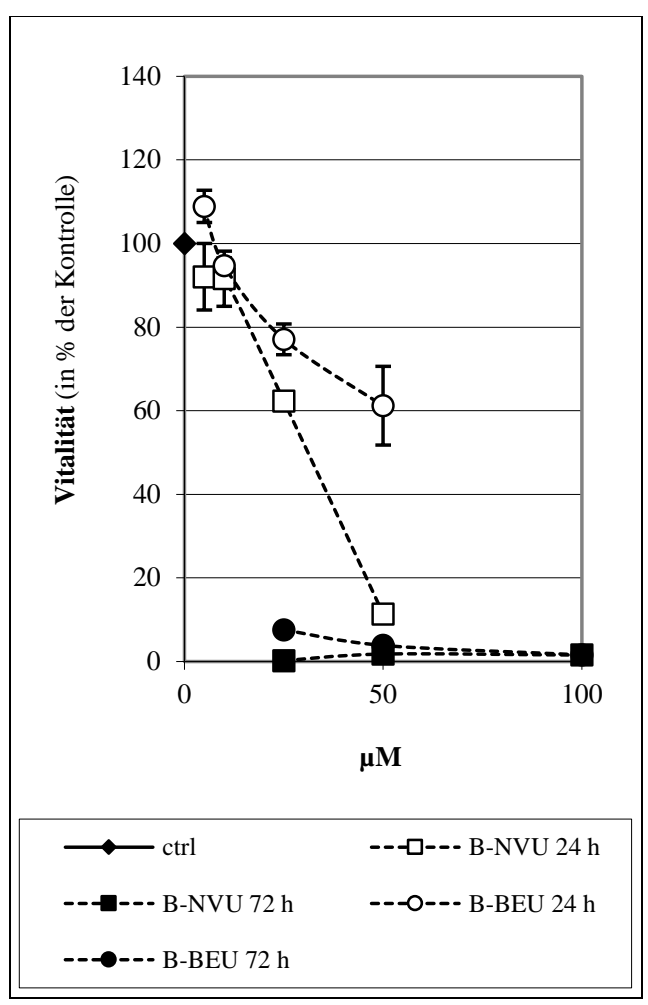

Abbildung 3.14: HCT für 24 und 72 h behandelt mit B-NVU und B-BEU, $n=4$ 


\subsection{Apoptoseinduktion}

Es werden als Hauptformen des Zelltodes die Nekrose und die Apoptose unterschieden. Die Nekrose stellt, als Folge einer sehr massiven Zellschädigung, einen ungeordneten Zelluntergang mit begleitender Entzündungsreaktion des umgebenden Gewebes dar. Die Apoptose erfolgt als programmiert ablaufender Zelltod, in dessen Rahmen die Zellbestandteile gezielt abgebaut und nur geringe Umgebungsreaktionen ausgelöst werden. Daher bietet sich die Apoptoseinduktion als Ziel einer zytostatischen Therapie an.

Zur weiteren Einschätzung des zytostatischen Potenzials der im Rahmen dieser Arbeit getesteten Verbindungen wurden die zentralen neuen Substanzen, die eine zytotoxische Wirkung aufwiesen, auf ihre Fähigkeit zur Induktion einer Apoptose untersucht.

Dafür wurde mittels eines Fluoreszenz-gestützten Assays die Aktivierung der Apoptosespezifischen Caspase-3 gemessen. Als weiterer Apoptosemarker wurde mit ausgewählten Substanzen auch eine Fragmentierung der genomischen DNA (DNA-Leiterphänomen) - als eine der Caspaseaktivierung nachgeschaltete nukleäre Reaktion - durchgeführt.

\subsubsection{Caspase-3-Aktivitätsmessung in Leukämiezellen}

Alle getesteten NVU- wie BEU-Verbindungen zeigten konzentrationsabhängig eine Aktivierung der Caspase-3, die jeweils als Vielfaches der Kontrolle dargestellt wurde.

Der potenteste Caspaseaktivator in HL60-Zellen war B-NVU, das bereits bei einer Konzentration von $5 \mu \mathrm{M}$ zu einer 4fachen Aktivierung führte, gefolgt vom BH-NVU, das bei $10 \mu \mathrm{M}$ eine 3fache Steigerung bedingte. Als Nächstes folgte A-NVU, das bei $25 \mu \mathrm{M}$ ebenfalls ein 3faches der Kontrolle erreichte, danach NVU mit dem das 3,5fache mit einer Konzentration von $50 \mu \mathrm{M}$ erzielt wurde. Am wenigsten potent zeigte sich mit HEM-NVU die hydrophilste der Verbindungen, die bei $100 \mu \mathrm{M}$ eine 2fache Aktivierung erreichte (s. Abb. 3.15).

Für U937-Zellen konnte eine ähnliche Rangfolge ermittelt werden. Am potentesten zeigte sich hier BH-NVU mit einer 6fachen Steigerung bei einer Konzentration von $5 \mu \mathrm{M}$, als nächste kam B-NVU mit einer 4fachen Aktivierung bei $25 \mu \mathrm{M}$, gefolgt vom A-NVU mit 4,5fachen Aktivität der Kontrolle bei $50 \mu \mathrm{M}$. NVU zeigte bei $50 \mu \mathrm{M}$ eine 4fache Steigerung 
und vom HEM-NVU benötigte man für das 2fache eine Konzentration von $200 \mu \mathrm{M}$ (s. Abb. 3.16).

Als Konsequenz dieser Versuche lässt sich festhalten, dass die Lipophilie der NVU-Derivate mit ihrer Potenz zur Apoptoseinduktion korreliert.

Die pro-apoptotische Potenz der BEU-Derivate stellte sich wie folgt dar: Potentester Caspaseaktivator in den HL60-Zellen war B-BEU mit einer 3fachen Steigerung bei einer Konzentration von $10 \mu \mathrm{M}$, dann BH-BEU mit dem 4fachen der Kontrolle bei $50 \mu \mathrm{M}$, A-BEU zeigte bei $50 \mu \mathrm{M}$ eine maximale Caspaseaktivierung mit einer 3fachen Steigerung. Am wenigsten potent war wiederum HEM-BEU mit einer 2fachen Aktivierung bei ebenfalls $50 \mu \mathrm{M}$ (s. Abb. 3.17).

In U937 war B-BEU ebenfalls am potentesten mit einem 3,5fachen der Kontrolle bei $10 \mu \mathrm{M}$, BH-BEU erreichte bei $25 \mu \mathrm{M}$ das 4fache der Kontrolle, gefolgt vom A-BEU das bei einer Konzentration von $50 \mu \mathrm{M}$ eine 6fache Steigerung erreichte. Beim BEU zeigte sich ebenfalls bei $50 \mu \mathrm{M}$ die maximale Caspaseaktivierung, aber nur auf ein 2faches der Kontrolle. Auch hier war HEM-BEU am wenigsten potent mit dem 3,5fachen bei $100 \mu \mathrm{M}$ (s. Abb. 3.18).

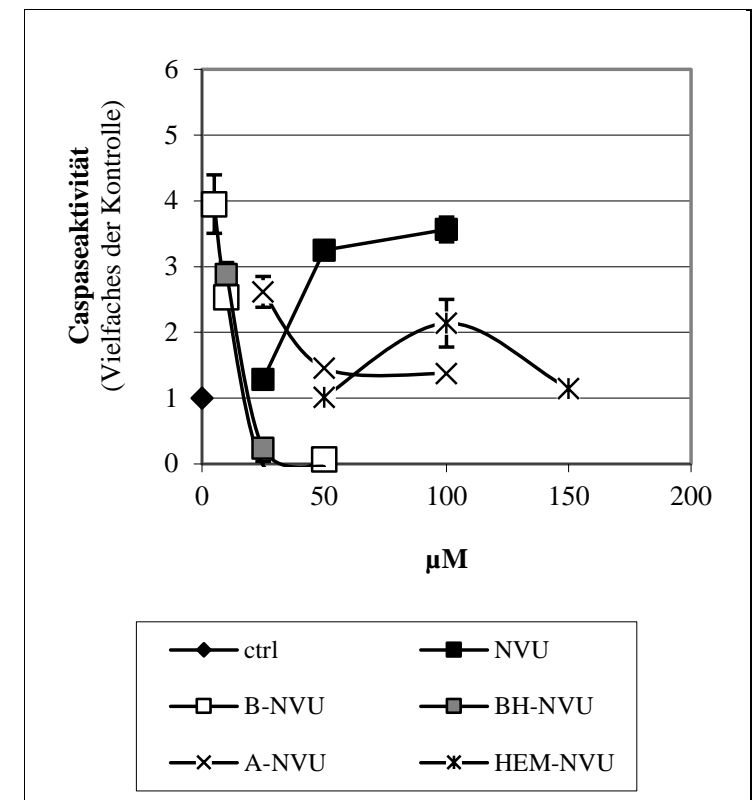

Abbildung 3.15: HL60 für 24 h behandelt mit NVU und Derivaten, $\mathrm{n}=4$

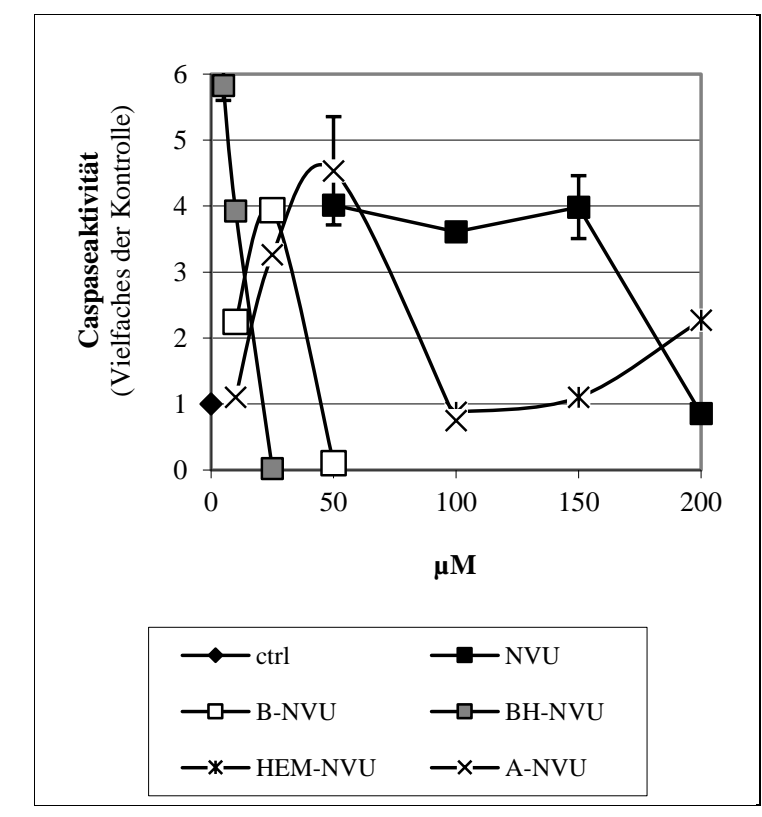

Abbildung 3.16: U937 für 24 h behandelt mit NVU und Derivaten, $\mathrm{n}=4$ 


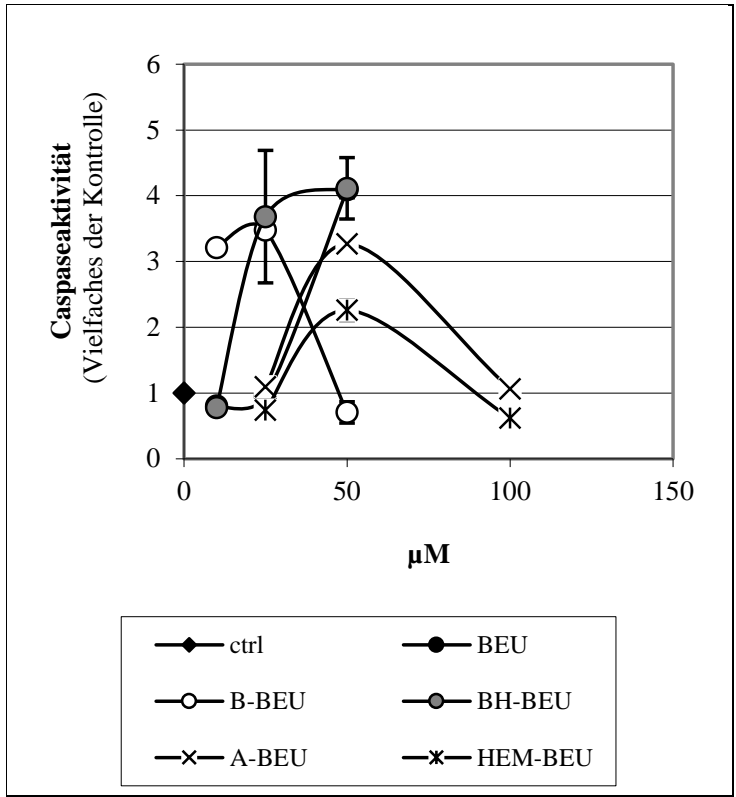

Abbildung 3.17: HL60 für 24 h behandelt mit BEU und Derivaten, $\mathrm{n}=4$

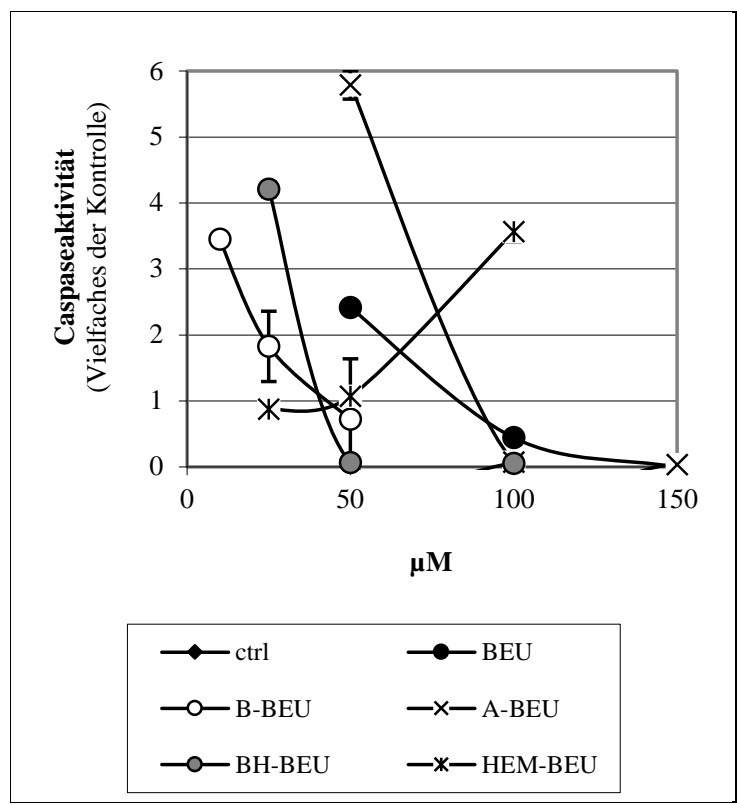

Abbildung 3.18: U937 für 24 h behandelt mit BEU und Derivaten, $\mathrm{n}=5$

Bei vergleichender Betrachtung der Befunde ließ sich feststellen, dass zytotoxische und pro-apoptotische Eigenschaften miteinander korrelierten, das Maximum der Caspaseaktivierung lag ungefähr im selben Konzentrationsbereich wie die LC50 der Substanzen in den Vitalitätstests. Wiederholt war bei Konzentrationssteigerungen, insbesondere der lipophilen Derivate, eine Abnahme der Caspaseaktivität, mutmaßlich als Ausdruck eines Übergangs in nekrotische Zellschädigung bei höheren Konzentrationen, zu beobachten, welches oft bei sehr potenten pro-apoptotischen Substanzen wie z. B. Nitrostyrol beobachtet wurde.

\subsubsection{Caspase-3-Aktivitätsmessung in Kolonkarzinomzellen}

Auch bei den adhärenten Zelllinien ließ sich durch eine Behandlung mit den Testsubstanzen Apoptose induzieren. NVU und BEU zeigten sich innerhalb einer Zelllinie ähnlich potent, die notwendige Inkubationszeit sowie Potenz unterschieden sich aber zwischen den beiden verschiedenen Zelllinien deutlich. Bei den LoVo-Zellen wurde das Caspasemaximum mit einer 5,5fachen Aktivierung bei einer Behandlung von $150 \mu \mathrm{M}$ nach $12 \mathrm{~h}$ erreicht (s. Abb. 3.19). Bei den HCT-Zellen lag das Maximum bereits bei $100 \mu \mathrm{M}$, dieses wurde aber erst nach einer Behandlungszeit von $24 \mathrm{~h}$ erreicht (s. Abb. 3.20). 


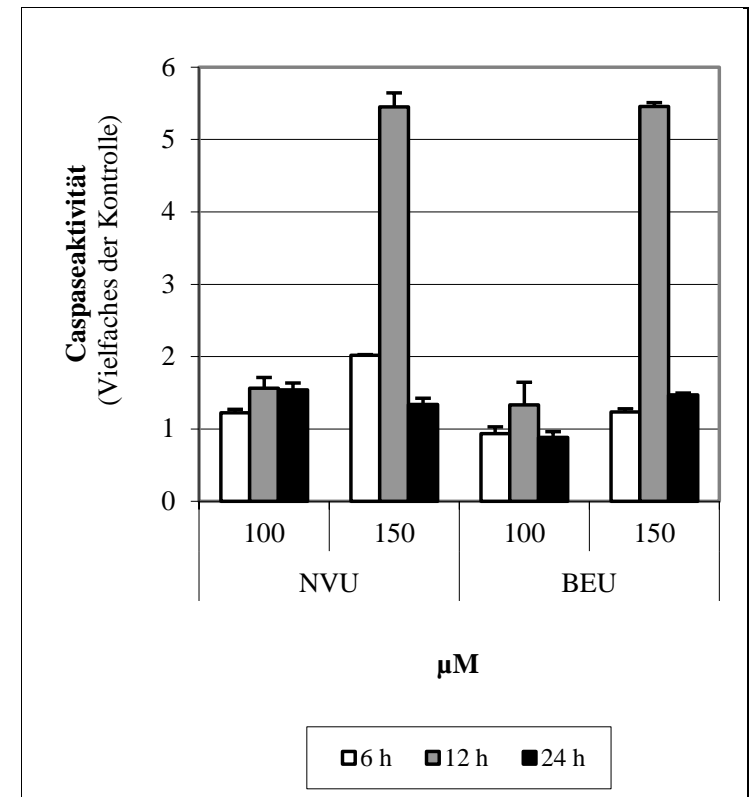

Abbildung 3.19: LoVo für 6, 12 und $24 \mathrm{~h}$ behandelt mit NVU und BEU, $n=4$

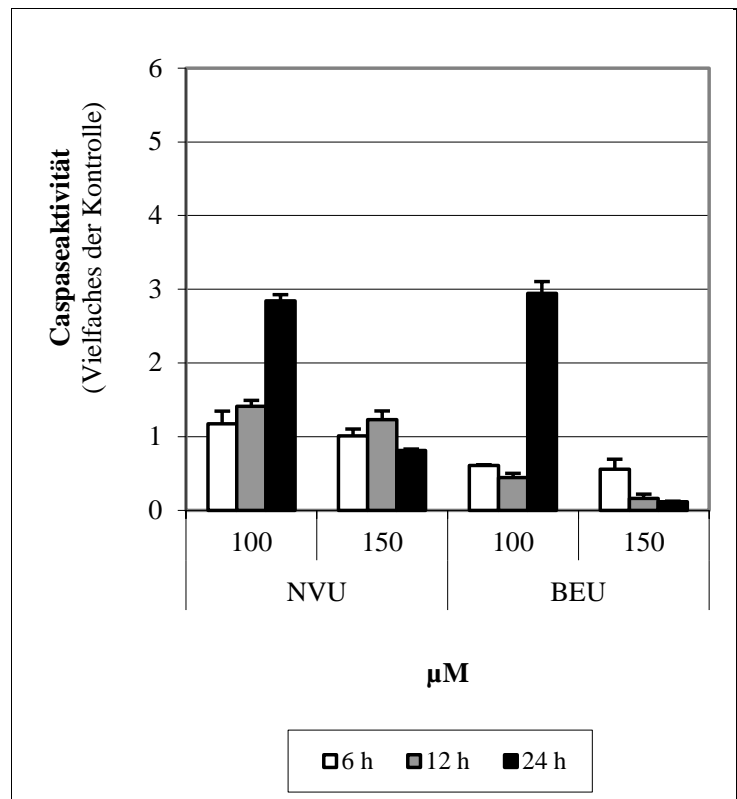

Abbildung 3.20: HCT für 6, 12 und 24 h behandelt mit NVU und BEU, $n=4$

\subsubsection{DNA-Fragmentierung in HL60-Zellen}

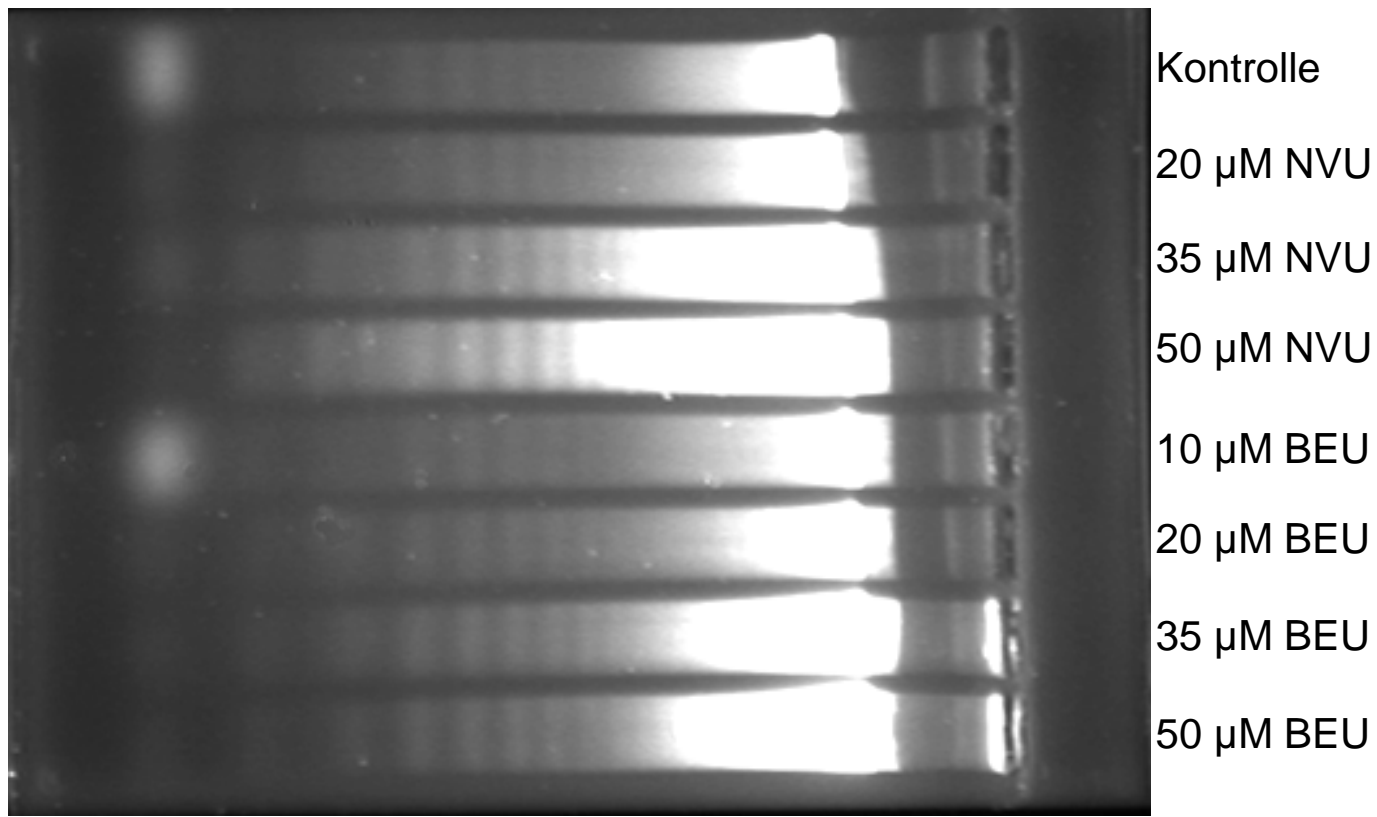

Abbildung 3.21: HL60 für 24 h mit NVU und BEU behandelt 
Die DNA-Fragmentierung in Form diskreter Banden mit einer Länge von 200 Basenpaaren bzw. einem Vielfachen davon ist ein entscheidender und charakteristischer finaler Schritt der Apoptose.

In dem vorliegenden Gel ließ sich eine von der Kontrolle abweichende Fragmentierung ab einer Konzentration von $35 \mu \mathrm{M}$ eindeutig bei beiden Verbindungen (NVU, BEU) nachweisen.

\subsection{NVU- und BEU-Wirkung bei Kombination mit Thiolen}

Aus Versuchen mit Nitrostyrol (NS) war bekannt, dass die Zugabe des Thiols $\mathrm{N}$-Acetylcystein (NAC) in ausreichender Konzentration einen zytoprotektiven Effekt hatte. Es wurde untersucht, ob NAC auch in Kombination mit den beiden Testsubstanzen (NVU, $\mathrm{BEU}$ ), die bei deren alleiniger Anwendung beobachtete Zytotoxität mindern konnte (Kaap 2004).

\subsubsection{Vitalitätstests}

MTT-Tests mit HL60-Zellen zeigten, dass wie bei NS auch die Effekte von NVU und BEU mit NAC aufhebbar waren. Bei NVU waren wie mit NS relativ hohe Dosen von NAC von $1000 \mu \mathrm{M}$ nötig um einen vollständigen zytoprotektiven Effekt zu erreichen. Die toxische Wirkung von BEU wurde dagegen bereits bei einer Kombination mit einer fast äquimolaren Konzentration von $75 \mu \mathrm{M}$ NAC aufgehoben (s. Abb. 3.22).

Im nächsten Schritt wurde untersucht wie groß das Intervall zwischen Behandlung und Zugabe vom Thiol sein durfte, um noch einen zytoprotektiven Effekt zu erreichen.

Auch hier wurden MTT-Tests mit HL60-Zellen durchgeführt. Diese wurden für $24 \mathrm{~h}$ behandelt, zu definierten Zeitpunkten nach Behandlungsbeginn erfolgte die Zugabe von jeweils $1000 \mu \mathrm{M}$ NAC. Im Falle des NVU zeigte sich, dass auch nach 8 h NVU-Behandlung die Zugabe von NAC die Toxizität komplett aufheben konnte, wohingegen im Falle des BEU bereits nach 2 h kein signifikanter Schutz mehr zu beobachten war (s. Abb. 3.23). 


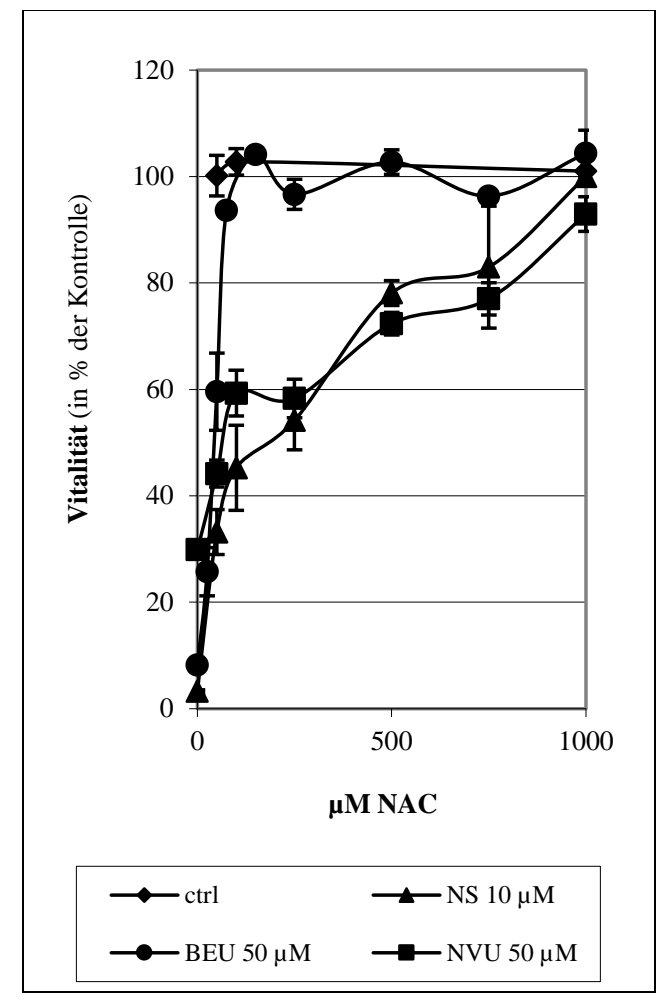

Abbildung 3.22: HL60 für 24 h behandelt mit NS, NVU und BEU, zusätzlich Zugabe von NAC, $n=5$

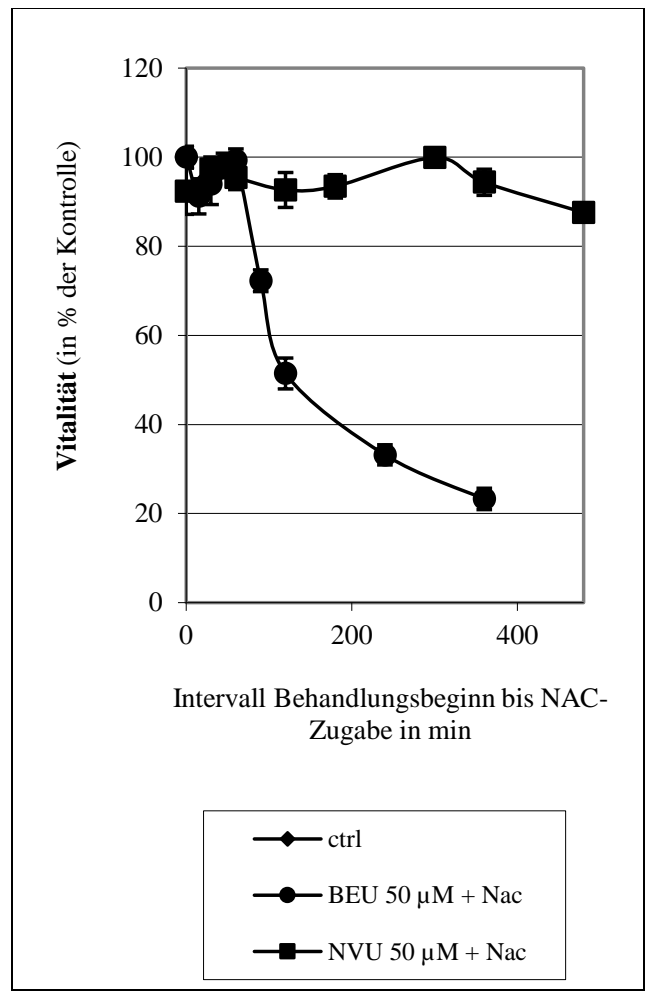

Abbildung 3.23: HL60 für 24 h behandelt mit NVU und BEU, zeitlich versetzte Zugabe von NAC, $n=5$

Im Anschluss wurde überprüft, ob sich diese Ergebnisse auch auf die jeweiligen BenzylDerivate übertragen lassen. Hierbei zeigte sich, dass nun beim B-NVU wie beim NVU hohe Konzentrationen von NAC im Bereich von $1000 \mu \mathrm{M}$ notwendig waren, um die Zellen zu schützen (s. Abb. 3.24). Während bei der Nukleobase BEU äquipotente NAC-Dosen ausreichten, waren beim wesentlich lipophileren Benzyl-Derivat B-BEU dagegen deutlich höhere Konzentrationen (um $1000 \mu \mathrm{M}$ ) erforderlich (s. Abb. 3.25).

Von Ghibelli et al. wurde 1998 beschrieben, dass der Efflux von GSH zur Apoptoseinduktion beiträgt. Die Autoren zeigten, dass neben der Cysteinvorstufe Cystathion auch die Aminosäure Methionin einen zytoprotektiven Effekt durch Verhinderung dieses GSHAusstromes bewirkte. Die Autoren postulieren, dass es im Rahmen der Apoptose zu einem Glutathionausstrom aus den betroffenen Zellen kommt, dieser funktioniere über bestimmte in der Zellmembran lokalisierte GSH-Transporter. Cystathion und Methionin würden diese Transporter blockieren und somit den GSH-Ausstrom sowie in dessen Folge die Induktion einer Apoptose verhindern. 


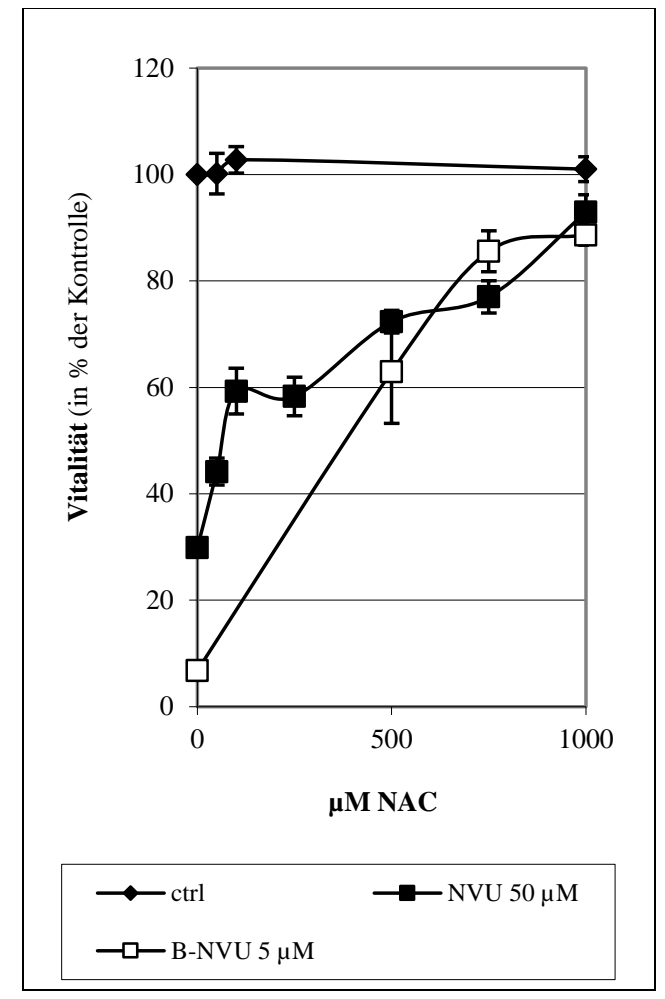

Abbildung 3.24: HL60 für 24 h behandelt mit NVU und B-NVU in Kombination mit NAC, $n=5$

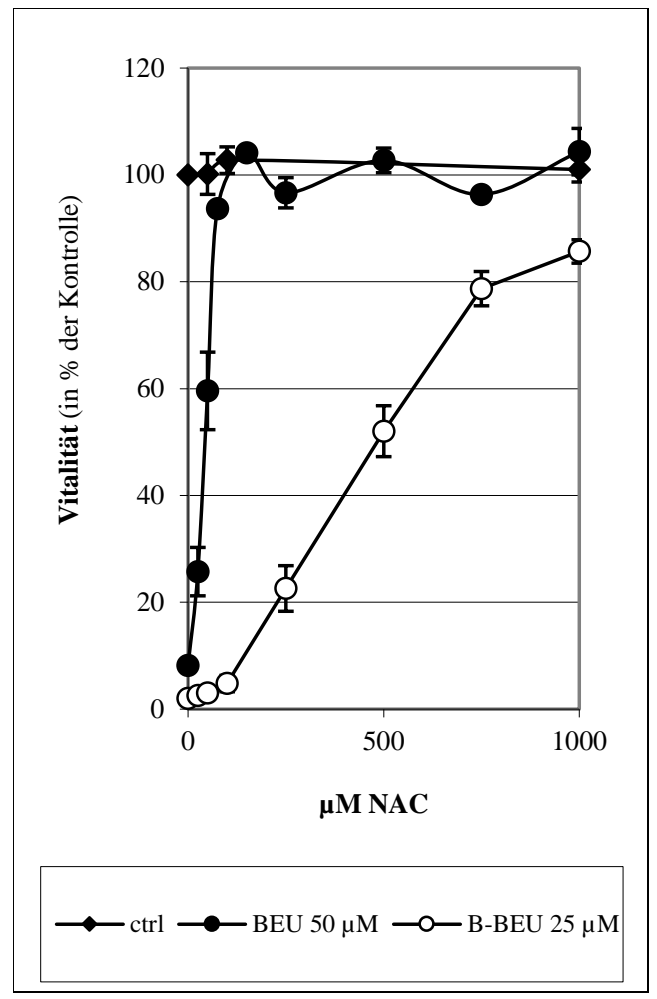

Abbildung 3.25: HL60 für 24 h behandelt mit BEU und B-BEU in Kombination mit NAC, $n=5$

Dies konnte für NVU- und BEU-Behandlungen nicht gezeigt werden (s. Abb. 3.26). Methionin in gleicher Konzentration konnte weder im Falle des NVU noch des BEU deren Zytotoxität verhindern. Eine freie Thiol-Gruppe wie beim NAC schien für einen zytoprotektiven Effekt gegen NVU und BEU funktionell entscheidend zu sein. So konnte NAC mit gleichem Erfolg durch Glutathion (GSH) ersetzt werden.

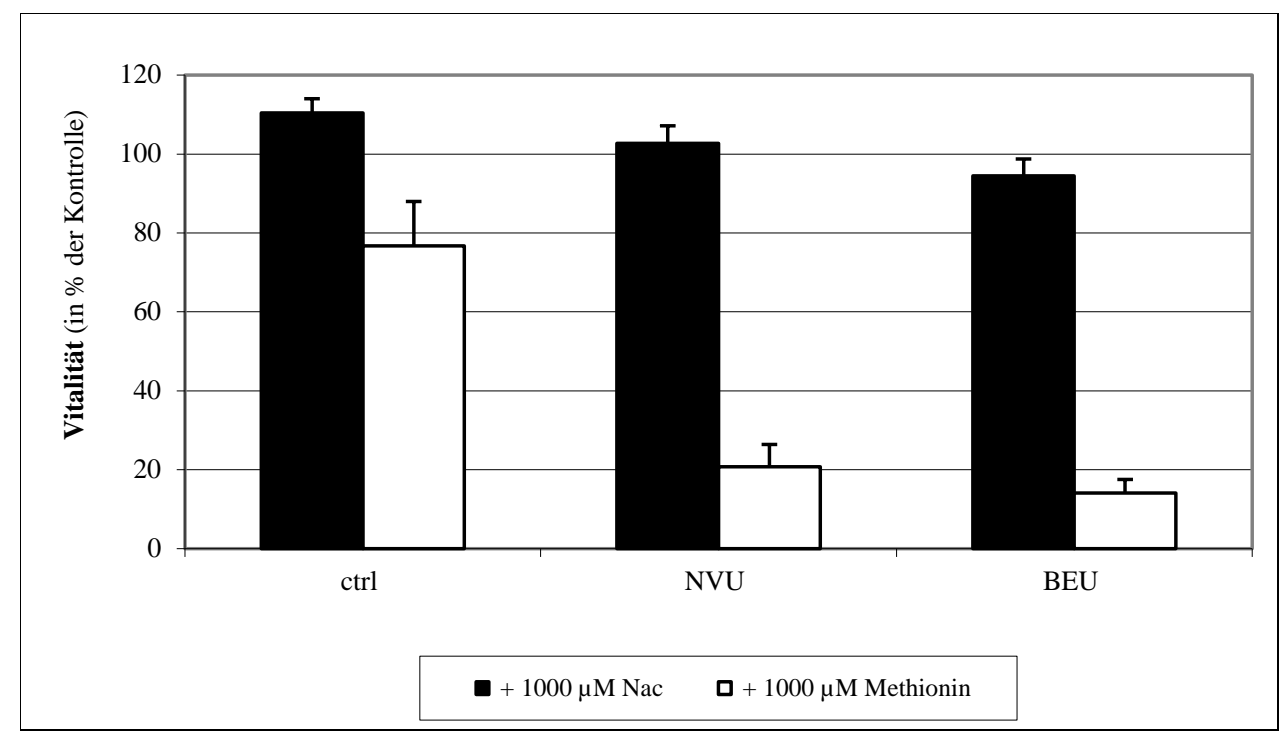

Abbildung 3.26: HL60 für 24 h behandelt mit $50 \mu \mathrm{M}$ NVU oder BEU in Kombination mit N-Acetylcystein oder Methionin 


\subsubsection{Apoptoseinduktion}

Im folgenden Arbeitsschritt wurde überprüft, ob sich diese Ergebnisse der Vitalitätstests auch in der Caspaseaktivierung widerspiegelten.

Wie auch im MTT-Test waren beim NVU hohe Dosen von NAC notwendig, um eine Zellschädigung zu verhindern (s. Abb. 3.27).

Auch die Ergebnisse der Zeitversuche fanden sich im Caspaseassay bestätigt. Während beim BEU bereits zwei Stunden nach Behandlungsbeginn eine Caspaseaktivierung nicht mehr verhindert werden konnte, wurde die maximale Aktivierung der Caspase beim NVU erst erreicht, wenn die NAC-Zugabe nach einem Intervall von 12 h erfolgte (s. Abb. 3.28).

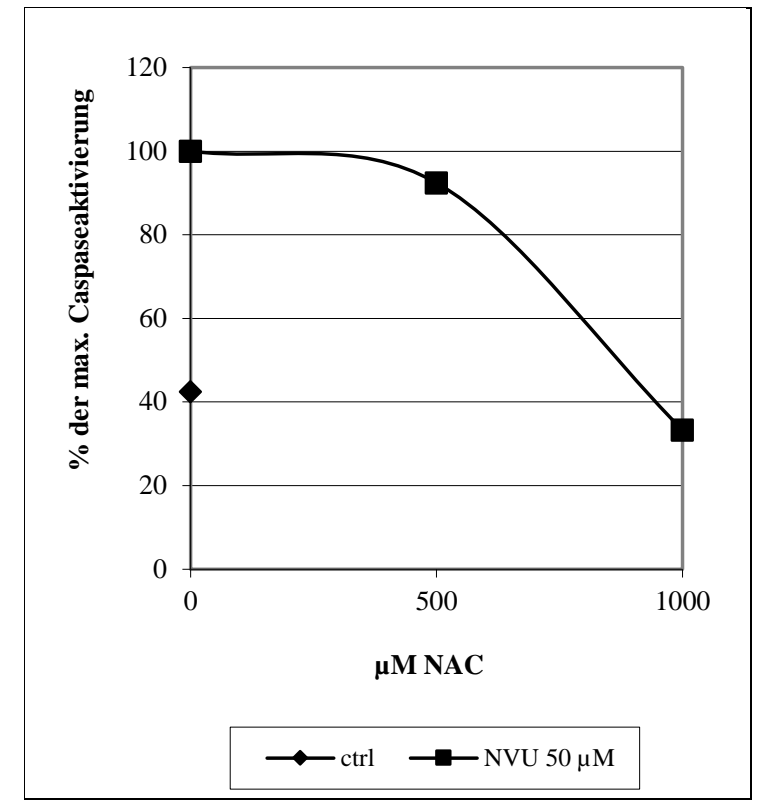

Abbildung 3.27: HL60 für 24 h behandelt mit NVU und verschiedenen Konzentrationen NAC, $n=3$

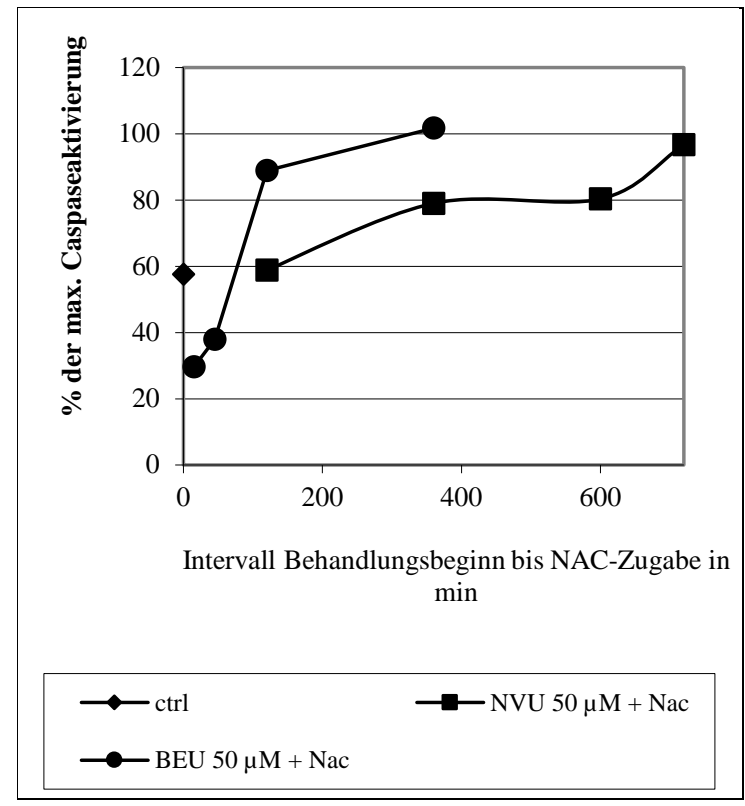

Abbildung 3.28: HL60 für 24 h behandelt mit BEU und NVU, zeitversetzte Zugabe von $1000 \mu \mathrm{M}$ NAC, $n=3$

\subsubsection{NVU- und BEU-Absorptionsspektren in Kombination mit Thiolen}

Es gibt verschiedene Mechanismen über die ein Thiol zytoprotektiv wirken kann. Die von Ghibelli (Ghibelli et al. 1998) postulierten GSH-Transporter schienen im vorliegenden Fall nicht die Erklärung zu sein, da nach seinen Beobachtungen sonst auch Methionin, also eine Substanz ohne freie SH-Gruppe, schützend wirken müsste. 
Im Rahmen der Untersuchung einer hemmenden Wirkung von Nitrostyrol (NS) auf Tyrosinphosphatasen, zeigten Park und Pei (Park und Pei 2004), dass die Hemmung des Enzyms durch Michael-Addition einer SH-Gruppe der PTB-Phosphatase an die Doppelbindung der Nitrovinylseitenkette von NS bedingt wurde. Dabei änderte sich das Absorptionsspektrum von NS. Ein Peak bei 320 nm verschwand konzentrationsabhängig bei Zugabe von Thiolen. Mit dem Ziel zu klären, ob für NVU oder BEU ein ähnlicher Mechanismus unterstellt werden kann, wurden Spektrenmessungen der Substanzen in Kombination mit dem Thiol N-Acetylcystein (NAC) durchgeführt.

Auch bei den im Rahmen dieser Arbeit durchgeführten Versuchen zeigte sich, dass bei NS wie auch NVU direkt nach NAC-Zugabe Veränderungen im Absorptionsspektrum zu sehen waren, die für intramolekulare Veränderungen sprachen. Der ursprüngliche Peak bei $325 \mathrm{~nm}$ (NS) bzw. $400 \mathrm{~nm}$ (NVU) verschwand, ein neuer Peak bei $250 \mathrm{~nm}$ entstand (s. Abb.3.29 + 3.30).

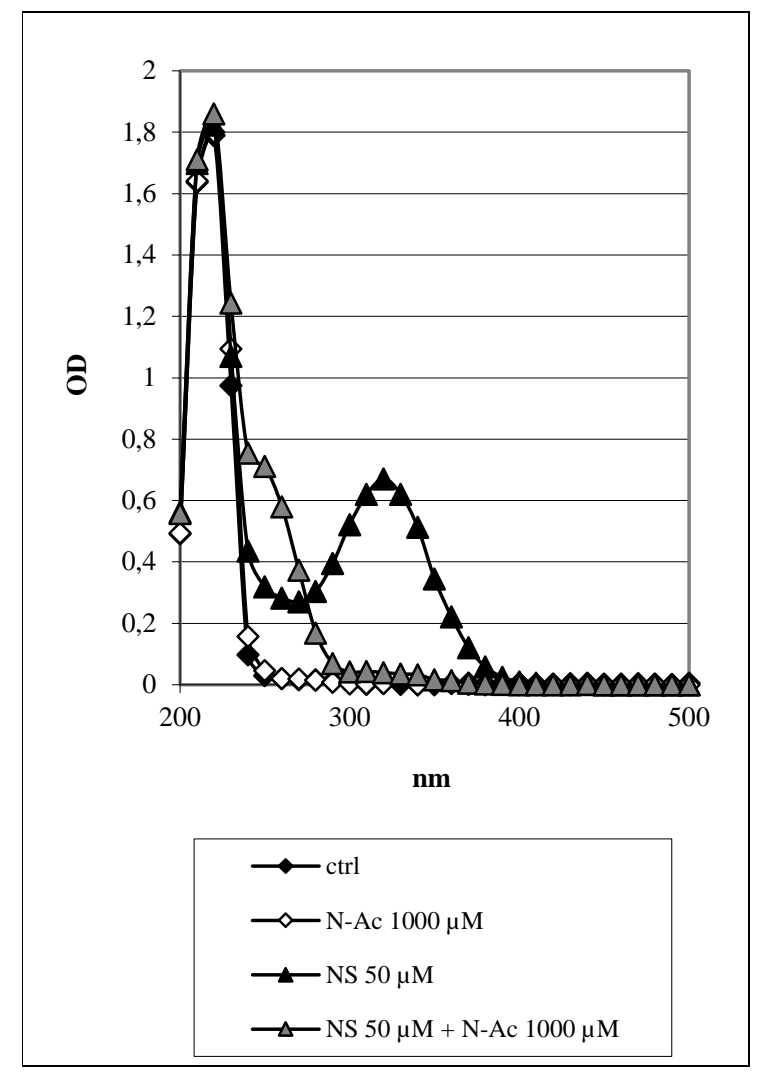

Abbildung 3.29: Spektrum NS und NS in Kombination mit NAC

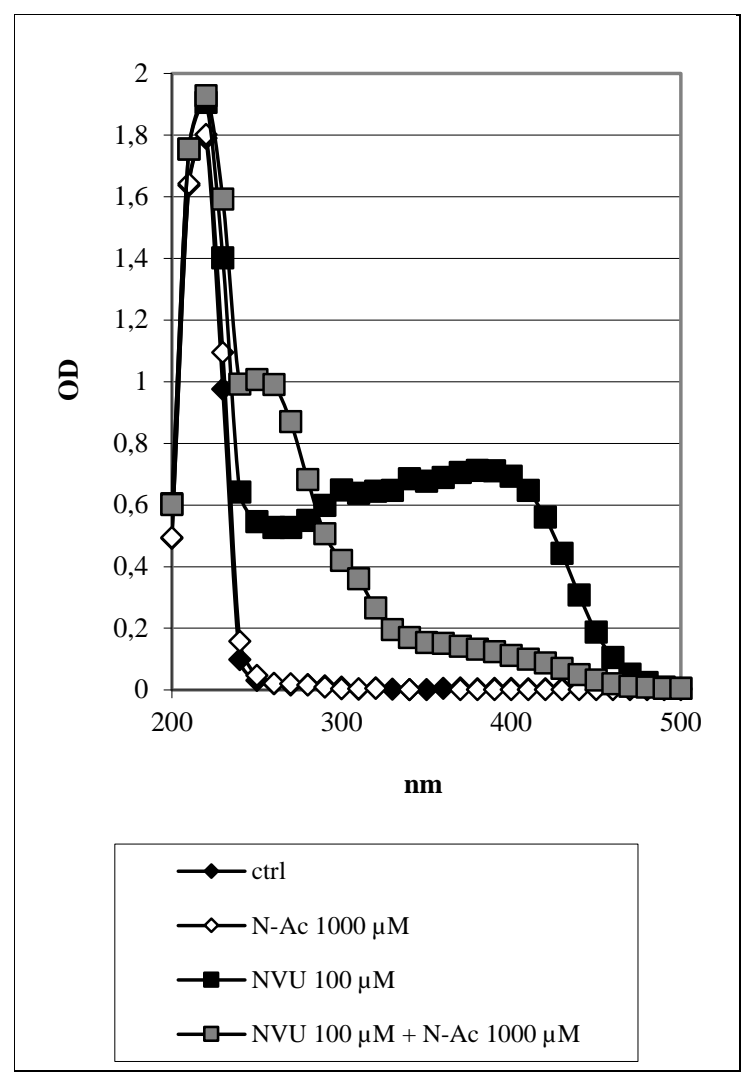

Abbildung 3.30: Spektrum NVU und NVU in Kombination mit NAC 


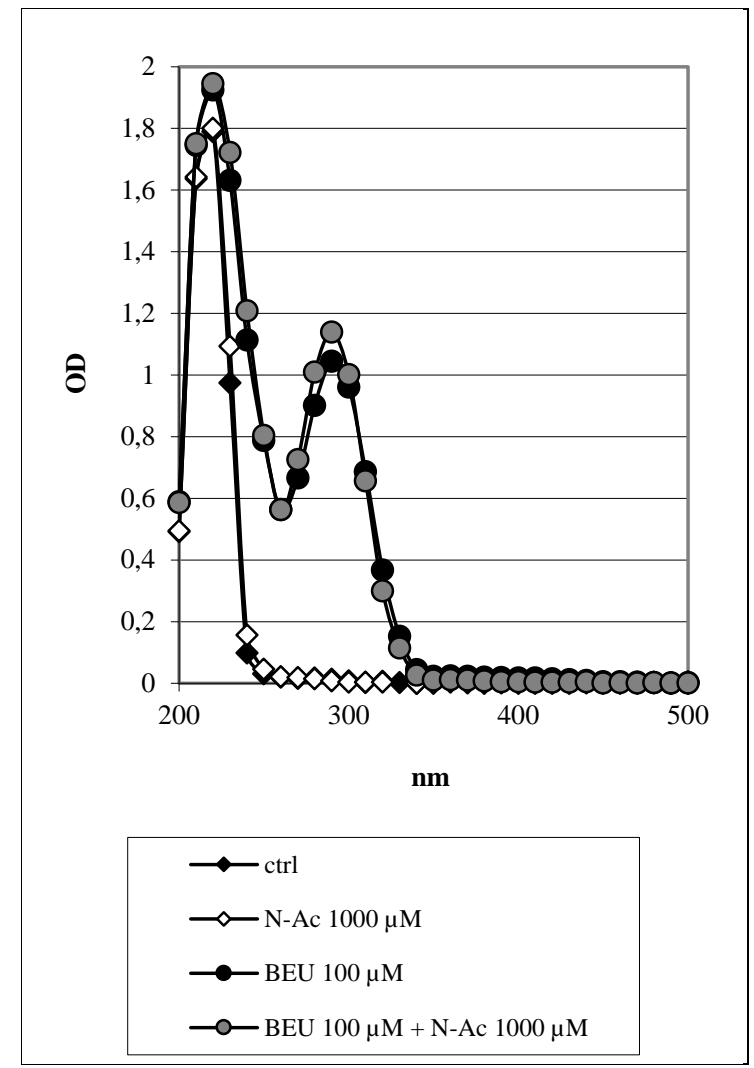

Abbildung 3.31: Spektrum BEU und BEU in Kombination mit NAC

Das Spektrum von BEU zeigte dagegen durch die Zugabe von NAC keine Veränderungen im Absorptionsverhalten (s. Abb. 3.31). Auch nach Inkubationszeiten von bis zu $20 \mathrm{~h}$ blieben die Spektren von BEU und BEU + NAC kongruent.

Ähnliche Veränderungen wie die Spektren von NVU und NS wies auch das Spektrum des NVU-Benzylderivates FB-NVU in Kombination mit Glutathion (GSH) auf. Auch hier sah man, bei Lösung einem hydrophilen Lösungsmittel wie PBS/BSA, eine Abnahme des Peaks bei $340 \mathrm{~nm}$ und eine Zunahme bei 275 nm (s. Abb. 3.32).

Löste man GSH und Substanz in einem lipophilen Lösungsmittel, wie z. B. Butanol, ließen sich spektrometrisch keine Veränderungen im Vergleich zur nativen FB-NVU-Kurve nachweisen (s. Abb. 3.33). 


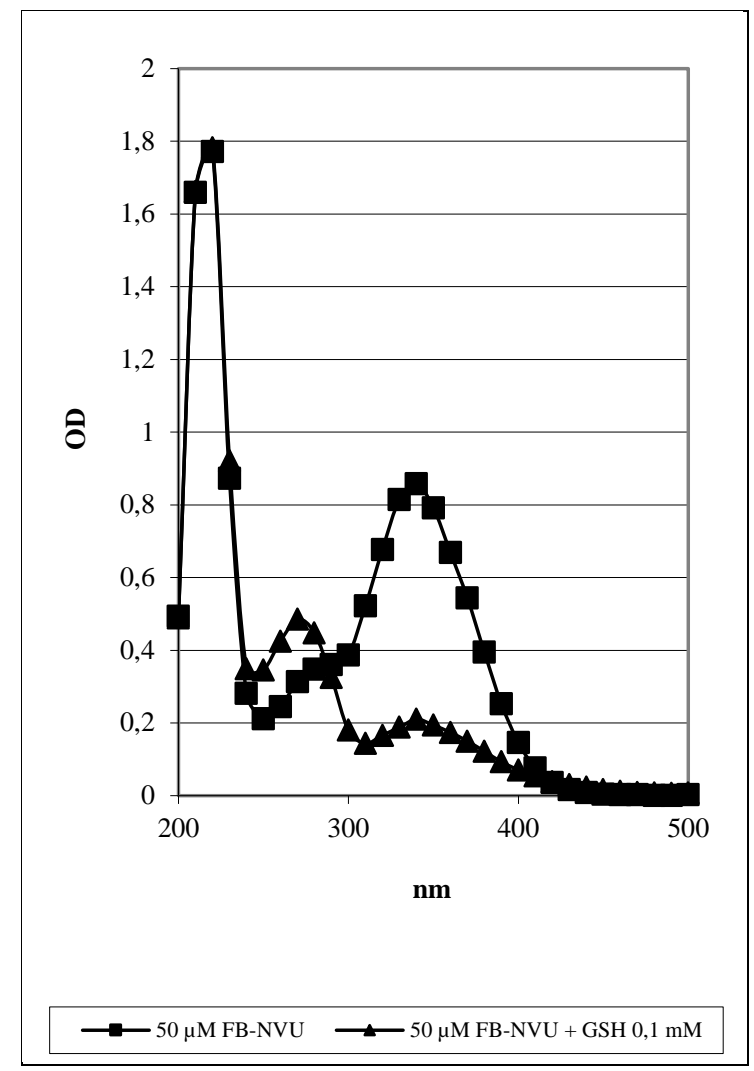

Abbildung 3.32: Spektrum FB-NVU in Kombination mit GSH in PBS/BSA gelöst

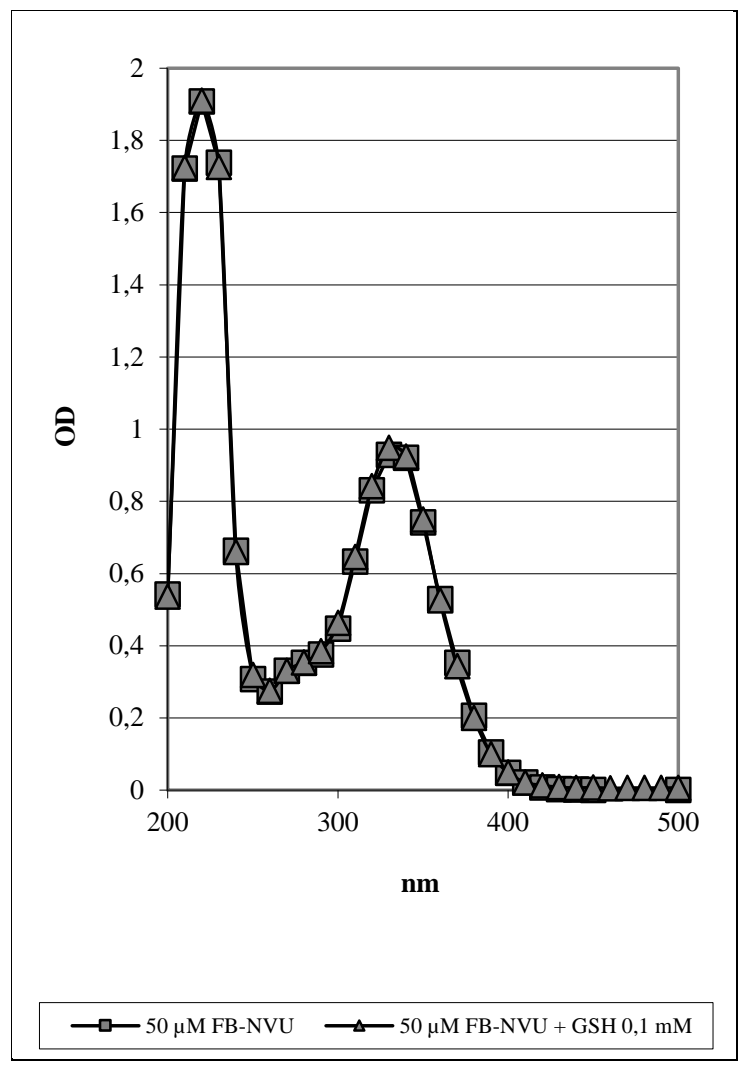

Abbildung 3.33: Spektrum FB-NVU in Kombination mit GSH in Butanol gelöst

\subsubsection{Butanolextraktion zur Erfassung intrazellulärer Anreicherung}

NVU schien durch die Zugabe von NAC sofort zu reagieren, während BEU keine Hinweise für eine strukturelle Veränderung zeigte. Es stellte sich ergänzend die Frage, wie sich die Substanzen in Gegenwart von Zellen verhielten, ob z. B. eine Aufnahme in die Zelle erfolgte. Da sich die Substanzen spektrometrisch gut darstellen ließen und lipophile Eigenschaften besaßen, wurde versucht, mittels Butanolextraktion die Aufnahme der Substanzen in die Zellen nachzuweisen. Da bei Zellaufschluss in Zellkulturmedium zu viele Störfaktoren entstanden, konnte dies nicht realisiert werden.

Allerdings ließ sich eine zellzahlabhängige Veränderung der Substanz im Medium nachweisen. Verschiedene Zellzahlen wurden für eine Stunde mit dem lipophilen Fluorbenzyl-NVU (FB-NVU) in einer Konzentration von $50 \mu \mathrm{M}$ behandelt. Als Medium wurde in diesem Versuch PBS/BSA verwendet, da das gängige RPMI-Zellkulturmedium zu viele Störfaktoren enthielt, sodass eine Spektrometrie damit nicht möglich war. Abb. 3.34 
zeigt, dass der charakteristische Peak bei $340 \mathrm{~nm}$ zellzahlabhängig abnahm und entsprechend ein Peak bei ca. $275 \mathrm{~nm}$ zunahm.

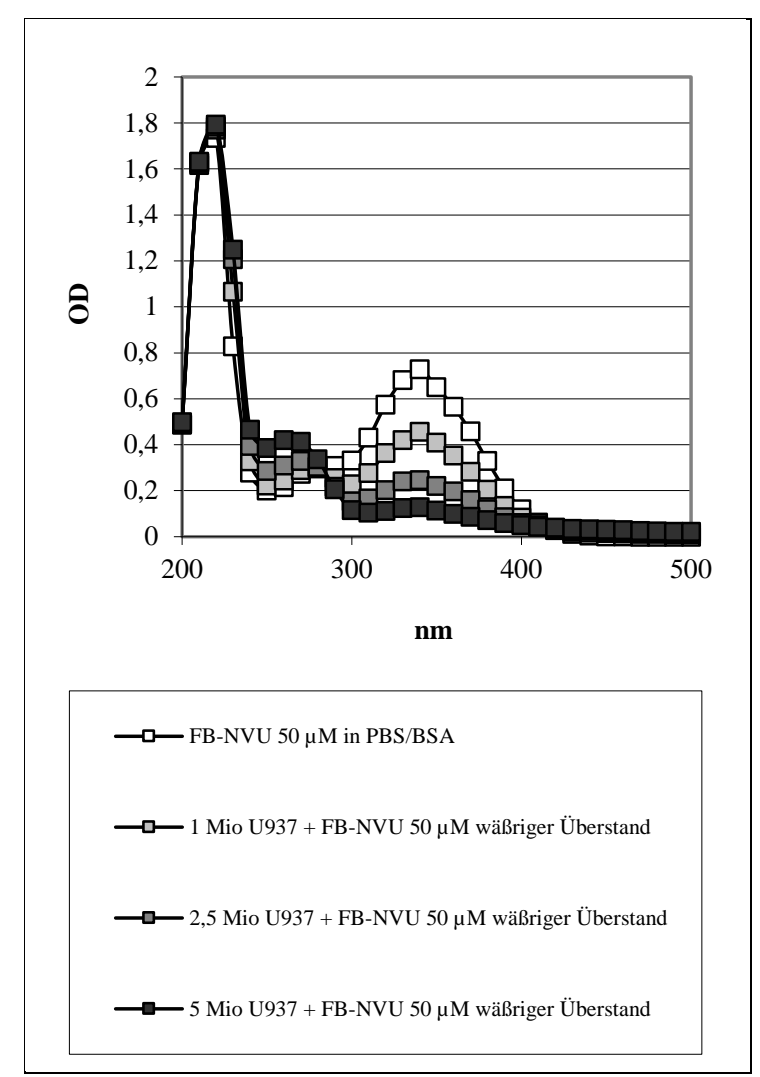

Abbildung 3.34: Verschiedene Zellzahlen in PBS/BSA für $1 \mathrm{~h}$ mit FB-NVU behandelt, Spektrometrie des Überstands

\subsection{GSH-Messungen nach Behandlung mit NVU und BEU bzw. deren Derivaten}

Die oben dargestellten Ergebnisse legten nahe, dass dem zelleigenen GSH-System eine zentrale Position hinsichtlich der Zytotoxität der neuen Wirkstoffe zukam. Das GSH-GSSGSystem ist ein Redox-System, das als Antioxidans dem Schutz der Zelle dient. Glutathion (GSH) ist ein Tripeptid aus drei Aminosäuren: Glutaminsäure, Cystein und Glycin.

Cystein enthält eine Thiol-Gruppe, diese kann bei oxidativem Stress mit der Thiol-Gruppe eines weiteren GSH-Moleküls unter Bildung der oxidierten Form des Glutathions (GSSG) reagieren. Daher wurde dieses Redox-System genauer untersucht. Es wurde das intrazelluläre 
GSH/GSSG dargestellt sowie das extrazelluläre GSH im Medium bestimmt. Da sich die bisher verwendeten zwei Suspensionszelllinien- sowie die adhärenten Zelllinien jeweils im GSH-Gehalt nicht signifikant unterschieden, wurden die Untersuchungen mit nur jeweils einer Zelllinie fortgesetzt.

Nativ hatten LoVo-Zellen einen GSH-Gehalt von ca. $140 \mathrm{nmol} / \mathrm{mg}$ Protein sowie einen GSSG-Gehalt von ca. 5 nmol/mg Protein, U937-Zellen lagen bei einem GSH-Gehalt von nur ca. $60 \mathrm{nmol} / \mathrm{mg}$ Protein und bei einem GSSG-Gehalt von ca. $2 \mathrm{nmol} / \mathrm{mg}$ Protein. Der unterschiedliche GSH-Gehalt könnte eine mögliche Erklärung für die Unterschiede in der Empfindlichkeit in Bezug auf die Zytotoxität von NVU und BEU sein.

\subsubsection{GSH-/GSSG-Messungen in Kolonkarzinomzellen}

Nach einer vierstündigen Behandlung von LoVo-Zellen mit NVU zeigte sich eine konzentrationsabhängige Abnahme der intrazellulären GSH-Konzentration, die extrazelluläre GSH-Konzentration verhielt sich gegenläufig (s. Abb. 3.35 + 3.36). Die intrazellulär verlorene Menge entsprach quantitativ ungefähr der Zunahme im Medium, da man berücksichtigen muss, dass die Werte für den intrazellulären GSH-Gehalt in der Grafik auf $10^{6}$ Zellen bezogen sind, im Test aber nur 500.000 pro $1,5 \mathrm{ml}$ Medium eingesetzt worden sind. Daher muss man, um die quantitative Abschätzungen vorzunehmen, den GSH-Gehalt im Medium verdoppeln.

Die intrazelluläre GSSG-Konzentration verdoppelte sich unter Behandlung, im Medium ließ sich das GSSG aufgrund zu geringer Mengen nicht darstellen.

Es kam also einerseits zu einem Ausstrom von GSH aus der Zelle und andererseits zu einer vermehrten Oxidation von GSH zu GSSG. Der intrazelluläre GSH-Spiegel sinkt also über beide Mechanismen.

Beim Einsatz von 10fach niedrigeren Konzentrationen von FB-NVU verhielt sich die GSHKonzentration ähnlich, es kam intrazellulär zu einer GSH-Abnahme, im Medium zu einer Zunahme (s. Abb. $3.37+3.38$ ). Auch hier entsprach die intrazelluläre Abnahme in etwa der extrazellulären Zunahme. Abweichend zur Behandlung mit NVU kam es unter Einsatz von FB-NVU auch zu einer Abnahme der GSSG-Konzentration, sodass das intrazelluläre GSH/GSSG-Verhältnis annähernd konstant blieb. 


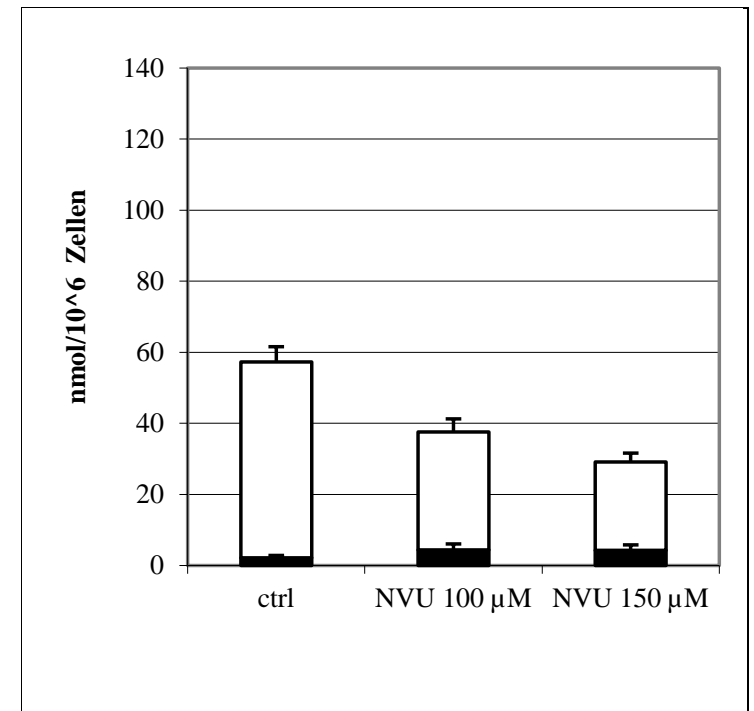

Abbildung 3.35: GSH (weiß)/GSSG(schwarz)Gehalt intrazellulär in nmol/10 ${ }^{6}$ LoVo-Zellen, nativ und für 4 h behandelt mit NVU, $n=8$

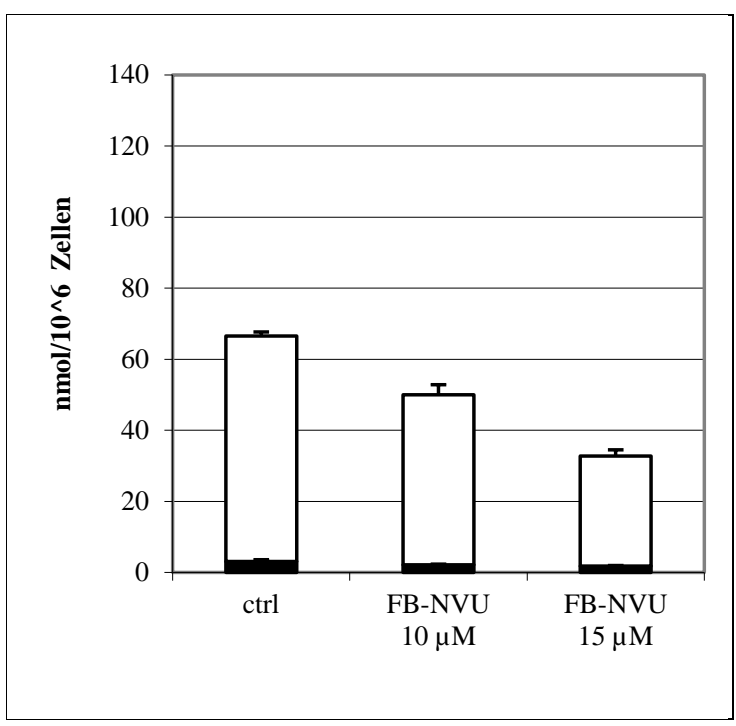

Abbildung 3.37: GSH (weiß)/GSSG(schwarz)Gehalt intrazellulär in nmol/10 $0^{6}$ LoVo-Zellen, nativ und für $4 \mathrm{~h}$ behandelt mit FB-NVU, n=8

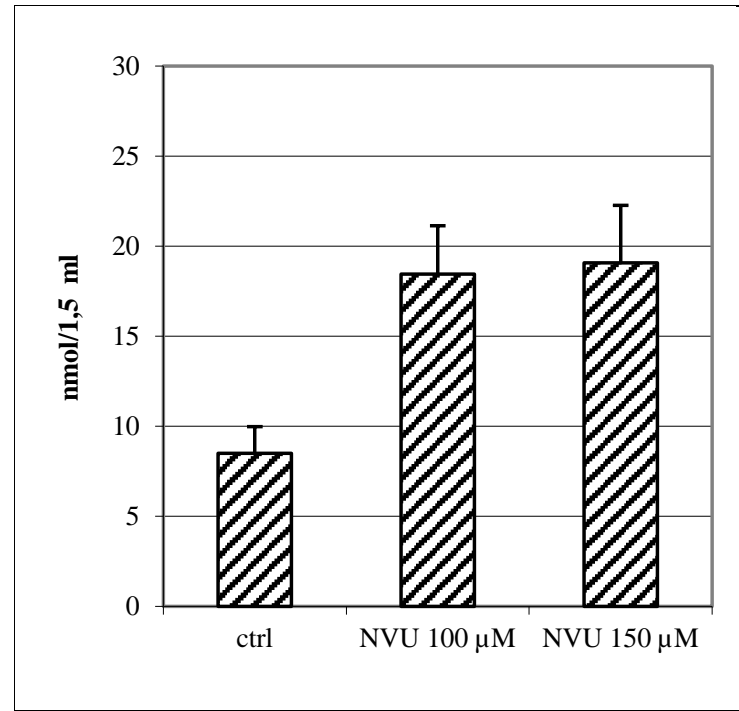

Abbildung 3.36: GSH-Gehalt im Medium in $\mathrm{nmol} / 1,5 \mathrm{ml}$ Medium, nativ und für $4 \mathrm{~h}$ behandelt mit NVU, $\mathrm{n}=8$

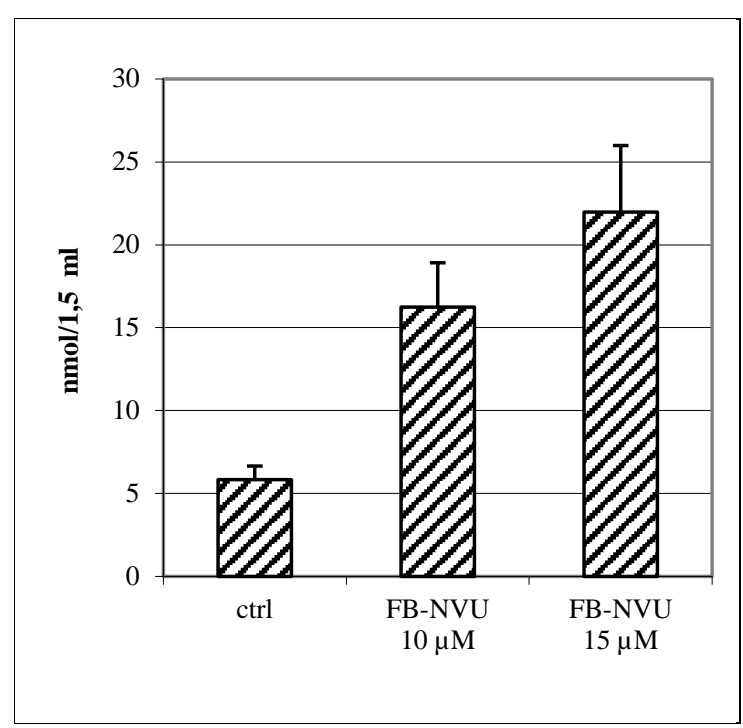

Abbildung 3.38: GSH-Gehalt im Medium in $\mathrm{nmol} / 1,5 \mathrm{ml}$ Medium, nativ und für $4 \mathrm{~h}$ behandelt mit FB-NVU, $n=8$

Beim BEU kam es unter Behandlung im untersuchten Konzentrationsbereich initial zu einer GSH-Zunahme und erst bei hohen Konzentrationen zu einer leichten GSH-Abnahme um ca. $10 \mathrm{nmol} / 10^{6}$ Zellen (s. Abb. 3.39). Im Medium (s. Abb. 3.40) zeigte sich eine konzentrationsabhängige Zunahme der GSH-Konzentration um ca. 10 nmol/1,5 ml Medium, also um ca. $20 \mathrm{nmol} / 10^{6}$ Zellen. Im Vergleich zu den NVU-Derivaten, bei denen die 
intrazelluläre GSH-Abnahme ungefähr der extrazellulären GSH-Zunahme entsprach, war die extrazelluläre GSH-Zunahme unter BEU-Behandlung ca. doppelt so groß wie die intrazelluläre GSH-Abnahme. Das intrazelluläre GSSG nahm deutlich um den Faktor 2,5 zu.

Unter Behandlung mit FB-BEU verhielten sich die GSH/GSSG-Konzentrationen bei 5-10fach niedrigeren Konzentrationen des BEU-Derivates ähnlich wie beim BEU (s. Abb. 3.41 + 3.42).

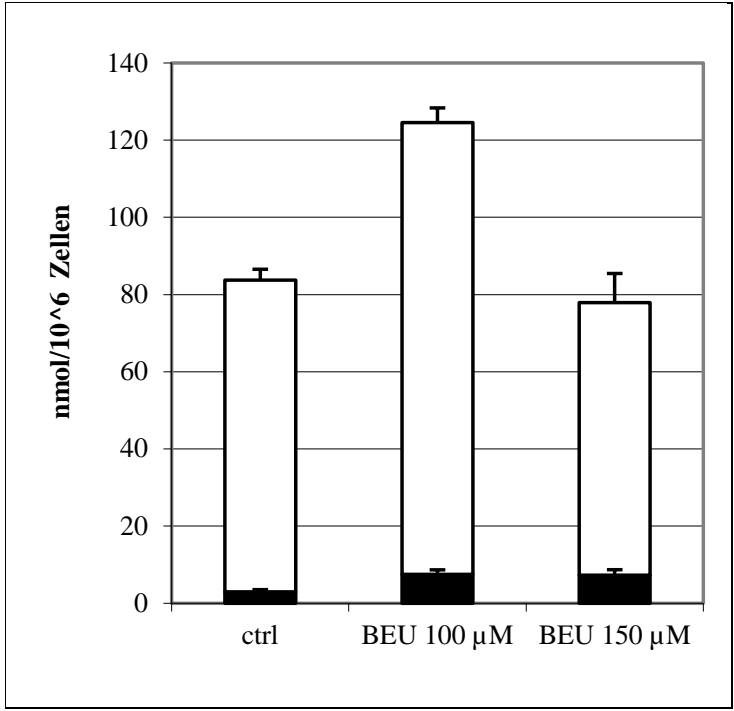

Abbildung 3.39: GSH (weiß)/GSSG(schwarz)Gehalt intrazellulär in nmol/106 LoVo-Zellen, nativ und für 4 h behandelt mit BEU, $n=8$

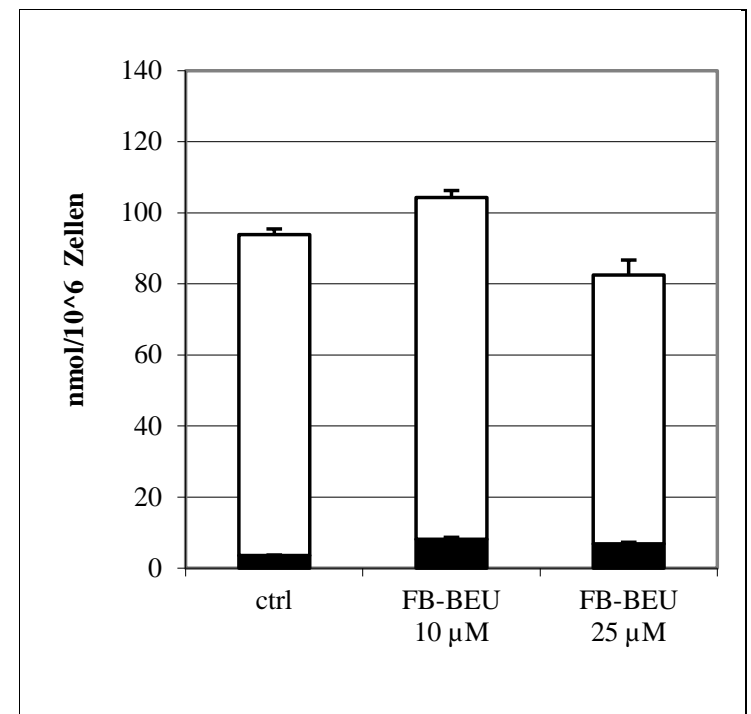

Abbildung 3.41: GSH (weiß)/GSSG(schwarz)Gehalt intrazellulär in nmol/10 $0^{6}$ LoVo-Zellen, nativ und für $4 \mathrm{~h}$ behandelt mit FB-BEU, $\mathrm{n}=8$

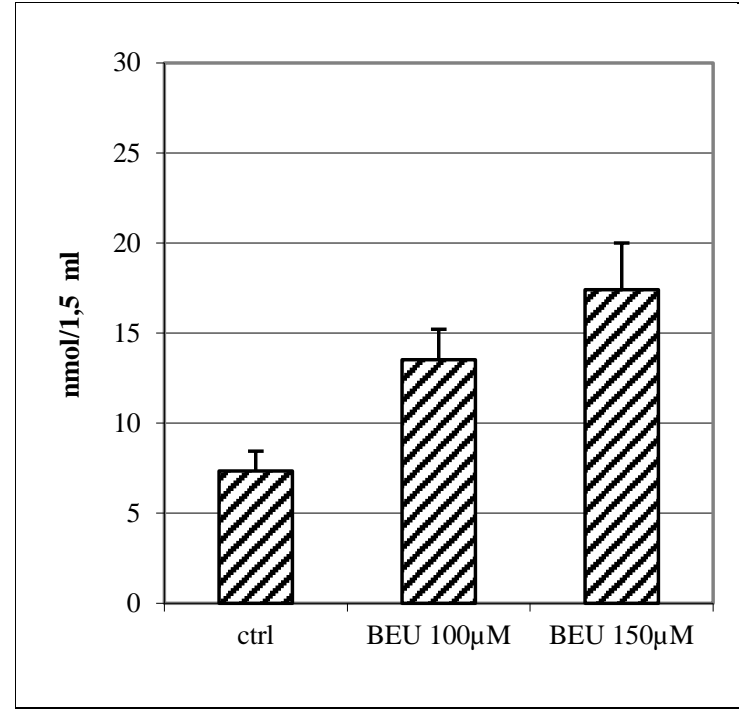

Abbildung 3.40: GSH-Gehalt im Medium in $\mathrm{nmol} / 1,5 \mathrm{ml}$ Medium, nativ und für $4 \mathrm{~h}$ behandelt mit BEU, $\mathrm{n}=8$

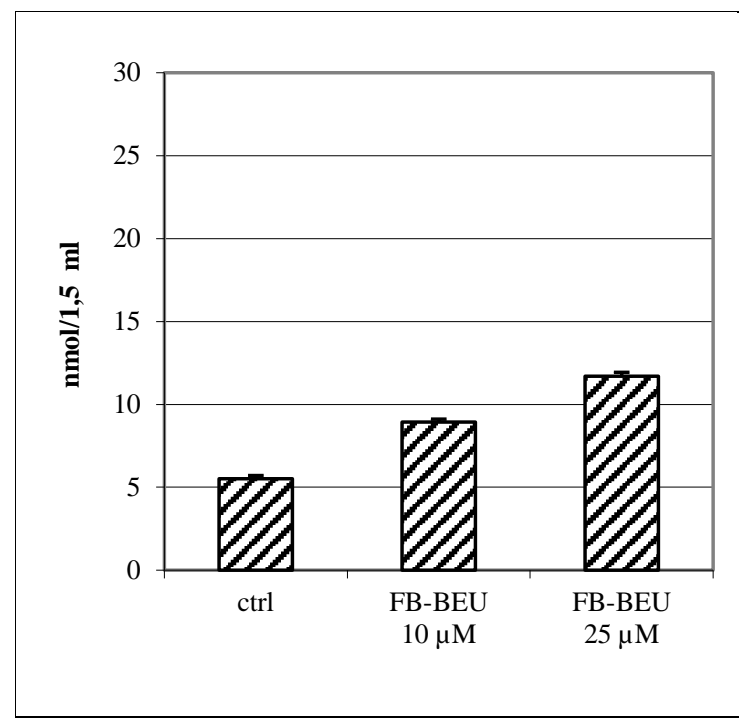

Abbildung 3.42: GSH-Gehalt im Medium in nmol/1,5 ml Medium, nativ und für $4 \mathrm{~h}$ behandelt mit FB-BEU, $n=8$ 


\subsubsection{GSH-/GSSG-Messungen in Leukämiezellen}

U937-Zellen zeigten nach Behandlung für $2 \mathrm{~h}$ sowohl mit NVU als auch mit BEU eine konzentrationsabhängige Abnahme der intrazellulären GSH-Menge (s. Abb. 3.43 + 3.44). Dabei erwiesen sich in den Leukämiezellen beide Substanzen als potenter als in den LoVoZellen, denn bereits unter $50 \mu \mathrm{M}$ war der GSH-Gehalt um ca. 50 \% vermindert.

Für eine extrazelluläre Darstellung war der GSH-Gehalt zu gering, der GSSG-Anteil konnte ebenfalls aufgrund $\mathrm{zu}$ geringer Konzentration weder intra- noch extrazellulär bestimmt werden.

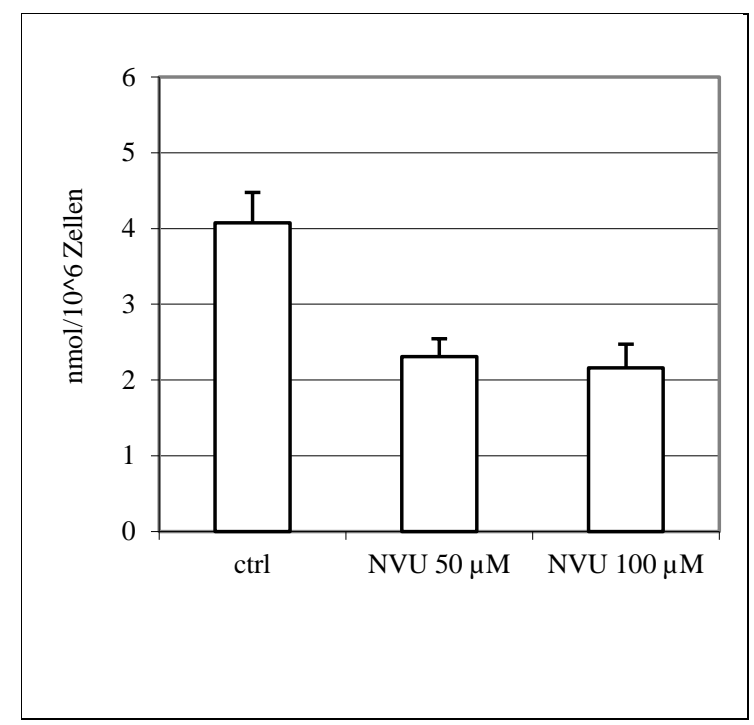

Abbildung 3.43: GSH-Gehalt intrazellulär in nmol/10 ${ }^{6}$ U937-Zellen, nativ und für $2 \mathrm{~h}$ behandelt mit NVU, $\mathrm{n}=8$

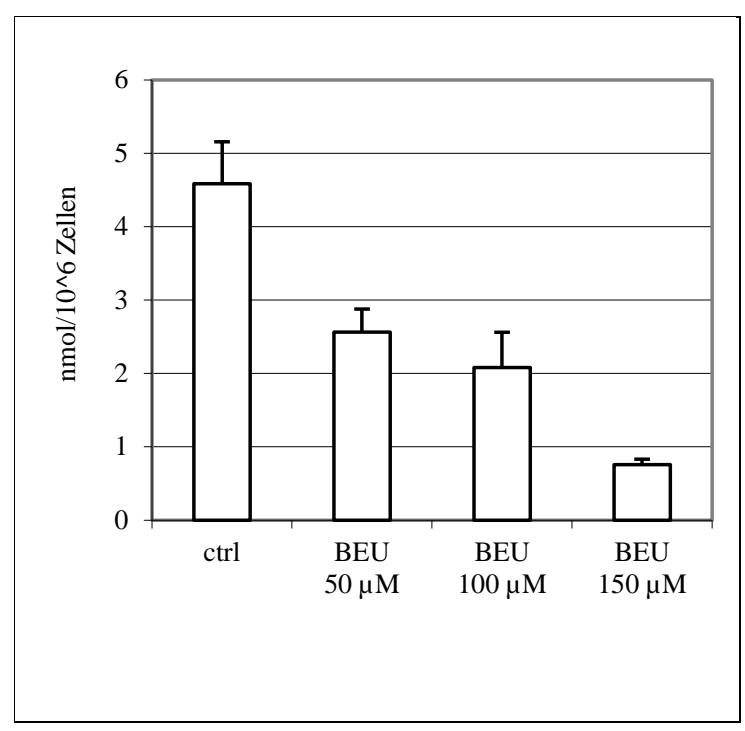

Abbildung 3.44: GSH-Gehalt intrazellulär in nmol/10 ${ }^{6}$ U937-Zellen, nativ und für $2 \mathrm{~h}$ behandelt mit BEU, $n=8$ 


\section{Diskussion}

Im Folgenden werden die erhobenen Ergebnisse im Hinblick auf die Fragestellung dieser Arbeit diskutiert.

\subsection{Zytotoxisches und pro-apoptotisches Potenzial von neusynthe- tisierten Uracilderivaten}

Modifizierte Nukleinsäurebestandteile in Form von Nukleobasen, Nukleosiden oder Nukleotiden finden in der Medizin vielfältige Anwendung. Dies gilt sowohl in der Onkologie als Zytostatika, wie in der Infektionstherapie als Virostatika, sowie auch in der Therapie von Autoimmunkrankheiten. Hierbei kann es sich um Purinderivate (z. B. Azathioprin, Mercaptopurin, Didanosin) als auch um Pyrimidinabkömmlinge (z. B. Cytosinarabinosid, Azidothymidin, 5-Fluoruracil) handeln.<smiles>O=c1[nH]cc(F)c(=O)[nH]1</smiles><smiles></smiles><smiles>O=c1[nH]c(=O)n(C23CC(O)C(O2)C3(O)CO)cc1/C=C/Br</smiles>

NS<smiles>O=[N+]([O-])C=Cc1ccccc1</smiles><smiles>O=c1[nH]cc(/C=C/[N+](=O)[O-])c(=O)[nH]1</smiles><smiles>O=c1[nH]cc(/C=C/Br)c(=O)[nH]1</smiles><smiles>O=c1[nH]cc(C=C(Br)Br)c(=O)[nH]1</smiles><smiles>CCCCC(C)(C)CCBr</smiles>

Abbildung 4.1: Uracil und Derivate sowie Nitrostyrol 
Ausgehend von Erfahrungen mit bekannten zytostatischen wie virostatischen Derivaten des Uracils war es Ziel dieser Arbeit, neue Uracilderivate mit modifizierten funktionellen Anteilen zu identifizieren und ggf. zytotoxische Wirkmechanismen zu charakterisieren.

Das an Position 5 mit Fluor substituierte Uracil findet als 5-Fluoruracil (5-FU) insbesondere in der Therapie des Kolonkarzinoms seinen therapeutischen Einsatz. Das Nukleosid Bromvinyldesoyxuridin (BVDU $=$ Brivudin) ist hingegen ein hochpotentes Virostatikum zur Therapie des Herpes zoster. Auch eine Apoptose-induzierende Potenz in bestimmten transfizierten Zellen wurde für BVDU beschrieben (Tomicic et al. 2003).

Für die neuen Verbindungen Nitrovinyluracil (NVU) und Bromethinyluracil (BEU) konnte eindeutig ein zytostatisches (siehe Ergebnisse der Vitalitätstests Unterpunkt 3.1) sowie pro-apoptotisches Potenzial (siehe Caspaseassays, Fragmentierungsversuche Unterpunkt 3.2 und GSH-Efflux Unterpunkt 3.4) gezeigt werden. Dies gelang sowohl in einer Leukämie- und Lymphomzelllinie- wie auch zwei Kolonkarzinomzelllinien.

Für das NVU lagen die Daten zur funktionellen Bedeutung der Nitrovinylseitenkette aus dem Nitrostyrol (Kaap et al. 2002, Werner et al. 2007) der Entwicklung der Hypothese einer zytostatischen Bedeutung eines entsprechenden Uracilderivates zugrunde. Weder das Bromvinyl- (BVU) noch das Dibromvinyl- (DiBVU) Derivat des Uracils zeigte eine deutliche und ausgeprägte zytotoxische und pro-apoptotische Wirkung in den untersuchten Tumorlinien, dagegen wurden bei Uracilderivaten mit Brom-substituierter Ethinylseitenkette (BEU) ebensolche Wirkungen beobachtet und weiter charakterisiert.

Die LC50-Werte lagen für NVU im Bereich zwischen ca. 40 und $90 \mu \mathrm{M}$, je nach Tumorzelltyp, damit rund einen Faktor 10 unter der Potenz von Nitrostyrol (NS). Für BEU lagen die LC50-Werte zwischen 20 und ca. $75 \mu \mathrm{M}$. In Leukämie-/Lymphomzellen war die Potenz beider neuer Substanzen größer als die des bekannten 5-FU, auch schien hier spätestens nach $24 \mathrm{~h}$ die maximale Wirkung erreicht zu sein. Im Vergleich zum etablierten Zytostatikum 5-Fluoruracil (5-FU) erwiesen sich die neuen Uracilderivate, auch in den Kolonkarzinomzelllinien, schneller wirksam und potenter. So war mit 5-FU in Leukämie-/Lymphomzellen erst nach 48 h eine Wirkung zu sehen, während mit NVU oder BEU eine vergleichbare Wirkung meist schon nach $24 \mathrm{~h}$ sichtbar war. In Kolonkarzinomzellen benötigte 5-FU gar eher 72 h für eine ausgeprägte Wirkung. 
Eingesetzt wurden für die Tests im Wesentlichen Konzentrationen unter $100 \mu \mathrm{M}$ der jeweiligen Testsubstanz, deshalb wurden jene Substanzen als unwirksam/ungeeignet angesehen, die bis $100 \mu \mathrm{M}$ nicht mindestens eine 25 prozentige Zytotoxizität aufwiesen.

Interessant war die Beobachtung, dass weder das dem BVDU zugrundeliegende Bromvinyluracil (BVU) noch das Dibromvinyluracil (DiBVU) wie auch das aus dem NVU weiterentwickelte Triazolpyrimidindion (TAU) in diesem Konzentrationsbereich eine hinreichende Zytotoxizität zeigten. Triazolverbindungen wie TAU fanden in anderen Arbeiten ein potenzielles Interesse als Tumortherapeutikum, da eine Hemmung der HER2Tyrosinkinase beschrieben wurde (Cheng et al. 2007).

Durch Einführung lipophiler Seitenketten (Benzyl- und Benzhydrylreste an Position 1) konnte die Potenz sowohl von NVU wie auch BEU noch um das bis zu Zehnfache gesteigert werden, wohingegen das Einbringen hydrophiler Substituenten (Allyl- und Hydroxymethylreste an Position 1) die Potenz von NVU und BEU senkte. Damit erreichten die lipophilen NVUDerivate nun eine dem Nitrostyrol (NS) vergleichbare Potenz (Kaap et al. 2002, Werner et al. 2007), allerdings auf Kosten einer schwierigeren Dosierbarkeit durch sehr steile Dosiswirkungskurven.

Selbst bei einigen, jedoch nicht allen, der primär unwirksam getesteten Uracilderivate konnte durch Einbringen lipophiler Seitenketten nun auch eine zytotoxische Wirkung unterhalb von $100 \mu \mathrm{M}$ dokumentiert werden. Dies galt z. B. beim Benzhydryl-DiBVU, dem DiBVU-Derivat mit der höchsten Lipophilie.

Beim TAU waren es das Benzyl- wie das Benzhydrylderivat, wobei auch hier das lipophilere Benzhydrylderivat am potentesten war. Jedoch waren diese Wirkungen jeweils weniger ausgeprägt als beim NVU oder BEU und deren Derivaten, die deshalb im Fokus der weiteren Untersuchungen blieben.

\subsection{Zytoprotektion durch freie Thiol-Gruppe}

Bei chemotherapeutischen Behandlungen werden unter bestimmten Voraussetzungen Begleitmedikamente zur Verminderung der Systemtoxizität routinemäßig eingesetzt. Außerdem stehen für manche Präparate Rescueverfahren zur Antagonisierung schwerer unerwünschter Arzneimittelwirkungen zur Verfügung. Als Beispiele aus der Praxis sind unter anderem die 
Folsäuresupplementation bei Behandlung mit Methotrexat (MTX) sowie Pemetrexed oder die Gabe von N-Acetylcystein bei Überdosierung von Paracetamol zu nennen.

Neben 5-FU wurde, wie bereits oben erwähnt, auch Nitrostyrol (NS), insbesondere aufgrund der strukturellen Verwandtschaft zum NVU (s. Abb. 4.1) als Referenz-/Vergleichssubstanz herangezogen. In den Arbeiten von Park und Pei (Park und Pei 2004) sowie Kaap (Kaap 2004) wurde ein zytoprotektiver Effekt von Substanzen mit freien Thiol-Gruppen im Rahmen von Behandlungen mit Nitrostyrol (NS) beschrieben. Daher wurde geprüft, ob auch bei Behandlung mit unseren Substanzen durch Zugabe von Thiolen ein zytoprotektiver Effekt gezeigt werden kann.

Eine Zytoprotektion konnte durch die Zugabe freier Thiol-Gruppen wie in N-Acetylcystein (NAC), jedoch nicht mit gebundenen wie z. B. in Methionin, erreicht werden. Beachtenswert scheint hier die doch recht unterschiedliche Verhaltensweise der untersuchten Substanzen BEU und NVU.

Um einen zytoprotektiven Effekt zu erreichen sind bei Behandlungen mit BEU im Vergleich zu Behandlungen mit NVU deutlich geringere Mengen NAC ausreichend. Bei BEU sind bereits äquimolare Konzentrationen hinreichend (siehe Unterpunkt 3.3.1), jedoch ist ein unmittelbarer Einsatz des Thiols nach Behandlungsbeginn erforderlich. Bei Behandlung mit NVU muss die Konzentration von NAC deutlich höher sein, das 10-fache der Behandlungskonzentration ist erforderlich, um eine vollständige Zytoprotektion zu erreichen. Dafür konnte jedoch ein zytoprotektiver Effekt für NAC-Zugaben bis zu 8 Stunden nach Behandlungsbeginn mit NVU gezeigt werden (siehe Unterpunkt 3.3.1). Diese Ergebnisse bestätigten sich ebenfalls in den Caspaseaktivitätsmessungen (siehe Unterpunkt 3.3.2). Das unterschiedliche Verhalten ist als ein Hinweis auf unterschiedliche Wirkmechanismen der beiden Substanzen NVU und BEU zu werten.

Zudem zeigte sich durch die Versuche, dass bei NS wie auch NVU direkt nach NAC-Zugabe Veränderungen im Absorptionsspektrum der Substanzen zu sehen waren, die für intramolekulare Veränderungen in den Testsubstanzen sprechen. Der ursprüngliche Peak bei 325 nm (NS) bzw. 400 nm (NVU) verschwand, ein neuer Peak bei $250 \mathrm{~nm}$ entstand (siehe Unterpunkt 3.3.3).

Diese Veränderungen konnten aber nur im wässrigen Medium nachgewiesen werden, in einem lipophilen Lösungsmittel blieben die Ausgangsspektren erhalten (s. Abb. 3.33). 
Park und Pei beschrieben in einem Artikel (Park und Pei 2004) in Bezug auf Nitrostyrolderivate ein ähnliches Phänomen. Bei Zugabe von Substanzen mit freien ThiolGruppen (in diesem Fall Phosphotyrosin-Bindungs-Domänen (PTB)-Phosphatasen), kam es zu einer Hemmung der NS-Wirkung. Es wurde ebenfalls eine Änderung des Absorptionsspektrums beschrieben, ein Peak bei 320 nm verschwand konzentrationsabhängig bei Zugabe von Thiolen.

Park und Pei konnten nachweisen, dass die Hemmung des Enzyms durch Addition (genauer im Sinne einer sogenannten Michael-Addition) einer freien SH-Gruppe der PTB-Phosphatase an die Doppelbindung der Nitrovinylseitenkette von NS bedingt wurde. Es liegt nahe, dass ein ähnlicher Mechanismus auch beim NVU zu Grunde liegt, da beide Substanzen strukturell verwandt und die Veränderungen im Absorptionsspektrum vergleichbar sind.

Beim BEU hingegen konnte nach Zugabe von NAC keine Veränderung des Absorptionsspektrums festgestellt werden (s. Abb. 3.31). Auch dieser Befund spricht für unterschiedliche Wirkmechanismen von NVU und BEU.

Wie oben bereits angemerkt, konnte gezeigt werden, dass für den zytoprotektiven Effekt im Rahmen einer Behandlung mit den beiden Testsubstanzen, NVU wie BEU, eine freie ThiolGruppe entscheidend ist. NAC konnte mit vergleichbarer Wirkung durch Glutathion (GSH), jedoch aber nicht durch Methionin - wie in den Arbeiten von Ghibelli (Ghibelli et al.(1998) (s. Abb. 3.26) ersetzt werden. Auch diese Beobachtung stützt die These, dass oben aufgeführtem Schutzmechanismus gegen die zytotoxische Wirkung des NVU, nämlich eine direkte Substanzinhibiton durch Addition an die Substanz, zu Grunde liegt. Allerdings ist anzumerken, dass auch beim BEU für eine Zytoprotektion eine freie Thiol-Gruppe erforderlich ist, ohne dass hier Hinweise auf intramolekulare Veränderungen vorliegen.

Als Fazit kann man daher beim NVU in Kombination mit einer freien Thiol-Gruppe von strukturellen Veränderungen analog zum NS ausgehen. Beim BEU kommt es hingegen offensichtlich nicht zu einer strukturellen Veränderung der Verbindung, da die Absorptionsspektren für BEU und BEU + NAC deckungsgleich sind.

Somit begründet sich der zytoprotektive Effekt von freien Thiol-Gruppen beim NVU auf intramolekulare Veränderungen der eigentlichen Substanz. Für BEU hingegen fanden wir keine Hinweise auf strukturelle Veränderungen, daher scheint der zytoprotektive Effekt hier über einen anderen Mechanismus zu greifen. 
<smiles>CC(=O)NC(CS)C(=O)O</smiles>

NAC<smiles>NC(CCC(=O)NC(CS)C(=O)NCC(=O)O)C(=O)O</smiles>

GSH<smiles>CSCCC(N)C(=O)O</smiles>

Methionin

Abbildung 4.2: Thiole

Eine interessante Beobachtung ist, dass sich die Wirkung von NVU noch ca. 8 Stunden nach Behandlungsbeginn durch Zugabe eines Thiols, zumindest teilweise, antagonisieren lässt. Das wirft die Frage auf, ob die Substanzveränderung der einzige Mechanismus der Zytoprotektion ist, da bereits nach 2 Stunden Behandlungsdauer Veränderungen im GSH-Haushalt nachweisbar sind (siehe Unterpunkt 3.4.2) und somit eine schnelle Wirkung der Substanz belegt ist. Offensichtlich lassen sich jedoch die Effekte, ausgelöst durch NVU, auch noch im weiteren Verlauf rückgängig machen. Das könnte einerseits für die Induktion von Zellreparaturmechanismen durch freie Thiole sprechen. Andererseits könnte die lange Latenzzeit, in der beim NVU im Vergleich zum BEU noch ein zytoprotektiver Effekt erreicht werden konnte, ein Hinweis dafür sein, dass das BEU schnell in die Zelle aufgenommen und das NVU länger extrazellulär verbleibt.

Ein als Arzneimittel zugelassener zytoprotektiver Wirkstoff ist das Amifostin - ein phosphorylierter Aminoalkohol - der durch alkalische Phosphatasen in 2-((Aminopropyl)amino)ethanthiol umgewandelt wird. Auch diese Substanz verfügt über eine freie Thiol-Gruppe (s. Abb. 4.3). 
<smiles>NCCCNCCCSP(=O)(O)O</smiles><smiles>NCCCNCCS</smiles>
alkalische Phosphatasen

Abbildung 4.3: Umsetzung von Amifostin in wirksames „Thiol“ (modifiziert nach Lüllmann et al. 2006)

Seine zytoprotektive Wirkung entfaltet Amifostin einerseits über Schutz vor freien Radikalen und reaktiven Sauerstoffspezies (direkt durch Abfangen dieser Substanzen und indirekt durch Induktion einer zellulären Hypoxie, was wiederum die Bildung freier Radikale und reaktiver Sauerstoffspezies reduziert) und andererseits über Schutz der DNA und Förderung von DNAReparaturmechanismen. Besonders hervorzuheben ist, das Amifostin selektiv gesunde Zellen schützt. Diese Selektivität entsteht über folgende Mechanismen:

1. Durch die Hypovaskularisierung von Tumoren wird der Wirkstoff in Tumorzellen in Relation zum gesunden Gewebe weniger zur Verfügung gestellt.

2. Durch das saure Milieu in Tumorzellen und geringer Expression von alkalischen Phosphatasen (in Tumorzellen herrschen saure Phosphatasen vor) wird das Prodrug Amifostin in Tumorzellen nicht in den eigentlichen Wirkstoff umgewandelt (dephosphoryliert) (Lüllmann et al. 2006, Wilder 2006, Koukourakis 2002).

Da für die im Rahmen dieser Arbeit verwendeten Testsubstanzen gezeigt werden konnte, dass eine freie Thiol-Gruppe für eine Zytoprotektion entscheidend ist, kann man annehmen, dass mit Amifostin bereits ein potenter und v. a. für gesunde Zellen selektiver sowie zugelassener Wirkstoff zur Verfügung steht. Somit besteht hier die Chance auf eine Reduktion der Systemtoxizität im Rahmen einer zytostatischen Behandlung mit den neuen Substanzen, sollte jemals ein klinischer Einsatz etabliert werden könnten.

Im Umkehrschluss kann man die vielfältigen Wirkungsweisen des Amifostins wahrscheinlich auch auf unsere Thiole übertragen: neben der zytoprotektiven Wirkung über direkte Substanzinhibition durch strukturelle Veränderungen, sind vermutlich auch die Funktionen als Radikalfänger und der Schutz der DNA anzunehmen. 


\subsection{Zelleigenes Glutathion}

Da die Wirkung der Testsubstanzen NVU und BEU sowie deren Derivaten offensichtlich durch Substanzen mit freier Thiol-Gruppe wie N-Acetylcystein (NAC) aber auch Glutathion (GSH) aufgehoben werden kann und zudem das GSH/GSSG-System ein wichtiges intrazelluläres Redox-System darstellt, welches auch entscheidend an der Apoptose beteiligt ist, kommt dem GSH auch in Verbindung mit unseren Substanzen eine zentrale Rolle zu.

In anderen Arbeiten konnte gezeigt werden, dass der GSH-Efflux aus der Zelle ein frühes Symptom (bereits nach ca. 2 Stunden nach Behandlungsbeginn / Apoptose-auslösendem Reiz) der Apoptose darstellt (Ghibelli et al. 1998).

Daher war ein weiterer Schritt im Rahmen der Untersuchungen die Messung der intra- und extrazellulären Konzentrationen von GSH und GSSG.

Aus diesen Messungen ließ sich als erste Beobachtung festhalten, dass die Suspensionszelllinien (HL60 - Leukämiezellen - und U937 - Lypmphomzellen) verglichen untereinander im GSH-Gehalt auf ähnlichem Niveau liegen, jedoch im Vergleich zu den Kolonkarzinomzelllinien (LoVo und HCT), die zwar ebenfalls miteinander einen vergleichbaren GSH-Gehalt aufwiesen, sich deutlich durch einen geringeren GSH-Gehalt unterschieden.

Dies kann eine mögliche Erklärung bzw. ein Faktor sein, warum die von uns verwendeten Leukämie-/Lymphomzellen empfindlicher auf die getesteten Substanzen reagieren als die Kolonkarzinomzelllinien.

Eine weitere Beobachtung war, dass durch eine Behandlung mit NVU in allen vier Zelllinien - Leukämie- und Lymphomzellen wie Kolonkarzinomzelle - einerseits durch einen vermehrten GSH-Efflux (auch als Beleg für eine Apoptoseinduktion zu werten (Ghibelli et al. 1998)) und anderseits durch eine vermehrte Oxidation von GSH zu GSSG, ein intrazellulärer Abfall der GSH-Konzentration verzeichnet werden konnte.

Beim BEU war dieser Effekt bei der Leukämie- und Lymphomzelllinie ebenso nachweisbar. In den Kolonkarzinomzellen hingegen, wurde nach einer Behandlung mit BEU in den mittleren Konzentrationen intrazellulär sogar ein GSH-Anstieg beobachtet, in den hohen Dosierungen dann jedoch auch ein Abfall der intrazellulären GSH-Konzentration. 


\subsection{Hypothesen zum Wirkmechanismus}

Zur Klärung des Wirkmechanismus bzw. zur Entwicklung von Hypothesen über einen möglichen Wirkmechanismus der getesteten Substanzen konnte man sich auf Beobachtungen im Verhalten der verschiedenen Stoffe sowie auch unter Hinzunahme von Vergleichen von chemisch verwandten Substanzen, wie NVU und NS, mit bereits bekanntem Wirkmechanismus, stützen. So konnte bei allen Substanzen beobachtet werden, dass das Einbringen lipophiler Seitenketten an Position 1, also eine Steigerung der Lipophilie der Grundsubstanz, jeweils auch eine Steigerung der Potenz, z. T. sogar auch der Wirksamkeit der Testsubstanzen erbrachte. Dieses kann als Hinweis auf einem intrazellulären Angriffspunkt der getesteten Substanzen gewertet werden.

Da sich die Testsubstanzen spektrometrisch gut erfassen ließen bzw. durch lipophile Lösungsmittel extrahierbar waren, wurde versucht, eine Substanzaufnahme in die Zellen nachzuweisen. Dieser Versuch scheiterte leider, da für eine spektrometrische Darstellung nach Zellaufschluss zu viele Störfaktoren vorhanden waren. Jedoch konnte im Behandlungsmedium für FB-NVU eine zellzahlabhängige Spektrenverschiebung, analog zu den Veränderungen im Rahmen der Kombinationsversuche mit NAC (s. Abb. 3.32 + 3.34), nachgewiesen werden. Diese Spektrenverschiebungen können aber nicht alleine auf den GSHEfflux aus den Zellen zurückgeführt werden, da hier nicht ausreichende Mengen an GSH freigesetzt wurden. Somit stützt diese Untersuchung die These einer intrazellulären Aufnahme.

Das als Referenz eingesetzte 5-FU entfaltet seine Wirkung als Antimetabolit. Es wird statt der Pyrimidinbasen als falscher Baustein in die Nukleinsäuren eingebaut und führt damit via Einbau in die RNA zur fehlerhaften Proteinbiosynthese und zur Synthese fehlerhafter DNA. Ferner erreicht es durch Hemmung der Thymidilatsynthase eine Beeinträchtigung der DNASynthese und damit eine Inhibition der Zellteilung (Lüllmann et al. 2006).

Aufgrund der erheblich schnelleren Wirksamkeit verglichen zum 5-FU erscheint jedoch eine primäre Wirkung der hier untersuchten Testsubstanzen als reine Antimetaboliten unwahrscheinlich.

Bromdesoxyvinyluridin (BVDU, Brivudin) als antivirales Nukleosid, welches zur Entwicklung der hier untersuchten Substanzen führte, entfaltet wohl seine antivirale Wirkung als Antimetabolit sowie über die Hemmung der viralen Thymidinkinase. Dagegen zeigt es seine potenziell tödlichen Interaktionen bei gleichzeitiger Gabe von 5-FU bzw. dessen 
Derivaten durch irreversible Hemmung der Dihydropyrimidin-Dehydrogenase der Säugetierzelle (Lüllmann et al. 2006, Keizer et al. 1994).

Für NVU konnten im Rahmen der Versuche viele Parallelen zum NS aufgezeigt werden. V. a. in den Spektrenversuchen verhielten sich die beiden Substanzen nahezu kongruent. Daher kann - insbesondere da die funktionellen Gruppen der beiden Substanzen identisch sind derselbe Wirkungsmechanismus angenommen werden. Kaap et al. konnten 2002 zeigen, dass für die pro-apoptotischen Effekte synthetischer Phosphatasehemmstoffe NS die essenzielle Kernstruktur ist. Diese Kernstruktur (Nitrovinylgruppe in beta-Position an aromatischem Gerüst) findet sich auch in den NVU-Derivaten. Allerdings ist NS, am ehesten wegen der höheren Lipophilie, deutlich potenter. Denn erst die lipophilen Derivate des NVU zeigen eine vergleichbare Potenz zu NS.

Über BEU können aufgrund der vorliegenden Daten kaum Rückschlüsse auf den Wirkmechanismus gezogen werden. Auch hier erscheint aufgrund der schnellen Kinetik eine alleinige Wirkungsentfaltung als Antimetabolit unwahrscheinlich.

Im Vergleich mit NVU gibt es Ähnlichkeiten in Bezug auf Wirksamkeit und Potenz, jedoch bestehen insbesondere in den Kombinationsversuchen mit freien Thiol-Gruppen und Spektrenmessungen deutliche Unterschiede.

Eine bekannte Substanz zu der aufgrund struktureller Ähnlichkeit Rückschlüsse über einen Wirkmechanismus gezogen werden könnte, steht leider ebenso nicht zur Verfügung. Somit verbleibt der Wirkmechanismus des BEU unklar. Eine genauere Charakterisierung bedarf weiterer zukünftiger Studien. 


\section{Zusammenfassung}

Als Aufgabenstellung dieser Arbeit erfolgte die biologische Testung neuer Uracilverbindungen. In Zusammenschau der vorliegenden Befunde kann man davon ausgehen, dass einige dieser Substanzen als potenzielle Chemotherapeutika mit Antitumorwirkung interessant sein könnten. Hier sind v. a. Nitrovinyluracil (NVU) sowie Bromethinyluracil (BEU) mit ihren Derivaten zu nennen. Sie erfüllen in der Zellkultur sowohl bei Leukämie-/Lymphomzellen wie auch bei Kolonkarzinomzelllinien das Kriterium der Zytotoxizität sowie der Apoptoseinduktion. Es konnte gezeigt werden, dass Substituenten (z. B. Benzyl- oder Benzhydrylrest) in Position 1, welche die Lipophilie der jeweiligen Testsubstanz erhöhten, z. T. die Wirksamkeit, v. a. aber die Potenz steigerten. Hydrophile Substituenten (z. B. Allyl- oder Hydroxymethylreste) hingegen erreichten das Gegenteil. Für die Wirkstoffe NVU und BEU sowie deren Derivate konnte gezeigt werden, dass ein zytoprotektiver Effekt durch Substanzen mit freien Thiol-Gruppen (N-Acetylcystein oder Glutathion) erreicht werden konnte. Somit verfügt man vermutlich auch mit Amifostin, einem in der Behandlung zur Abmilderung zytotoxischer Effekte, von Chemo- aber auch von Strahlentherapie bereits zugelassenem Präparat, über ein potenzielles Rescueverfahren. Die Ergebnisse im Rahmen der Kombinationsversuche mit den Thiolen bestärkten die Vorstellung, dass die Substanzen in das Redox-System der Zelle wesentlich eingreifen. Zur weiteren Charakterisierung erfolgte daher die Bestimmung der intrazellulären Glutathiongehalte. Hier konnte gezeigt werden, dass sich jeweils die Leukämie- und Lymphomzelllinie sowie die beiden Kolonkarzinomzelllinien untereinander im GSH-Gehalt ähnelten, jedoch miteinander verglichen, deutlich unterschieden. Der Unterschied im intrazellulären GSH-Gehalt stellt eine Erklärung für die unterschiedliche Empfindlichkeit der verschiedenen Zelllinien gegenüber den getesteten Substanzen dar, da der geringere GSHGehalt in der Leukämie-/Lymphomzelllinie gut mit der größeren Empfindlichkeit gegenüber den Testsubstanzen korreliert. Eine Hypothese zum möglichen Wirkmechanismus konnte für NVU und seine Derivate entwickelt werden. Aufgrund der strukturellen Verwandtschaft zum Nitrostyrol sowie Ähnlichkeiten im biologischen Verhalten sowie in spektrometrischen Untersuchungen ist von einem identischen Wirkmechanismus als Phosphatasehemmstoff auszugehen. Für BEU und dessen Derivate gelang mit den vorliegenden Daten kein Rückschluss auf den Wirkmechanismus, auch konnte keine Substanz mit bekanntem Wirkmechanismus und struktureller Ähnlichkeit zur Entwicklung einer Hypothese herangezogen werden. 


\section{Literaturverzeichnis}

Brawley OW, Kramer BS, Dietel M: Prävention und Früherkennung von Krebserkrankungen. In: Dietel M, Suttorp N, Zeitz M (Hrsg.): Harrisons Innere Medizin. 17. Auflage, ABW Wissenschaftsverlag, Berlin 2009, 606-613

Cheng ZY, Li WJ, He F, Zhou JM, Zhu XF (2007): Synthesis and biological evaluation of 4-aryl-5-cyano-2H-1,2,3-triazoles as inhibitor of HER2 tyrosine kinase. Bioorg Med Chem $\underline{15}(3), 1533-8$

Chowdhary A, Spence AM, Sales L, Rostomily RC, Rockhill JK, Silbergeld DL (2012): Radiation associated tumors following therapeutic cranial radiation. Surg Neurol Int $\underline{3}, 48$

Fritz P, Hensley FW, Muskalla K, Weber KJ, Wannenmacher M, Roth SL, Macha HN: Grundlagen und Technik der Brachytherapie. In: Wannenmacher M, Debus J, Wenz F (Hrsg.): Strahlentherapie. Springer-Verlag Berlin Heidelberg 2006, 93-136

Führer M: Synthese und biologische Testung von Derivaten des (E)-5-(2-Bromvinyl)-2 desoxyuridins. Biowiss. Diss. Leipzig 2008

Gewies A (2003): Introduction to Apoptosis. http://www.celldeath.de/encyclo/aporev/ apointro.pdf, letzter Zugriff am 30.10.2015

Ghibelli L, Fanelli C, Rotilio G, Lafavia E, Coppola S, Colussi C, Civitareale P, Ciriolo MR (1998): Rescue of cells from apoptosis by inhibition of active GSH extrusion. FASEB J $\underline{12}(6), 479-86$

Griffith OW (1980): Determination of glutathione and glutathione disulfide using glutathione reductase and 2-vinylpyridine. Anal Biochem $\underline{106}(1), 207-12$

Heinze N: Synthese von Derivaten des 5-Bromethinyl-2`-desoxyuridins mit potentieller chemotherapeutischer Wirksamkeit. Biowiss. Diss. Leipzig 2008

Herold G und Mitarbeiter: Innere Medizin. Herold, Köln 2012

Kaap S: Nitrostyrolderivate als Apoptoseauslöser - Strukturelle Anforderungen, Mechanismus und Tumorselektivität. Biowiss. Diss. Leipzig 2004 
Kaap S, Quentin I, Tamiru D, Shaheen M, Eger K, Steinfelder HJ (2002): Structure activity analysis of the pro-apoptotic, antitumor effect of nitrostyrene adducts and related compounds. Biochem Pharmacol 65(4), 603-10

Keizer HJ, De Bruijn EA, Tjaden UR, De Clercq E (1994): Inhibition of fluorouracil catabolism in cancer patients by the antiviral agent (E)-5-(2-bromovinyl)-2'-deoxyuridine. J Cancer Res Clin Oncol 120(9), 545-9

Kerr JF, Wyllie AH, Currie AR (1972): Apoptosis: a basic biological phenomenon with wideranging implications in tissue kinetics. Br J Cancer 26(4), 239-57

Kischkel FC, Hellbardt S, Behrmann I, Germer M, Pawlita M, Krammer PH, Peter ME (1995): Cytotoxicity-dependent APO-1 (Fas/CD95)-associated proteins form a death-inducing signaling complex (DISC) with the receptor. EMBO J 14(22), 5579-88

Koukourakis MI (2002): Amifostine in clinical oncology: current use and future applications. Anticancer Drugs 13(3), 181-209

Krammer PH (2000): Apoptose. Dtsch Arztebl 97(25), 1752-59

Kuida K, Zheng TS, Na S, Kuan C, Yang D, Karasuyama H, Rakic P, Flavell RA (1996): Decreased apoptosis in the brain and premature lethality in CPP32-deficient mice. Nature 384(6607), 368-72

Lawen A (2003): Apoptosis - an introduction. Bioessays 25(9), 888-96

Lüllmann H, Mohr K, Hein L: Pharmakologie und Toxikologie. 16. Auflage; Thieme Verlag, Stuttgart 2006

Morin PJ, Trent JM, Collins, Vogelstein B, Kölble K: Tumorgenetik. In: Dietel M, Suttorp N, Zeitz M (Hrsg.): Harrisons Innere Medizin. 17. Auflage, ABW Wissenschaftsverlag, Berlin 2009, 614-621

Mosmann T (1983): Rapid colorimetric assay for cellular growth and survival: application to proliferation and cytotoxicity assays. J Immunol Methods 65(1-2), 55-63

Müller RP, Bischof M: Tumoren des lymphatischen Systems. In: Wannenmacher M, Debus J, Wenz F (Hrsg.): Strahlentherapie. Springer-Verlag Berlin Heidelberg 2006, 657-704 
Nicholson DW, Ali A, Thornberry NA, Vaillancourt JP, Ding CK, Gallant M, Gareau Y, Griffin PR, Labelle M, Lazebnik YA (1995): Identification and inhibition of the ICE/CED-3 protease necessary for mammalian apoptosis. Nature $\underline{376}$ (6535), 37-43

Park J, Pei D (2004): Trans-Beta-nitrostyrene derivatives as slow-binding inhibitors of protein tyrosine phosphatases. Biochemistry $\underline{43}(47), 15014-21$

Peitsch MC, Tschopp J (1995): Comparative molecular modelling of the Fas-ligand and other members of the TNF family. Mol Immunol 32(10), 761-72

Robert Koch-Institut (Hrsg.) und die Gesellschaft der epidemiologischen Krebsregister in Deutschland e.V. (Hrsg.): Krebs in Deutschland 2009/2010. 9. Ausgabe, Berlin 2013

Sausville EA, Longo DL, Le Coutre P: Grundlagen der Malignom: Chirurgie, Chemotherapie und biologische Therapien. In: Dietel M, Suttorp N, Zeitz M (Hrsg.): Harrisons Innere Medizin. 17. Auflage, ABW Wissenschaftsverlag, Berlin 2009, 641-662

Scaffidi C, Schmitz I, Krammer PH, Peter ME (1999): The role of c-FLIP in modulation of CD95-induced apoptosis. J Biol Chem 274(3), 1541-8

Slee EA, Adrain C, Martin SJ (1999): Serial killers: ordering caspase activation events in apoptosis. Cell Death Differ $\underline{6}(11), 1067-74$

Statistisches Bundesamt (2015a): Krebs war 2013 die zweithäufigste Todesursache, Pressemitteilung 34/15. https://www.destatis.de/DE/PresseService/Presse/Pressemitteilungen/ 2015/02/PD15_034_232.html, Zugriff am 24.10.2015

Statistisches Bundesamt (2015b): Krankheitskosten: Deutschland, Jahre, Krankheitsdiagnosen (Ergebnis 23631-0001). https://www-genesis.destatis.de/genesis/online/logon?sequenz= tabelleErgebnis\&selectionname=23631-0001\&sachmerkmal=ICD10Y\&sachschluessel=ICD 10-C00-C97,ICD10-C00-C14,ICD10-C15-C26,ICD10-C16,ICD10-C18,ICD10-C20,ICD10C25,ICD10-C30-C39,ICD10-C33-C34,ICD10C43-C44,ICD10-C50,ICD10-C51-C58,ICD10C53,ICD10-C60-C63,ICD10-C61,ICD10-C64-C68,ICD10-C67,ICD10-C81-C96,ICD10-C91 -C95, Zugriff am 24.10.2015

Steinfelder HJ, Quentin I, Ritz V (2000): A fast and sensitive technique to study the kinetics and the concentration dependencies of DNA-Fragmentation during drug-induced apoptosis. J Pharmacol Toxicol Methods $\underline{43}(1), 79-84$ 
Szegezdi E, Fitzgerald U, Samali A (2003): Caspase-12 and ER-stress-mediated apoptosis: the story so far. Ann N Y Acad Sci $\underline{1010}$, 186-94

Temel JS, Greer JA, Muzikansky A, Gallagher ER, Admane S, Jackson VA, Dahlin CM, Blinderman CD, Jacobsen J, Pirl WF et al. (2010): Early palliative care for patients with metastatic non-small-cell lung cancer. N Engl J Med 363(8), 733-42

Thornberry NA1, Lazebnik Y (1998): Caspases: enemies within. Science 281(5381), 1312-6

Tietze F (1969): Enzymic method for quantitative determination of nanogram amounts of total and oxidized glutathione: applications to mammalian blood and other tissues. Anal Biochem 27(3), 502-22

Tomicic MT, Friedrichs C, Christmann M, Wutzler P, Thust R, Kaina B (2003): Apoptosis induced by (E)-5-(2-bromovinyl)-2'-deoxyuridine in varicella zoster virus thymidine kinaseexpressing cells is driven by activation of c-Jun/activator protein-1 and Fas ligand/caspase-8. Mol Pharmacol 63(2), 439-49

Trauth BC, Klas C, Peters AM, Matzku S, Möller P, Falk W, Debatin KM, Krammer PH (1989): Monoclonal antibody-mediated tumor regression by induction of apoptosis. Science $\underline{245}(4915), 301-5$

Treiber M, Krempien R, Wannenmacher M: Knochenmetastasen. In: Wannenmacher M, Debus J, Wenz F (Hrsg.): Strahlentherapie. Springer-Verlag Berlin Heidelberg 2006, 745-754

Treiber M, Oertel S: Intraoperative Radiotherapie. In: Wannenmacher M, Debus J, Wenz F (Hrsg.): Strahlentherapie. Springer-Verlag Berlin Heidelberg 2006, 155-160

Varfolomeev EE, Schuchmann M, Luria V, Chiannilkulchai N, Beckmann JS, Mett IL, Rebrikov D, Brodianski VM, Kemper OC, Kollet O et al. (1998): Targeted disruption of the mouse Caspase 8 gene ablates cell death induction by the TNF receptors, Fas/Apo1, and DR3 and is lethal prenatally. Immunity $\underline{9}(2), 267-76$

Vogelstein B, Fearon ER, Hamilton SR, Kern SE, Preisinger AC, Leppert M, Nakamura Y, White R, Smits AM, Bos JL (1988): Genetic alterations during colorectal-tumor development N Engl J Med $\underline{319}(9), 525-32$

Vogt C: Untersuchungen über die Entwicklungsgeschichte der Geburtshelferkröte. (Alytes obstetricians). Jent und Gassmann, Solothurn 1842 
Von Zezschwitz C, Vorwerk H, Tergau F, Steinfelder HJ (1997): Apoptosis induction by inhibitors of Ser/Thr phosphatases 1 and 2A is associated with transglutaminase activation in two different human epithelial tumour lines. FEBS Lett $\underline{413}(1), 147-51$

Werner JM: Etablierung fluoreszenzmikroskopischer Techniken zur Evaluierung der pro-apoptotischen Wirkung der experimentellen Verbindung Nitrostyrol und des etablierten Zytostatikums 5-FU in Kolonkarzinomzellen. Med. Diss. Göttingen 2005

Werner JM, Eger K, Steinfelder HJ (2007): Comparison of the rapid pro-apoptotic effect of trans-beta-nitrostyrenes with delayed apoptosis induced by the standard agent 5-fluorouracil in colon cancer cells. Apoptosis 12(1), 235-46

Wilder DW: Amifostin in subkutaner Anwendung bei Patienten mit Kopf-Hals-Tumoren.

Med. Diss. Tübingen 2006

Zierhut D: Prostatakarzinom. In: Wannenmacher M, Debus J, Wenz F (Hrsg.): Strahlentherapie. Springer-Verlag Berlin Heidelberg 2006, 595-610 


\section{Danksagung:}

Ganz herzlich möchte ich mich bei Herrn Professor Steinfelder für die Überlassung des interessanten Themas sowie die stete und langjährig gute Betreuung sowohl während des experimentellen Teils als auch während der Abfassung dieser Arbeit bedanken.

Zudem möchte ich mich bei Iris Quentin und Ursel Leonhardt herzlich bedanken. Sie haben mich als Mitglieder der Arbeitsgruppe ebenfalls stets mit Rat und Tat unterstützt. 